\title{
Phenotyping Studies to Assess the Effects of Phytopharmaceuticals on In Vivo Activity of Main Human Cytochrome P450 Enzymes
}

Authors

Affiliations
Gregor Zadoyan ${ }^{1}$, Uwe Fuhr ${ }^{1,2}$

1 ITECRA GmbH \& Co. KG, Cologne, Germany

${ }^{2}$ Department of Pharmacology, Clinical Pharmacology Unit, University of Cologne, Cologne, Germany
Key words

- cytochrome P450

- cocktail interaction studies

- herb-drug interaction

- phytopharmaceuticals

- botanicals

- herbal products received January 25, 2012 revised April 11, 2012 accepted April 15, 2012

\section{Bibliography}

DOI http://dx.doi.org/ 10.1055/s-0031-1298536

Published online May 15, 2012

Planta Med 2012; 78 :

1428-1457 @ Georg Thieme

Verlag KG Stuttgart - New York . ISSN 0032-0943

\section{Correspondence}

Prof. Dr. med. Uwe Fuhr Department of Pharmacology Clinical Pharmacology Unit University of Cologne

Gleueler Str. 24

50931 Cologne

Germany

Phone: + 492214785230

Fax: + 492214787011

uwe.fuhr@uk-koeln.de

\section{Abstract}

The extensive use of herbal drugs and their multiple components and modes of action suggests that they may also cause drug interactions by changing the activity of human cytochrome P450 enzymes. The purpose of the present review is to present the available data for the top 14 herbal drug sales in the U.S. Studies describing the effects of herbal drugs on phenotyping substrates for individual CYPs were identified by a comprehensive MEDLINE search. Drugs included Allium sativum (Liliaceae), Echinacea purpurea (Asteraceae), Serenoa repens (Arecaceae), Ginkgo biloba (Ginkgoaceae), Vaccinium macrocarpon (Ericaceae), Glycine $\max$ (Fabaceae), Panax ginseng (Araliaceae), Actea racemosa (Ranunculaceae), Hypericum perforatum (Hypericaceae), Silybum marianum (Asteraceae), Camellia sinensis (Theaceae), Valeriana officinalis (Valerianaceae), Piper methysticum (Piperaceae), and Hydrastis canadensis (Ranunculaceae) preparations. We identified 70 clinical studies in 69 publications. The majority of the herbal drugs appeared to have no clear effects on most of the CYPs examined. If there was an effect, there was mild inhibition in almost all cases, as seen with garlic or kava effects on CYP2E1 and with soybean components on CY$\mathrm{P} 1 \mathrm{~A} 2$. The most pronounced effects were induction of CYP3A and other CYPs by St. John's wort

\section{Introduction}

Herbal drugs are claimed to exert their unique mode of action by the complex interplay of many different constituents. Beyond actions of various constituents on more than a single target, it is postulated to also arise from mutual interactions of related chemical moieties at both the pharmacokinetic and pharmacodynamic level. It is therefore not surprising that herbal drugs may also and the inhibitory effect of goldenseal on CYP3A and CYP2D6, both being borderline between mild and moderate in magnitude. With the exceptions of St. John's wort and goldenseal, the information currently available suggests that concomitant intake of the herbal drugs addressed here is not a major risk for drugs that are metabolized by CYPs.

\section{Abbreviations}

$\nabla$

$\mathrm{AUC}_{(0-\infty)}$ : area under the concentration-time curve from 0 to infinity

$\mathrm{C}_{\text {max }}$ : maximum serum concentration

CI: confidence interval

CYP: $\quad$ cytochrome P450 enzyme

EGCG: epigallocatechin gallate

EMA: $\quad$ European Medicines Agency

FDA: $\quad$ Food and Drug Administration

GABA: gamma-aminobutyric acid

GBE: $\quad$ Ginkgo biloba extract

(d)GTE: (decaffeinated) green tea extract

INR: international normalized ratio of prothrombin time

LSS: limited sampling strategy

p: $\quad$ p value

Poly E: $\quad$ Polyphenon $\mathrm{E}^{\circledR}$

rac: racemic

SJW: $\quad$ St. John's wort

$t_{1 / 2}$ : elimination half-life

have an effect on the activity of cytochrome P450 enzymes (CYPs), the most important enzyme family to mediate phase I metabolism of small molecule drugs and other human xenobiotics. This became particularly obvious when St. John's wort was recognized to be a potent inducer of $\mathrm{CY}$ P3A [1] and other proteins involved in pharmacokinetics, and the detection of the inhibitory effects of grapefruit juice on gut wall CYP3A was a 
reminder that natural products may be involved in drug interactions [2].

Nowadays, there is general agreement that the potential of herbal drugs to cause drug-drug interactions needs to be assessed as thoroughly as for non-herbal drugs, including interactions at the level of CYP-mediated metabolism. In vitro studies with herbal drugs probably are less reliable than those with individual chemicals because both effective concentrations in vitro as well as in vivo processing of the complex mixtures can hardly be predicted. Because not all potential combinations with other drugs can be tested, the effect of drugs on individual enzymes is usually assessed using the phenotyping approach. Phenotyping for a CYP enzyme, i.e., quantification of its actual in vivo activity in an individual, is performed by administration of a selective substrate for this enzyme and subsequent determination of appropriate pharmacokinetic metrics closely reflecting enzyme activity [3]. Phenotyping substrates are usually marketed drugs with therapeutic indications, which are chosen mainly based on their selectivity for the CYP to be examined, on tolerability, and on availability. The standard design of a respective clinical study is a crossover design with administration of the phenotyping agents in both periods, combined with coadministration of the drug to be tested at its highest chronic therapeutic dose in one period [3]. Current regulatory guidance has adopted this procedure and also provides recommendations on individual phenotyping agents $[4,5]$. It is beyond the scope of this review to evaluate all individual substances and metrics used to quantify the effects of herbal drugs on individual CYPs in detail; for a respective assessment, see [3]. CYP phenotyping drugs recommended by the FDA [4,5] include the following: CYP1A2, theophylline, caffeine; CYP2B6, efavirenz, bupropion; CYP2C8, amodiaquine, cerivastatin, repaglinide, rosiglitazone; CYP2C9, warfarin, tolbutamide; CYP2C19, omeprazole, esoprazole, lansoprazole, pantoprazole; CYP2D6, metoprolol, desipramine, dextromethorphan, atomoxetine; CYP2E1, chlorzoxazone; CYP3A4, midazolam, buspirone, felodipine, lovastatin, eletriptan, sildenafil, simvastatin, triazolam. The EMA list is more limited, comments on the lack of exhaustive validation of some agents, and also occasionally asks for monitoring of specific reactions. The FDA created and posted an additional extensive list in 2011 [6] presenting sensitive substrates (as mentioned in the 1999 document "Guidance for Industry: In Vivo Drug Metabolism/Drug Interaction Studies - Study Design, Data Analysis, and Recommendations for Dosing and Labeling", which formally is still valid today) and substrates with a narrow therapeutic range, but provides little advice on the selection of the individual agent. While caffeine, warfarin, tolbutamide, and midazolam, and most respective metrics derived from plasma concentrations may be considered as fully validated (with the limitations described above) [3], caveats apply for the other listed substances, as additional metabolic pathways are known and/or validation data are limited. Several substances present in EMA and FDA lists had been withdrawn from the market prior to generation of the lists.

A combination of substances in a phenotyping cocktail in order to address a panel of CYPs in a single clinical study has been studied extensively $[3,7,8]$. There should be no mutual interaction of the drugs within a cocktail; an excellent example how to study this in detail has been published [9]. The EMA guidance addresses cocktail studies, while for the FDA, only semiofficial information is available (see $[10,11]$ ), showing that the FDA also accepts data from cocktail studies. While in general the cocktail approach appears to be appropriate, the inclusion of "historical" substances with limited validation and/or affinity to several CYPs such as dapsone or quinidine may compromise the results for other cocktail components.

Pharmacokinetic metrics, which reflect CYP activity best, may be metabolic ratios of a metabolite over a parent drug in plasma or urine, clearance of the parent drug, or partial clearance via a specific pathway, depending on the individual phenotyping substrate used. It is desirable to use metrics without the need of drawing many blood samples during the entire concentration vs. time profile of the phenotyping drug in order to keep burdens for both study participants and investigators as low as possible. Some metrics can indeed be derived using a limited sampling strategy (LSS) or even from a single sample [3]. However, the most recent 2010 EMA (draft) guidelines on the investigation of drug interactions (CPMP/EWP/560/95/Rev. 1 - Corr.) as well as the respective FDA guidance website [12] ask explicitly for the determination of complete area under the curve (AUC) values of phenotyping substrates, requiring at least 8-10 samples per study period, and discourages the use of single concentrations and metabolic ratios. The reason for this reluctance to accept metrics derived using an LSS probably is that their validation is limited to the quantification of baseline activity in individuals without major diseases with effects on pharmacokinetics and in the absence of factors with a major impact on pharmacokinetics. However, any effects of interacting drugs may not be limited to the activity of the CYP to be investigated, but may also affect absorption, secondary metabolism, and other pharmacokinetic processes of the phenotyping substrate. Because of their multiple ingredients, herbal drugs would be at risk to unexpectedly exert such additional effects. LLS-based metrics presumably are less robust to such effects, with the risk that these would either be erroneously identified as an effect on CYP activity, or that existing effects on CYPs would be hidden. While the confounding mechanism could then be identified by a change in the entire concentration vs. time profile of the phenotyping drug, these may well go unnoticed with LLS-based metrics only. Furthermore, LLS and complete sampling may also reach different results in interaction studies [13] because the concentration of interacting moieties and, thus, the extent of interaction change during a dosing interval - which is only partially covered by an LLS.

A second caveat concerns the estimation of the sample size required in interaction studies with herbal drugs. We repeatedly observed that the apparent intraindividual variability of phenotyping agent pharmacokinetics was clearly higher than reported in previous studies with small molecule drugs $[14,15]$. The reason for this observation is unclear; one could speculate that nonspecific effects on gastrointestinal motility are involved. A higher safety margin when calculating the sample size appears to be the only way to handle this problem as long as the mechanisms are unclear.

The regulatory (i.e., safety) purpose of interaction studies with any drugs including herbal drugs is to investigate the maximal extent of interaction for maximal exposure towards the "perpetrator". To this end, effects on phenotyping metrics should be larger rather than smaller than the true effects on CYP activity (sensitive metrics). In contrast, true effects on CYP activity for a given dose would theoretically be required to adapt the dose of concomitantly given drugs subject to this interaction. For the latter approach, changes in enzyme activity could then be incorporated in simulations to predict the extent of interactions with other drugs [11]; however, as these methods are at an early stage, the former approach currently still seems to be more appropriate. 
In summary, the phenotyping approach is the method of choice to study the potential of drugs including herbal drugs to change CYP activity and thus the pharmacokinetics of their drug substrates, but much expertise and very close attention to the details of individual studies is required in order to understand the consequences of respective results. More research is needed especially to achieve better transferability of results to quantitatively predict effects of other drug substrates in treated patients.

\section{Methods}

$\nabla$

The aim of the present review was to give a concise overview on herb-drug interactions in human clinical studies, especially phenotyping and phenotyping cocktail studies, with respect to the major human drug metabolizing cytochrome P450 enzymes.

A literature search was conducted in MEDLINE (as accessed via PubMed on December 2, 2011) using the search terms of the plant's name in combination with "cytochrome P450", plus "drug interaction" or "herb-drug interaction". The search was limited to English and German language papers. For further information, reviews and additional publications from all reference lists were read and relevant data were extracted. The discussion of case reports, animal data as well as in vitro experiments were not the primary objective of the present review and were not included.

\section{Results}

$\nabla$

We identified 70 clinical studies in 69 publications. An overview of the data is presented in Table 1 (at the end of the paper). Herb-drug interactions were present for 10 of the top 14 selling botanicals in the U.S. for 2006, including garlic with 2 drugs (chlorzoxazone, saquinavir), echinacea with 3 drugs (caffeine, midazolam, tolbutamide), ginkgo with 3 drugs (midazolam, omeprazole, tolbutamide), soy with 2 drugs (caffeine, theophylline), ginseng with 1 drug (debrisoquine), black cohosh with 1 drug (debrisoquine), St. John's wort with 19 drugs (alprazolam, atorvastatin, chlorzoxazone, cortisol, cyclosporine, desogestrel, ethinyl estradiol, gliclazide, imatinib, indinavir, ivabradine, mephenytoin, midazolam, norethindrone, omeprazole, quazepam, verapamil, voriconazole, and warfarin), kava with 1 drug (chlorzoxazone), and goldenseal with 2 drugs (debrisoquine, midazolam).

In addition to the 14 plants described in detail (see discussion), we found positive herb-drug interactions for Angelica dahurica with 1 drug (caffeine), Scutelleria baicalensis with 3 drugs (bupropion, chlorzoxazone, losartan), grapes/red wine with 4 drugs (buspirone, caffeine, dextromethorphan, losartan), and curcuma with 1 drug (caffeine).

The following detailed description of the respective botanicals is sorted in descending order of their U.S. sales ranking according to Blumenthal et al. [16].

\section{Garlic [Allium sativum (L.) (Liliaceae)]}

Garlic is the most popular herbal remedy. Postulated pharmacological actions of garlic include antibacterial, antiviral, antifungal, antihypertensive, blood glucose lowering, antithrombotic, antimutagenic, and antiplatelet actions [17]. Responsible for these activities are organosulfur compounds like alliin, allicin, diallyl disulfide, ajoene, and many others [18]. When the bulb is processed, alliin reacts with the enzyme allinase to produce the ac- tive constituent of garlic, allicin. Allicin is the compound often used to standardize many garlic formulations [19]. Garlic is available in different forms of pharmaceutical preparations, such as dry powder products, oil-macerated, volatile garlic oil, and juices of fresh garlic [20].

A clinical study assessed the effect of short-term administration of garlic supplements on single-dose ritonavir [21], a protease inhibitor that is mainly metabolized by CYP3A4 [22]. Acute dosing of this garlic extract over 4 days did not significantly alter the pharmacokinetics of ritonavir. In another trial, 11 female patients with metastatic breast cancer were treated with the CYP3A4 substrate docetaxel and garlic for 12 consecutive days. Garlic supplementation had no statistically significant effects on the pharmacokinetic profile of docetaxel when administered over the short term (4 days) or long term (12 days) [23]. A further study investigated the effect of garlic (over 12 days) on CYP2C9 activity by using warfarin as the probe substrate and showed no effect on pharmacokinetics or pharmacodynamics of the probe [24]. Another clinical study with 14 normal volunteers found no influence of garlic on the activity of CYP3A4 and CYP2D6 by a consecutive intake of garlic for 14 days [25]. In contrast, other studies showed an effect of garlic preparations by long-term use longer than 14 days: A clinical study with 10 healthy volunteers demonstrated that long-term (21 days) use of garlic caplets led to a significant decline in the plasma concentrations of saquinavir [26], an HIV-1 protease inhibitor that is metabolized by CYP3A4 [22]. The similarity in the magnitude of the decreases in AUC (-51\%), $\mathrm{C}_{\max }(-54 \%)$, and concentration at 8 hours $\left(\mathrm{C}_{8}\right)(-49 \%)$ suggested that garlic affected the bioavailability of saquinavir rather than its systemic clearance [26]. A cocktail interaction study in 12 healthy elderly subjects ( mean $=67$ years) who took garlic oil for 28 days showed no significant effects on CYP1A2, CYP2D6, and CYP3A4 activity, but it produced a significant decrease in CYP2E1 activity [27].

In summary, garlic appears to have only a minor potential to cause herb-drug interactions, with CYP2E1 as the only identifiable target. The saquinavir case needs further investigation.

Echinacea [Echinacea purpurea (L.) Moench (Asteraceae)] Echinacea has anti-inflammatory and immunomodulating properties and is widely used for the treatment of the upper respiratory tract [28]. Echinacea preparations are made from the roots and/or other parts of the plant by juicing, alcohol extraction, infusion, decoction, or consumed as tablets or capsules [29]. Echinacea preparations are not chemically standardized. The constituent base is complex, consisting of phenols (cichoric and caftaric acid), polysaccharides, and alkylamides. The immunomodulatory effect was reported to be caused by alkylamides, which bind to human cannabinoid receptors 1 and 2 , and inhibit tumor necrosis factor $\alpha[30]$.

With a sales ranking of \#2 in the U.S. market [16], it is very important to determine the ability of echinacea to effect metabolic drug-drug interactions. Clinical studies indicate conflicting data about the effect of echinacea on the hepatic drug oxidation system. In a cocktail interaction study with 12 healthy volunteers, CYP1A2 was inhibited as assessed by a reduced oral clearance of the CYP1A2 probe caffeine $(-27 \%, \mathrm{p}=0.049)$, there was a minor inhibitory effect on CYP2C9 $(-11 \%, p=0.001)$, while there was no effect on CYP2D6 or CYP3A4 [31]. Two further clinical studies determined the influence of echinacea on CYP3A4. In one of these studies, 13 healthy volunteers were dosed with lopinavirritonavir and the probe substrate midazolam. Neither lopinavir 
nor ritonavir pharmacokinetic parameter values were significantly altered after 14 days of echinacea administration [32]. The other study in 12 healthy male volunteers conducted with warfarin, a substrate of CYP2C9 and CYP3A4 for S-warfarin, and CYP3A4 and CYP1A2 for R-warfarin [33], found no clinically significant pharmacokinetic and pharmacodynamic interaction [34]. In a cocktail interaction study with 12 healthy volunteers determined by Gurley et al. [35], long-term supplementation of echinacea had no effect on CYP1A2, CYP2D6, CYP2E1, or CYP3A4 activity [35]. The same research group assessed the influence of echinacea on the activity of CYP2D6 in a clinical study with 18 normal volunteers, again with no effects [36].

In summary, the results of all described studies propose that echinacea has a fairly low capability for causing herb-drug interactions with human cytochrome P450 enzymes.

\section{Saw palmetto [Serenoa repens (W. Bartram) Small (Arecaceae)]}

Saw palmetto is the most popular herbal remedy used to alleviate the symptoms related to benign prostatic hyperplasia [37]. It has an ability to improve urologic symptoms and urine flow measures comparable to that of finasteride [35]. Saw palmetto extracts gained from the ripe, dried fruit have anti-inflammatory and spasmolytic properties. Most saw palmetto extracts are composed of mixtures of fatty acids including capric, caprylic, lauric, linoleic, linolenic, myristic, oleic, palmitic, and stearic acids, which typically account for $80-90 \%$ of the extract [38].

There are only two clinical studies that have assessed the impact of saw palmetto on human cytochrome P450 enzymes. A cocktail interaction study with 12 healthy volunteers demonstrated that saw palmetto had no significant modulatory effects on CYP1A2, CYP2D6, CYP2E1, and CYP3A4 [35]. Another clinical study with 12 normal volunteers determined whether saw palmetto affects the activity of CYP2D6 and CYP3A4. For the probe substrates dextromethorphan (CYP2D6 activity) and alprazolam (CYP3A4 activity), the results indicated a lack of effect [38].

Overall, saw palmetto extract at generally recommended doses seems to be an unlikely candidate for CYP-mediated herb-drug interactions.

\section{Ginkgo [Ginkgo biloba (L.) (Ginkgoaceae)]}

Ginkgo extract is a popular herbal remedy used for a variety of disorders. EGb $761^{\circledR}$ special extract, for example, is a dry extract from Ginkgo biloba leaves (drug-extract ratio 35-67:1) that has been adjusted to $22-27 \%$ ginkgo flavonoids and $5.0-7.0 \%$ terpene lactones consisting of 2.8-3.4\% ginkgolides A, B, C and 2.6-3.2\% bilobalides, with a ginkgolic acid content less than 5 ppm [39]. EGb $761^{\circledR}$ interferes with various pathomechanisms relevant to dementing disorders [40-42]. A large number of clinical studies suggest that Ginkgo biloba extract (GBE) may have beneficial effects on memory, cognition, and the vascular system [43-47].

For an herbal drug to be taken by elderly people, often with several chronic diseases, the ability of GBE to cause metabolic drugdrug interactions should be known. The literature exhibits conflicting data, particularly on long-term treatment of 12 days and more. A clinical study in 11 healthy volunteers assessed the effect of GBE on the activity of CYP2C9 using flurbiprofen as a substrate. The subjects took $2 \times 60 \mathrm{mg}$ EGb $761^{\circledR}$ tablets thrice daily for 1 day. There was no significant difference between ginkgo or placebo treatment in any of flurbiprofen's kinetic parameters [48]. Another research group also could not find any effect of ginkgo, neither inducing nor inhibiting, on CYP1A2, CYP3A4 and
CYP2C9 activity using racemic warfarin as a probe drug in 12 healthy male subjects, who took ginkgo for 7 consecutive days [49]. Using a cocktail phenotyping approach, a study with 18 healthy volunteers provided evidence that EGb $761^{\circledR}$ had no clinically relevant inhibitory or inducing effects towards human CYP1A2, CYP2C9, CYP2C19, CYP2D6, and CYP3A4 when administered at chronic therapeutic doses for 8 days [15]. A clinical study with 18 healthy Chinese subjects investigated the potential herbdrug interaction between ginkgo and omeprazole, a widely used CYP2C19 substrate [50]. The volunteers had taken ginkgo tablets $2 \times 70 \mathrm{mg}$ twice daily for 12 days. In this study, plasma concentrations of omeprazole were significantly decreased and 5-hydroxyomeprazole as its metabolite significantly increased following ginkgo administration in comparison to baseline indicating an induction of CYP2C19 [50]. In contrast, a clinical study performed in 14 Chinese volunteers examined the possible effects of ginkgo as an inducer of CYP2C19 on single-dose pharmacokinetics of voriconazole [51]. Ginkgo pretreatment for 12 days did not significantly affect pharmacokinetic parameters of voriconazole [51]. A clinical study evaluated as the primary objective the effect of GBE on the exposure of lopinavir, an HIV protease inhibitor metabolized by CYP3A4, in 14 healthy volunteers [52]. The secondary objectives were to compare ritonavir exposure pre- and post-GBE, and assess the effect of GBE on single doses of the probe drug midazolam. Ginkgo biloba extract decreased midazolam $\operatorname{AUC}_{(0-\infty)}$ by $34 \%(\mathrm{p}=0.03)$ and $\mathrm{C}_{\max }$ by $31 \%(\mathrm{p}=0.03)$ but did not significantly affect the exposures of lopinavir and ritonavir [52]. A clinical study performed in 14 healthy male volunteers determined the effects of GBE on the pharmacokinetics of bupropion, a substrate of CYP2B6. Ginkgo biloba extract administration of $240 \mathrm{mg} \cdot$ day $^{-1}$ (two 60-mg capsules taken twice daily) for 14 days did not significantly alter the basic pharmacokinetic parameters of bupropion [53]. Another clinical study with 12 healthy volunteers assessed the influence of GBE on the activity of CYP2D6 and CYP3A4 for about 14 days. For the probe substrates dextromethorphan (CYP2D6 activity) and alprazolam (CYP3A4 activity), no statistical differences were observed between baseline and post-GBE treatment indicating a lack of effect on CYP2D6 and CYP3A4 [54]. In a cocktail interaction study with 12 healthy volunteers and treatment duration of 28 days, no significant effect on CYP1A2, CYP2D6, CYP2E1, and CYP3A4 activity for Ginkgo biloba was found [27]. But other studies observed that ginkgo inhibits CYP3A4 $[55,56]$. A study with 15 subjects showed that the geometric mean midazolam $\mathrm{AUC}_{(0-\infty)}$ prior to $\mathrm{GBE}$ administration was reduced by $34 \%$ after GBE administration [55]. The outcome of the study of Uchida and colleagues performed in 10 male healthy volunteers was an inhibiting effect of GBE on CYP3A4 activity as shown by an increased $\mathrm{AUC}_{(0-\infty)}$ by $25 \%$ and decreased oral clearance by $26 \%$ of midazolam, and an inducing effect on CYP2C9 activity according to a reduced $\mathrm{AUC}_{(0-\infty)}$ by $16 \%$ of tolbutamide [56]. A pharmacokinetic study in healthy volunteers conducted with diazepam as a substrate of CYP2C19 did not suggest the presence of an herb-drug interaction [57].

Altogether, it appears that GBE may have some effect on the activity of CYP enzymes when applied in patients, probably depending on the preparation used.

\section{Cranberry [Vaccinium macrocarpon (Aiton) (Ericaceae)]}

Cranberries are primarily cultivated for consumption as foods and beverages [58]. Products of the cranberry industry include fresh fruit (5\%), juices (60\%), sauces, dried fruit, and ingredients (35\%), such as frozen fruit, juice concentrates, and spray-dried 
powders $[59,60]$. Cranberry juice contains phytochemicals such as proanthocyanidins, flavonols, and quercetin [61]. The juice and concentrated extracts of cranberries are increasingly popular among consumers because of its use for the prevention and adjunctive treatment of urinary tract infections [58]. Moreover, cranberry juice shows efficacy in reducing urinary tract infections by acidifying the urine [62] and in reducing bacteriuria in elderly persons [63]. It also features positive effects against drug-resistant bacteria [64].

The large popularity of cranberry juice should give reason to examine its ability to cause herb-drug interactions. There are only a few data available. A clinical study in 8 healthy volunteers investigated the potential interaction between cranberry juice and diclofenac, a substrate of CYP2C9. An intake of $180 \mathrm{~mL}$ of cranberry juice twice a day for 5 days did not change the pharmacokinetics of diclofenac [65]. Another clinical study evaluated the effect of cranberry juice and other beverages on CYP2C9 activity. Fourteen healthy volunteers received flurbiprofen as a probe substrate for CYP2C9 in combination with $8 \mathrm{oz}$. of cranberry juice. None of the beverages altered CYP2C9-mediated clearance of flurbiprofen in humans [66]. Further investigations on CYP2C9 in clinical studies showed that cranberry juice also had no interaction potential on the pharmacokinetics of warfarin $[67,68]$. In addition to CYP2C9, Lilja and colleagues assessed the effect of cranberry juice on the activities of CYP1A2 and CYP3A4. Ten healthy volunteers took $200 \mathrm{~mL}$ cranberry juice thrice daily for 10 days. They observed no effects of cranberry juice on the pharmacokinetics of tizanidine (as CYP1A2 probe) and midazolam (as the CYP3A4 probe) [68]. Another clinical study in 12 healthy male volunteers revealed that an intake of $240 \mathrm{~mL}$ of cranberry juice did not affect the pharmacokinetics of cyclosporine as a substrate of CYP3A [69].

In summary, daily ingestion of more than 1 glass of cranberry juice seems not to alter the activities of cytochrome P450 enzymes.

\section{Soy [Glycine max (L.) Merr. (Fabaceae)]}

Soy is a plant native to East Asia, commonly grown for its bean, which has been reported to have various health benefits. Soybeans provide ample amounts of $\alpha$-linolenic acid [70] and significant amounts of isoflavones. Three soybean isoflavones, genistein, daidzein, and glycitein, and their various glycoside forms account for roughly 50,40 , and $10 \%$, respectively, of total isoflavone content [71]. Epidemiological and experimental researchers have provided extensive information on the anti-estrogenic effects of soy isoflavones on human health [72]. In China, Japan, Korea, and other countries in the Far East as well as lately in Western countries, the bean and products made from it such as soy sauce, soy flour, soy milk, and tofu are a popular part of the diet.

Hence, it is very important to take the ability of soy for an herbdrug interaction into account. A clinical study performed in 20 healthy volunteers examined the potential effect of daidzein on CYP1A2 activity and on the pharmacokinetics of theophylline as a probe substrate [73]. Plasma concentrations and derived parameters including $\mathrm{AUC}_{(0-48)}, \mathrm{C}_{\max }$, and $t_{1 / 2}$ were significantly increased by approximately one-third [73]. Another clinical study investigated the effect of $1 \mathrm{~g}$ genistein once daily for 14 days on the caffeine-based metrics of CYP1A2 and CYP2A6 in 18 healthy female volunteers [74]. Genistein decreased the urinary caffeine metabolite ratio used to assess CYP1A2 activity by $41 \%$, whereas the urinary ratio for CYP2A6 activity increased by $47 \%$, suggesting that genistein inhibited CYP1A2 and induced CYP2A6 [74]. A clinical study in 18 healthy Chinese female volunteers provided no effects of soy extract on the pharmacokinetics of losartan as a substrate of CYP2C9 and CYP3A4 [75]. A clinical study assessed the drug interaction potential of soy extract on CYP3A using the urinary excretion of the $6 \beta$-hydroxycortisol/cortisol ratio as a marker of enzyme induction. Twenty healthy subjects received a soy extract containing $50 \mathrm{mg}$ isoflavones twice daily for 14 days. The soy extract had no effect [76].

Altogether, soybean constituents may be weak inhibitors of CYP1A2, which translates into clinical relevance only in extraordinary situations.

\section{Asian ginseng [Panax ginseng (L.) (Araliaceae)]}

Asian ginseng (ginseng) is marketed for a wide range of indications, which include erectile dysfunction, cancer prevention, enhanced physical function, and improved cognitive functions [77]. Ginseng extracts are generally standardized to ginsenosides. Ginsenosides are a class of steroid glycosides and triterpene saponins [78]. The roots of Panax ginseng contain at least 25 different triterpene saponins [79]. Ginsenosides Rb1, Rb2, Rc, Rd, Re, Rf, and Rg1 are reported as major constituents and each ginsenoside has been shown to have different pharmacological effects, including immune system modulation, antistress activities, and antihyperglycemic activities, anti-inflammatory, antioxidant, and anticancer effects, antiplatelet, antithrombotic, vasodilatory, cardiotonic, angiogenic, and neuroprotective effects [79-82].

For an herbal drug to be widely used by the elderly community for a variety of indications, the ability of ginseng to cause metabolic drug-drug interactions should be determined. Clinical studies in humans have shown that Panax ginseng has no effect on a number of CYP enzymes [77]. In a cocktail interaction study with 12 healthy elderly volunteers (mean $=67$ years), Panax ginseng inhibited CYP2D6 activity assessed using debrisoquine urinary recovery ratios significantly, but only by $7.0 \%$ [27]. No significant effect on CYP1A2, CYP3A4, or CYP2E1 activity for Panax ginseng was found [27]. One trial investigated the interaction between warfarin and Panax ginseng in ischemic stroke patients. Twentyfive patients were enrolled in the study; twelve patients in the ginseng group received Panax ginseng and warfarin for 2 weeks, and the control group $(n=13)$ received only warfarin for the same duration of time. There were no statistically significant differences between the ginseng group and control group [80]. Another study in 12 healthy male subjects conducted to investigate the effect of ginseng on the pharmacokinetics and pharmacodynamics of warfarin found no clinically significant changes in AUC, $t_{1 / 2}$, and apparent total clearance [83]. This study confirmed that ginseng had no effect on the activity of CYP1A2, CYP3A4, or CYP2C9 in healthy volunteers [83]. Another clinical study could also not show any effect of Panax ginseng on CYP3A. Twenty healthy subjects received $100 \mathrm{mg}$ Panax ginseng standardized to $4 \%$ ginsenosides twice daily for 14 days. The urinary excretion of the $6 \beta$-hydroxycortisol/cortisol ratio was used as a marker of $\mathrm{CY}$ P3A induction but no significant alteration was observed for Panax ginseng [76].

In summary, it appears that Asian ginseng has no effect on the activity of CYP enzymes in vivo.

\section{Black cohosh [Actaea racemosa (L.) Nutt. (Ranunculaceae)]}

Extracts of black cohosh are made from the roots and rhizomes of the plant. Black cohosh preparations (tinctures or tablets of dried materials) are commonly used as an alternative to hormone ther- 
apy in perimenopausal women to treat symptoms such as hot flashes, vaginal dryness, and mood swings [19,84].

A few clinical studies conducted the effect of black cohosh on human cytochrome P450 enzymes. A cocktail interaction study with 12 healthy volunteers showed no significant effects of black cohosh on CYP1A2, CYP2E1, and CYP3A4 activity, but it did have an effect on CYP2D6 [85]. Black cohosh exhibited a statistically significant decrease in the CYP2D6 phenotype $(p=0.02)$, but the magnitude of the result $(\sim 7.0 \%$ reduction) is not clinically relevant [85]. In another clinical study with 18 normal volunteers, Gurley et al. assessed the influence of black cohosh only on the activity of CYP2D6 to corroborate their earlier findings. This time, comparisons of pre- and post-supplementation of 8-hour debrisoquine urinary recovery ratios revealed no statistically significant effects on CYP2D6 [36]. Another pharmacokinetic study in 19 healthy volunteers conducted with midazolam as a substrate of CYP3A also did not suggest the presence of an herb-drug interaction [86].

In summary, black cohosh appears to have no clinically relevant effects on cytochrome P450 activity.

\section{St. John's wort [Hypericum perforatum (L.) (Hypericaceae)]}

St. John's wort (SJW) is an herbaceous perennial plant native to Europe. Extracts obtained from the aerial parts of Hypericum perforatum have been recommended traditionally for a wide range of medical conditions [87]. St. John's wort is commonly used to treat mild-to-moderate depression but is also used to treat anxiety, obsessive-compulsive disorder, and premenstrual syndrome [19]. The extracts of SJW contain numerous pharmacologically active ingredients, including naphthodianthrones (e.g., hypericin and its derivatives) and phloroglucinols derivatives (e.g., hyperforin, which inhibits the reuptake of a number of neurotransmitters, including serotonin) [87]. The most common recommended dose is $900 \mathrm{mg}$ per day standardized to $0.3 \%$ hypericin to treat depression [19].

Several clinical studies have clearly revealed that SJW may alter CYP activity. Many of the interaction studies indicate that SJW is a potent inducer of CYP3A4, CYP2E1, and CYP2C19, with no effect on CYP1A2, CYP2D6, or CYP2C9 [20,77]. The effect of SJW on CYP3A4 is seen after long-term treatment. Markowitz et al. assessed the effects of SJW on CYP2D6 and CYP3A4 activity. Seven normal subjects received 3 times daily a commercial SJW formulation $\left(\right.$ Solaray $^{\circledR}$ ) $300 \mathrm{mg}$, standardized to $0.3 \%$ hypericin for 4 days. Dextromethorphan (CYP2D6 activity) and alprazolam (CYP3A4 activity) were administered as probe substrates. No statistically significant differences were found in any estimated pharmacokinetic parameter for alprazolam or dextromethorphan for this short-term treatment [88]. A cocktail interaction study with 12 healthy volunteers examined the effect of SJW on CYP activity. Tolbutamide (CYP2C9), caffeine (CYP1A2), dextromethorphan (CYP2D6), oral midazolam (intestinal wall and hepatic CYP3A), and intravenous midazolam (hepatic CYP3A) were administered before, with short-term SJW dosing (900 mg), and after 2 weeks of intake (300 mg 3 times a day) to determine CYP activities [89]. Short-term administration of SJW had no effect on CYP activities. Long-term SJW administration caused a significant $(p<0.05)$ increase in oral clearance of midazolam and a corresponding significant decline in oral bioavailability [89]. There are many other clinical studies that confirm these findings. Another clinical cocktail interaction study assessed the influence of SJW on the activity of CYP1A2, CYP2D6, and CYP3A4. Eight healthy male and 8 healthy female subjects were treated with SJW extract $\left(3 \times 300 \mathrm{mg} \cdot\right.$ day $\left.^{-1}\right)$ for 14 days [90]. After 2 weeks of treatment with SJW, the mean increase in the $6 \beta$-hydroxycortisol/cortisol molar concentration ratio in urine, used as an index of activity of CYP3A4, was $85 \%$. Additionally, the authors found a slight (but not significant) increase in the paraxanthine/caffeine ratio in saliva after SJW. However, most of the subjects exhibiting an apparent induction of CYP1A2 were females [90]. No influence of SJW on CYP2D6 activity was found [90]. A clinical cocktail interaction study performed in 12 elderly subjects (mean $=67$ years) assessed the pre- and post-supplementation phenotypic ratios for CYP3A4, CYP1A2, CYP2E1, and CYP2D6 [27]. Twentyeight days of SJW supplementation resulted in a $141 \%$ increase in the mean one-hour 1-hydroxymidazolam/midazolam serum ratio ( $p<0.001$ ) [27]. Similar to its effect on CYP3A4, SJW produced significant increases in CYP2E1 activity $(p=0.006)$. No statistically significant differences in mean values were noted for CYP1A2 and CYP2D6 [27]. In a later clinical study performed by the same researchers [36], no significant differences were observed among the mean baseline debrisoquine urinary recovery ratio by supplementation of 14 days of SJW. In contrast to Wenk and colleagues, no sex-related changes in CYP phenotypes were noted. Two further clinical studies suggested that SJW is an inducer of CYP3A4 following 14 days of treatment [91,92]. There are also two clinical studies which determined the effect of SJW on CYP2C19 activity. In each study, 12 healthy volunteers received a 300-mg SJW tablet 3 times daily for 14 days. In one study, the activities of CYP2C19 and CYP1A2 were measured using mephenytoin and caffeine, respectively [93], and in the other study, the activities of CYP2C19 and CYP3A4 were measured using omeprazole [94]. In both studies, it was found that SJW treatment significantly increased CYP2C19 activity.

Furthermore, clinical data imply that hyperforin content affects the extent of SJW interactions, since extracts with a low hyperforin amount had a weak or no effect on CYP activity. A clinical study compared the effects of 2 SJW preparations with high and low hyperforin content on the pharmacokinetics of cyclosporine. In a crossover study, 10 renal transplant patients were randomized into 2 groups and received SJW extract $300 \mathrm{mg}$ (two $150 \mathrm{mg}$ capsules) 3 times a day (total dose, $900 \mathrm{mg} / \mathrm{d}$ ) containing low or high concentrations of hyperforin for 14 days in addition to their regular regimen of cyclosporine [95]. The study showed a significant difference between the effects of the 2 SJW preparations on cyclosporine pharmacokinetics. The area under the plasma concentration-time curve, within one dosing interval $\left(\mathrm{AUC}_{0-12}\right.$; $\mathrm{p}<0.0001$ ), values with high hyperforin SJW comedication were $45 \%$ lower ( $95 \%$ CI $-37 \%$ to $-54 \%$; $\mathrm{p}<0.05$ ) than for low hyperforin SJW [95]. Arold and colleagues performed two clinical interaction studies with 28 healthy volunteers in each study. In study A, alprazolam (CYP3A4) and caffeine (CYP1A2), and in study B, tolbutamide (CYP2C9) and digoxin (p-glycoprotein), were given as probe substrates, respectively. The participants received SJW with a low hyperforin content (Esbericum ${ }^{\circledR}$ capsules; $240 \mathrm{mg}$. day $^{-1}, 3.5 \mathrm{mg}$ hyperforin) or placebo for 10 days. No statistically significant differences were found in the primary kinetic parameters between the placebo group and the SJW group at the end of both studies [96]. Another two clinical studies conducted by Mueller and colleagues evaluated the effect on CYP3A function of SJW preparations with a wide range from very low to high hyperforin content. In the first study, 42 healthy volunteers were randomized into 6 different SJW medication groups for 14 days. A single oral dose of midazolam was used as a probe substrate. 
All SJW preparations tested resulted in a decrease in midazolam AUC, although the extent of the effect differed [97]. St. John's wort extract with a hyperforin content of $41 \mathrm{mg} /$ day decreased midazolam $\mathrm{AUC}_{0-12}$ by $79.4 \%$ (95\% CI -88.6 to - 70.1). St. John's wort powder tablets with a hyperforin content of $12 \mathrm{mg} /$ day resulted in a decrease of $47.9 \%(95 \% \mathrm{CI}-59.7$ to - 36.2), while SJW powder tablets with an amount of $0.13 \mathrm{mg} /$ day of hyperforin reduced midazolam $\mathrm{AUC}_{0-12}$ by only $21.1 \%$ (95\% CI -33.9 to -8.3 ) [97]. The second study evaluated the effect of an SJW powder only with a low hyperforin content on CYP3A function. Twenty healthy male volunteers received SJW as capsules containing $500 \mathrm{mg}$ Hyperici herba powder with $0.06 \mathrm{mg}$ total hyperforin per capsule and had to take two capsules per day, for 14 days. Midazolam $\mathrm{AUC}_{0-\infty}$ was reduced by $11.3 \%$ (95\% CI -22.8 to 0.21 ) indicating a significant but mild induction of CYP3A function [98]. No significant changes were observed after SJW treatment regarding midazolam $\mathrm{C}_{\max }, t_{\max }$, and $t_{1 / 2}(\mathrm{p}>0.05)$ [98].

Apart from using probe drugs in clinical interaction studies to show that SJW is a potential inducer of CYP3A4, CYP2E1, and CYP2C19, SJW has also been shown to have the ability to clinically interact with a number of frequently used drugs. St. John's wort may reduce the efficacy of oral contraceptives (e.g., induction of ethinyl estradiol-norethindrone metabolism $[99,100]$; decrease in serum 3-ketodesogestrel concentrations [101]), may reduce the pharmacokinetics of imatinib by increasing its clearance $[102,103]$, may interact with cardiovascular drugs (e.g., decreased plasma concentrations of atorvastatin [104], ivabradine [105], and R- and S-verapamil [106]), may induce the apparent clearance of both S- and R-warfarin, which in turn resulted in a significant reduction in the pharmacological effect of rac-warfarin [83], may interact with drugs acting on the central nervous system (e.g., decreased plasma concentration of quazepam [107], alprazolam [92], and midazolam [27,89,97,99]), may reduce plasma voriconazole concentrations after long-term but not short-term administration [108], may alter gliclazide pharmacokinetics [109], and may reduce the AUC of the HIV-1 protease inhibitor indinavir [110].

In summary, clinical evidence of the effects of SJW on CYP enzymes is undisputed. There are numerous studies which have shown that the inducing effect of SJW depends on treatment duration and the preparation, primarily the amount of hyperforin. Patients and physicians should be well informed about the interaction potential of St. John's wort.

Milk thistle [Silybum marianum (L.) Gaertn. (Asteraceae)] Extracts of milk thistle are recognized for the treatment of liver injury. The active principle is a mixture of flavolignans called Silymarin [20]. Silymarin is made from the seeds of milk thistle and is composed of six closely related flavonolignans (silibinin, isosilybin A, isosilybin B, silychristin, isosilychristin, silydianin) and one flavonoid (taxifolin) [111]. Silibinin, the major active constituent of silymarin, consists of 2 diasteroisomers, silybin A and silybin B $[111,112]$. Silymarin has cytoprotective, antioxidative, and radical scavenging as well as anti-inflammatory and antifibrotic properties [14]. It is used to self-treat hepatic disorders, including hepatitis $C$ and cirrhosis, and as a hepatoprotectant, particularly for mushroom poisoning [113].

For a popular herbal product to be taken for hepatoprotection and chemoprevention, the ability of milk thistle extract to cause metabolic drug-drug interactions should be known. Several in vivo studies in humans indicate that milk thistle has no effect on the hepatic drug oxidation system. A clinical study was con- ducted to examine the effect of silymarin on cytochrome P450 3A4. Sixteen healthy male volunteers were administered with immediate release nifedipine as a CYP3A4 test drug either alone or with the coadministration of silymarin. The coadministration of silymarin for 1 day did not considerably change the extent of absorption or metabolism of nifedipine but might decrease the absorption rate. Silymarin was not a potent CYP3A4 inhibitor in vivo [14]. Van Erp and colleagues investigated the effect of milk thistle on the pharmacokinetics of irinotecan, a substrate for CYP3A4. Neither short-term intake (4 days) nor long-term intake (12 days) of milk thistle showed significant effects on irinotecan clearance [114]. Gurley et al. investigated the in vivo effect of milk thistle on human cytochrome P450 three times. A clinical study with 19 normal subjects assessed the clinical significance of milk thistle supplementation on human cytochrome P450 3A activity. The study's purpose was to compare the effect of milk thistle on CYP3A to a clinically recognized inducer, rifampin, and inhibitor, clarithromycin. In contrast to rifampin and clarithromycin, no significant changes in the probe substrate midazolam pharmacokinetics were observed as a result of milk thistle supplementation [86]. In a similar study, 18 healthy volunteers were administered with a standardized milk thistle extract to assess the effect on cytochrome P450 2D6. The study conducted with debrisoquine as a substrate of CYP2D6 also did not suggest the presence of an herb-drug interaction [36]. In a cocktail interaction study with 12 healthy volunteers, he and his colleagues determined long-term supplementation of milk thistle extracts on CYP1A2, CYP2D6, CYP2E1, or CYP3A4 activity. They found no statistically significant differences in mean CYP1A2, CYP2D6, CYP2E1, or CYP3A4 phenotypic ratios [35].

In summary, current data suggest that milk thistle has no major effects on the activity of CYP enzymes when applied in patients.

\section{Green tea [Camellia sinensis (L.) Kuntze (Theaceae)]}

After withering the freshly picked leaves, a brief heating, roasting, or steaming prevents the fermentation of the tea leaves. For this reason, almost all active ingredients such as catechins (70\%), minor flavonols (10\%), and polymeric flavonoids (20\%) contained in the fresh leaves will remain [19]. The main catechin component of green tea is epigallocatechin gallate (EGCG) that accounts for $50-80 \%$ of the catechins in green tea $[115,116]$. Polyphenon $\mathrm{E}^{\circledR}$ (Poly E), for example, is a widely used concentrated green tea extract (GTE) from green tea leaves. It contains a total catechin fraction of $89 \%$ with EGCG as the main component accounting for $65 \%$ of the material followed by $9.0 \%$ epicatechin, $6.6 \%$ epicatechin gallate, $3.8 \%$ epigallate catechin, $1.0 \%$ catechin, $0.2 \%$ gallocatechin, and $0.2 \%$ catechin gallate [117]. Green tea, GTE, and its major active compound ECGC demonstrated antioxidant, anticarcinogenic, anti-inflammatory, antiatherogenic, immunomodulatory, and chemopreventive properties [118-121]. It has antiatherosclerotic effects on dysfunctional vessels in smokers through increasing the level of nitric oxide and reducing oxidative stress $[122,123]$. Green tea may have cardiovascular protecting effects through inhibition of angiotensin-converting enzyme activity [124]. Standardized green tea compounds are effective for decreasing blood pressure, low-density lipoprotein cholesterol, and oxidative stress [125].

The large variety of assumed medical uses of green tea imply that the potential for drug interactions could be high. A clinical study with 11 healthy volunteers assessed the influence of decaffeinated GTE (dGTE) on the activity of CYP2D6 and CYP3A4. The probe substrates dextromethorphan (CYP2D6 activity) and al- 
prazolam (CYP3A4 activity) were administered orally at baseline, and again after treatment with four dGTE capsules $(<1 \mathrm{mg}$ caffeine) per day for 14 days. No significant differences in dextromethorphan and alprazolam pharmacokinetics were observed at baseline and after treatment with dGTE indicating a lack of effect on CYP2D6 and CYP3A4 [126]. In a clinical cocktail interaction study with 42 healthy volunteers, no clinically significant effects on CYP1A2, CYP2C9, CYP2D6, and CYP3A4 activity for GTE were found [127]. The study participants received a cocktail of CYP metabolic probe drugs, including caffeine, losartan, dextromethorphan, and buspirone for assessing the activity of CYP1A2, CYP2C9, CYP2D6, and CYP3A4, respectively. The subjects underwent 4 weeks of green tea catechin intervention at a dose that contains $800 \mathrm{mg}$ EGCG daily. The intervention did not alter the phenotypic indices of CYP1A2, CYP2C9, and CYP2D6, but resulted in a $20 \%$ increase $(p=0.01)$ in the area under the plasma buspirone concentration-time profile, suggesting a small reduction in CYP3A4 activity [127].

Overall, both authors concluded that repeated green tea catechin administration is unlikely to modify the disposition of medications metabolized by CYPs.

\section{Valerian [Valeriana officinalis (L。) (Valerianaceae)]}

Valerian is a popular remedy prepared from its roots, rhizomes (underground stems), and stolons (horizontal stems). The root is chiefly used for medicinal benefits. It can be found in capsule, tea, tablet, or liquid extract forms. The most abundant constituents of valerian are monoterpenes and sesquiterpenes, including the genus-specific valepotriates and valerenic acid [128]. Valerian root also contains appreciable levels of gamma-aminobutyric acid (GABA) [129] and has sedative, anxiolytic, and hypnotic properties [130]. It is often taken to help alleviate insomnia. There are several clinical studies to evaluate the evidence of efficacy of valerian as a treatment for insomnia [131-134].

A clinical study with 12 normal volunteers assessed the influence of a valerian supplement on the activity of CYP2D6 and CYP3A4. The probe substrates dextromethorphan (CYP2D6 activity) and alprazolam (CYP3A4 activity) were administered orally at baseline, and again after exposure to two valerian tablets nightly for 14 days. Valerian showed no clinically relevant effects on the disposition of medications primarily dependent on the CYP2D6 or CYP3A4 pathways for metabolism [135]. In a clinical interaction study with 12 healthy volunteers, the study participants received valerian for 28 days. Probe drug cocktails of caffeine for CYP1A2 activity and midazolam for CYP3A4 activity, followed 24 hours later by debrisoquine for CYP2D6 activity and chlorzoxazone for CYP2E1 activity to avoid potential interference, were administered before (baseline) and at the end of supplementation. Valerian had no significant effect on any CYP phenotypes [85].

In summary, valerian appears unlikely to produce CYP-mediated herb-drug interactions.

\section{Kava [Piper methysticum (G.) Forst. (Piperaceae)]}

Kava is still a popular herbal beverage. The commercial products, if not withdrawn from the market for hepatotoxicity, are prepared from dried rhizomes of the kava plant, and the more contemporary dosage form is a capsule, which usually contain a standard $30 \%$ of kavalactones. The constituents of kava extract are kavalactones, kawain, methysticin, dihydromethysticin, desmethoxyyangonin, and dihydrokawain [19]. Kavalactones, the assumed active principles, are predominantly concentrated in the plant's rhizome rather than in its upper stems or leaves [136]. Ka- valactones effects are a slight numbing of the gums and mouth, and vivid dreams. Kava has been reported to improve cognitive performance and promote a cheerful mood [137]. Kava has anxiolytic and sedative properties and is often suggested to alleviate the symptoms of anxiety [138].

There are only a few clinical studies which revealed the clinical influence of potential interactions mediated by cytochrome P450 enzymes. A clinical study performed by Gurley and colleagues assessed the kava supplementation on human CYP3A activity using midazolam as a phenotypic probe. Sixteen healthy volunteers received kava for 14 days. Midazolam disposition was not affected by kava supplementation [139]. The same research group assessed the influence of kava on the activity of CYP2D6 in a clinical study with 18 healthy volunteers. Kava was not a potent modulator of human CYP2D6 in vivo [36]. A cocktail interaction study in 12 healthy subjects for 28 days showed no significant effects on CYP1A2, CYP2D6, and CYP3A4 activity for kava, but significantly reduced phenotypic ratios for CYP2E1 $(\sim 40 \%$, $\mathrm{p}=0.009)[85]$.

In summary, kava may interact with CYP2E1 substrates. Thus, concomitant ingestion of kava and drugs that are CYP2E1 substrates may increase their therapeutic and adverse effects.

\section{Goldenseal [Hydrastis canadensis (L.) (Ranunculaceae)]}

Goldenseal is used as a versatile herbal remedy and has many different medicinal properties. Its roots and rhizomes, which internally are bright yellow in color, have been used as a traditional medicine for the treatment of infection, inflammation, and as an immune system booster. It is taken orally to treat upper respiratory infections and gastrointestinal tract disorders [140]. Modern herbalists consider it an alternative anticatarrhal, anti-inflammatory, antiseptic, astringent, bitter tonic, laxative, and muscular stimulant [140]. Commercial preparations of goldenseal may be purchased in tincture form or as a liquid extract [141]. Goldenseal extract contains isoquinoline alkaloids, including berberine, (+)- and (-)-hydrastine, and lesser amounts of hydrastinine [142]. Chemically, these three goldenseal alkaloids possess a methylenedioxyphenyl moiety, which, in studies of cytochrome P450 (P450) -dependent drug metabolism, frequently give rise to inhibition [142].

Gurley et al. determined the effects of goldenseal supplementation only on human CYP3A activity. Sixteen healthy volunteers received goldenseal for 14 days. Statistically significant increases $(\mathrm{p}<0.05)$ in midazolam $\mathrm{AUC}_{(0-\infty)}(62 \%)$, elimination half-life (57\%), and $C_{\max }(41 \%)$ were observed after goldenseal extract supplementation. Goldenseal reduced midazolam apparent oral clearance by $36 \%(p<0.001)$ [139]. The same research group conducted a clinical assessment in 18 healthy volunteers on the effects of goldenseal only on human CYP2D6 activity. Pre- and post-supplementation phenotypic trait measurements were determined for CYP2D6 using 8-hour debrisoquine urinary recovery ratios. Comparisons of pre- and post-supplementation 8hour debrisoquine urinary recovery ratios revealed significant inhibition $(\sim 50 \%)$ of CYP2D6 activity for goldenseal [36]. In a cocktail interaction study, 12 healthy volunteers received goldenseal for 28 days. The probe drug cocktail of midazolam (for CYP3A4/5 activity) and caffeine (CYP1A2 activity), followed 24 hours later by chlorzoxazone (CYP2E1 activity) and debrisoquine (CYP2D6 activity), were administered before (baseline) and at the end of supplementation. Goldenseal produced significant reductions in CYP2D6 $(\mathrm{p}<0.0001)$ and CYP3A4/5 $(\mathrm{p}<0.0001)$ phenotypes [85]. 
Overall, goldenseal seems to be a mild to moderate inhibitor of CYP3A4/5 and CYP2D6. Accordingly, patients should refrain from taking goldenseal supplements concomitantly with prescriptive medications, particularly those extensively metabolized by CYP2D6 and CYP3A4/5.

\section{Other herb-drug interactions}

In addition to the herbs described above, there are further plants with therapeutic benefits, which have been investigated with regard to effects on the human cytochrome P450 drug metabolizing system. A clinical study in 12 healthy male subjects showed no effect of ginger [Zingiber officinale (R.) (Zingiberaceae)] on the pharmacokinetic parameters of S- or R-warfarin [49]. A cocktail interaction study investigated the effects of multiple doses of three herbal medicines on metabolic activities of CYP1A2, 2C9, 2C19, 2D6, 2E1, and 3A4 [143]. The roots of Angelica tenuissima (L.) [Apiaceae], Angelica dahurica (L.) [Apiaceae], and Scutellaria baicalensis (L.) [Lamiaceae] were administered to 24 healthy male volunteers. Angelicae tenuissimae radix had no influences on CYP activities. Angelicae dahuricae radix significantly decreased CYP1A2 activity to $10 \%$ of baseline activity (95\% CI $0.05-0.21)$. Scutellariae radix showed significant changes in CYP2C9 and CYP2E1 activities. Baseline values for losartan as a CYP2C9 probe were decreased to $71 \%(0.54-0.94)$ and the metabolic activity of chlorzoxazone as a CYP2E1 probe showed a 1.42fold (1.03-1.97) increase [143]. Furthermore, in another study with 17 healthy male subjects, baicalin, a flavone glucuronide of baicalein extracted from Scutellariae radix, significantly induced CYP2B6 activity as measured by bupropion hydroxylation (an average $63 \%$ increase in the AUC ratio of hydroxybupropion over bupropion and an $87 \%$ increase in the AUC of hydroxybupropion) [144]. There are also several other single constituents of plants which may have effects on cytochrome P450 enzymes. For example, resveratrol as the main non-flavonoid polyphenol found in red wine and grapes [Vitis vinifera (L.) (Vitaceae)] has a wide range of biological and pharmacological activities including antioxidant, anti-inflammatory, antimutagenic, and anticarcinogenic effects [145]. A cocktail interaction study in 42 healthy volunteers determined the effect of pharmacological doses of resveratrol on CYP1A2, CYP2C9, CYP2D6, and CYP3A4. Resveratrol intervention was found to inhibit the phenotypic indices of $\mathrm{CY}$ P3A4, 2D6, and 2C9, and to induce the phenotypic index of $1 \mathrm{~A} 2$ [146]. Curcumin, a yellow curry spice extracted from the rhizome of Curcuma longa (L.) [Zingiberaceae], is a polyphenolic non-flavonoidic that displays anti-inflammatory and antioxidant activities [145]. A clinical study with 16 unrelated, healthy Chinese men investigated the effect of curcumin on the activities of CYP1A2 and CYP2A6 using caffeine as a probe drug. Cytochrome P450 1A2 activity was decreased by $28.6 \%$ (95\% CI 15.6-41.8; $\mathrm{p}<0.000$ ), while increases were observed in CYP2A6 (by $48.9 \%$; $95 \%$ CI 25.3-72.4; p<0.000) [147].

\section{Limitations}

Reported drug-herb interaction studies used a broad range of specific preparations of the respective herbs. The information on these preparations is sparse in many of the studies, and even if commercial products have been used, other batches will have different compositions and thus may have different potentials do cause drug-drug interactions. Phytopharmaceuticals composed of different fractions from parts of a plant (leaves, roots, seeds, fruit, other parts) may have completely different compositions. Thus, any extrapolation of the data gathered here to other prod- ucts is flawed to an unknown extent. Furthermore, many studies used invalid phenotyping metrics and/or had small numbers of participants without proper estimation of the sample size required to answer the scientific question. The published literature thus provides only a rough estimate to which extent marketed drugs prepared from specific plants or other preparations of these plants, such as infusions, would indeed cause clinically relevant drug interactions in patients.

\section{Conclusions}

Our article provides a brief description of clinical interaction studies between phytopharmaceuticals and human cytochrome P450 enzymes for the top 14 common botanicals sales in the U.S. The majority of the herbal drugs appeared to have no clear effects on most of the CYPs examined. If there were an effect, the herbal drugs would qualify as mild inhibitors (less than a 2fold change in enzyme activity) in almost all cases, e.g., in the case of inhibition of CYP2E1 by garlic and by kava or for inhibitory effects of soybean components on CYP1A2. The most pronounced effects were the well-known induction of several members of the CYP family by St. John's wort and the inhibitory effect of goldenseal on CYP3A and CYP2D6, both being borderline between mild and moderate (more than 2-fold but less than 5-fold) in magnitude. With these two exceptions, concomitant intake of herbal drugs is not a major risk for drugs that are metabolized by CYPs.

\section{Conflict of Interest \\ $\nabla$}

No conflict of interest is to be declared. 


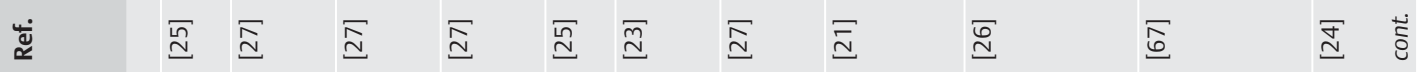

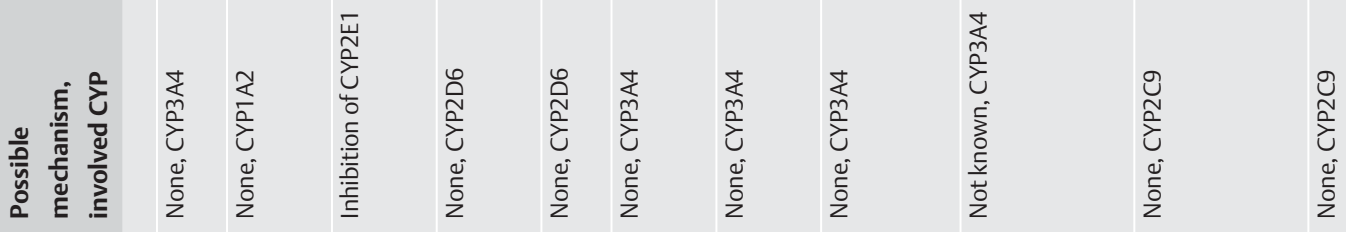

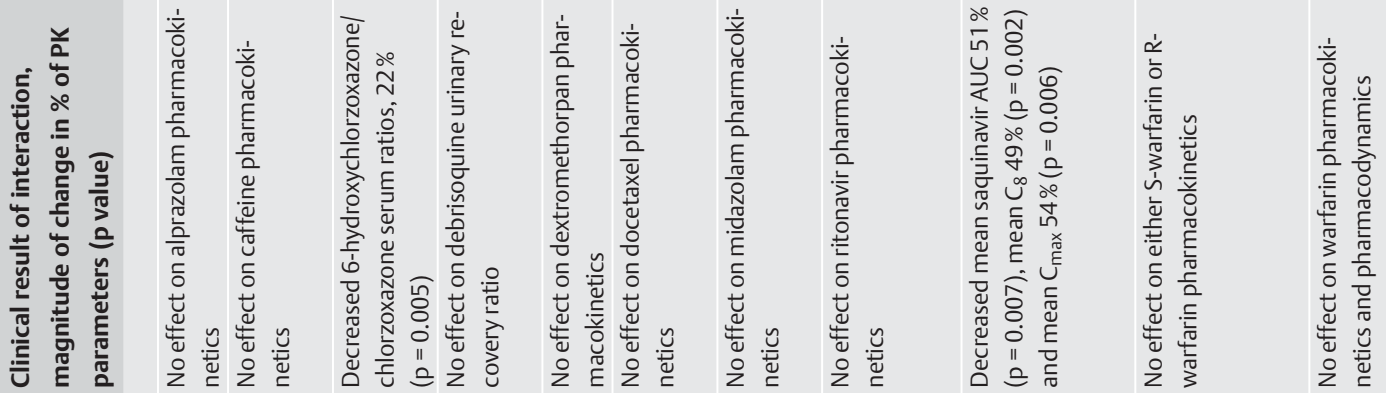

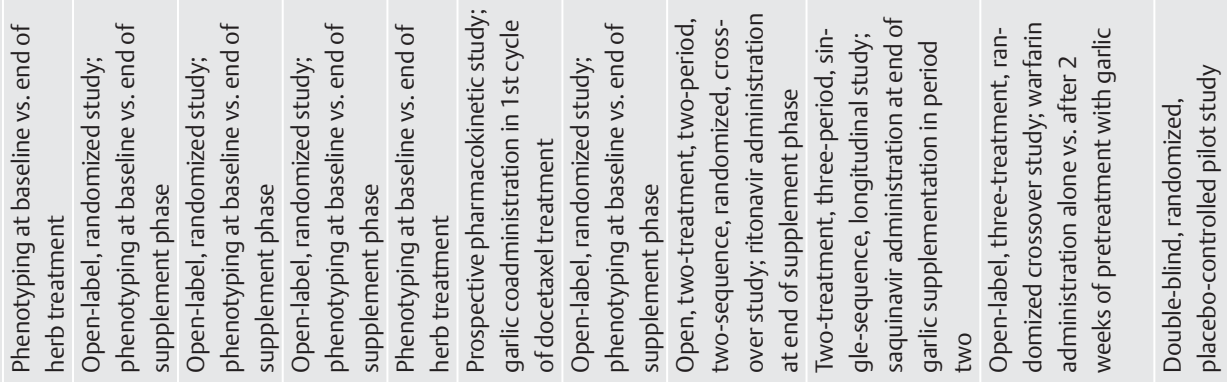

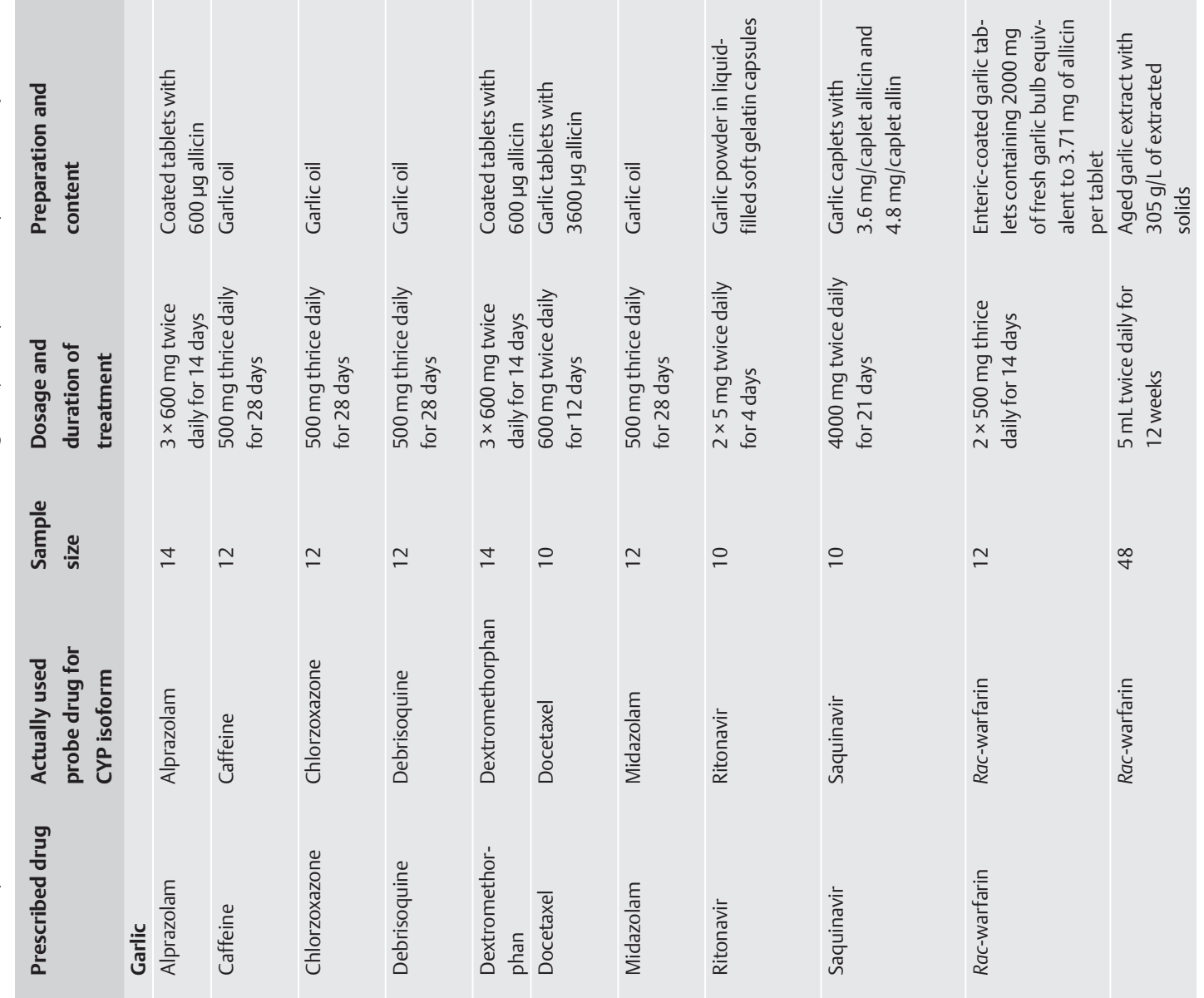




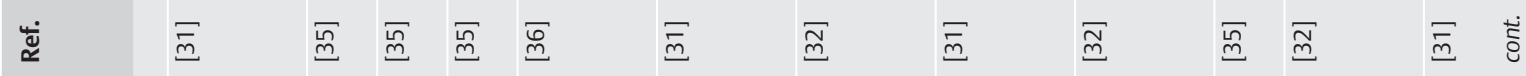

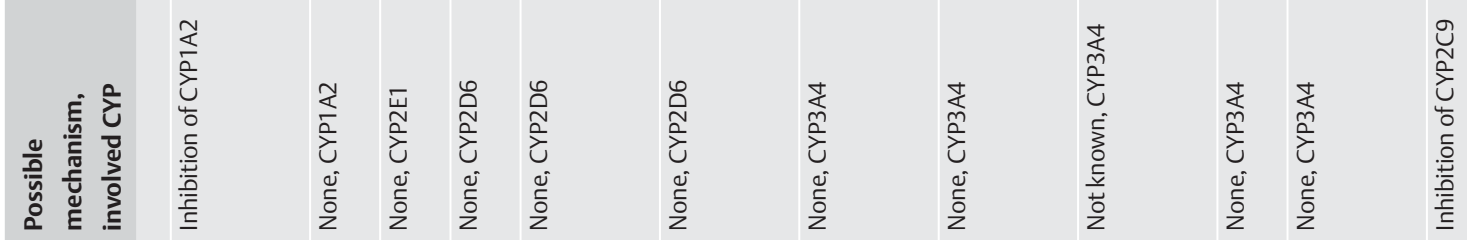

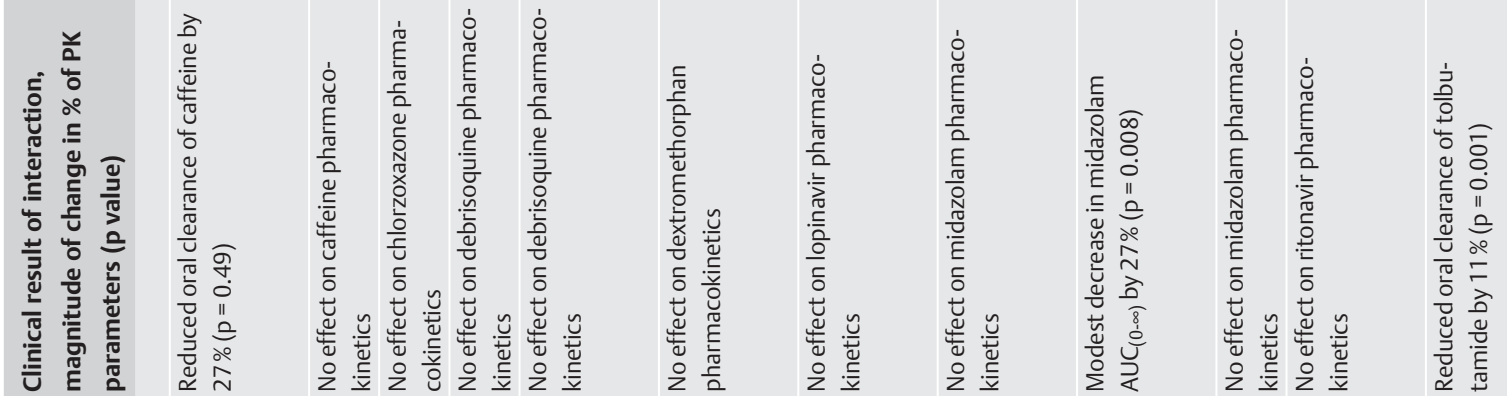

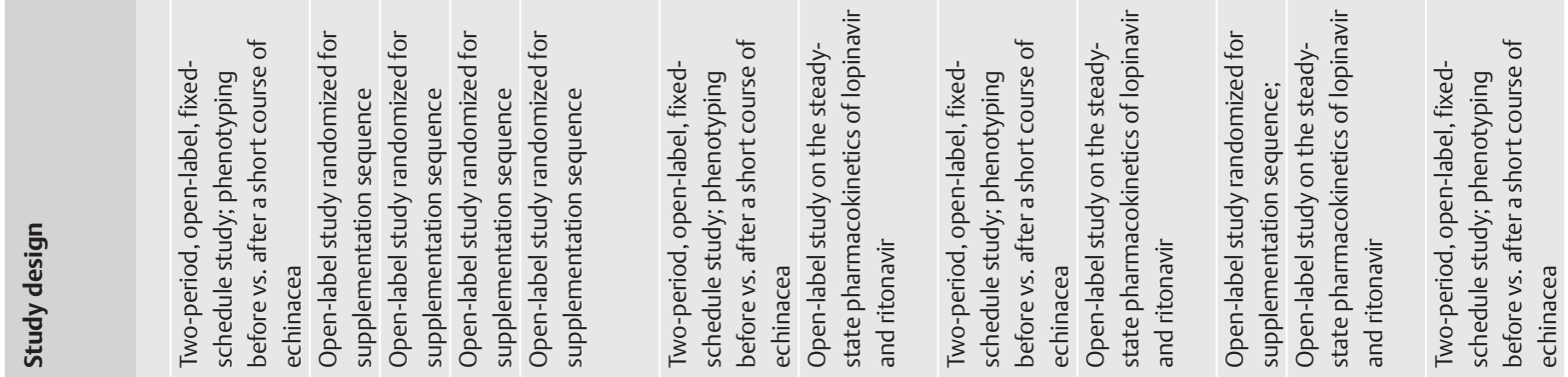
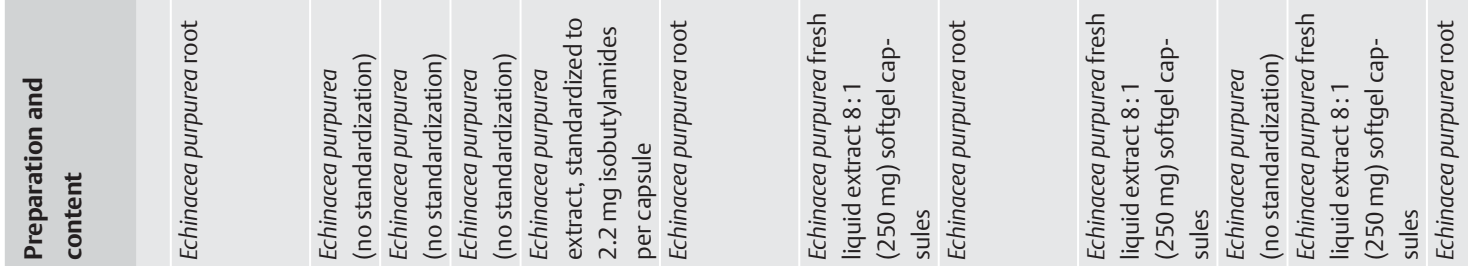

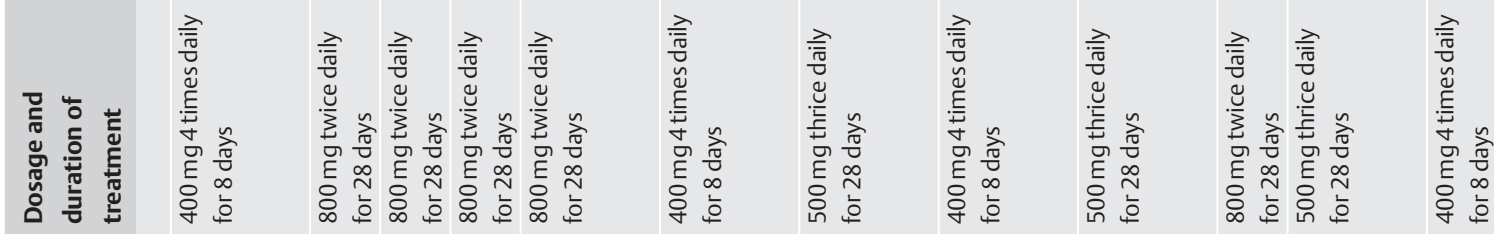
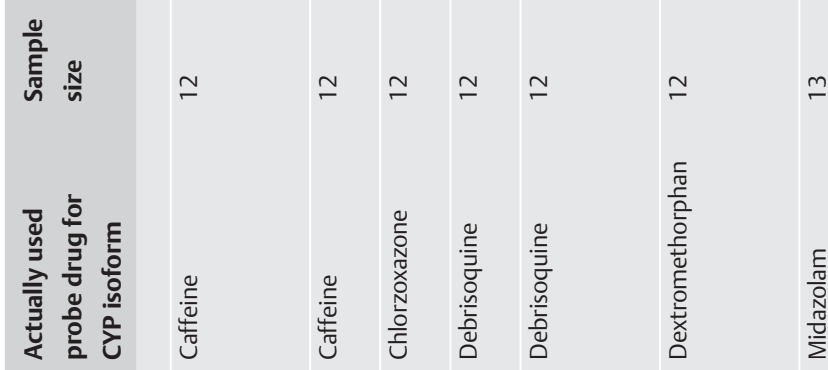

$\frac{1}{0}$
$\frac{\pi}{0}$
$\frac{\pi}{2}$
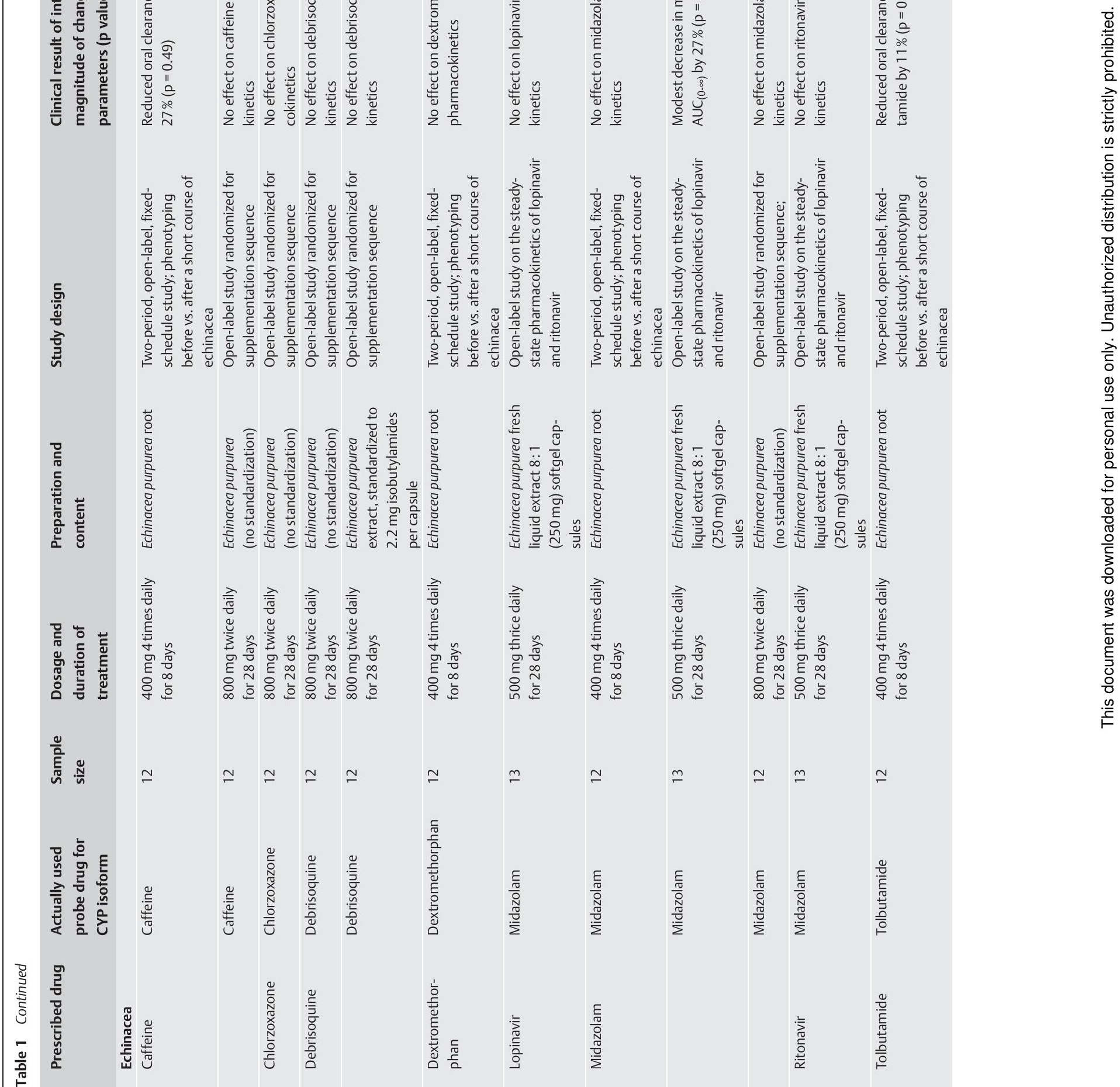

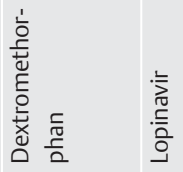

$\frac{E}{2}$
$\frac{\pi}{0}$
$\frac{\pi}{2}$

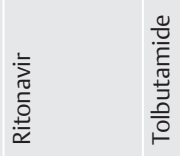




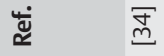

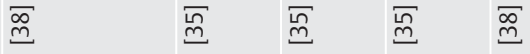

邑 胥

$\underline{\tilde{n}}$

હ

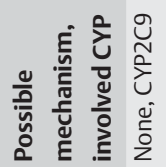

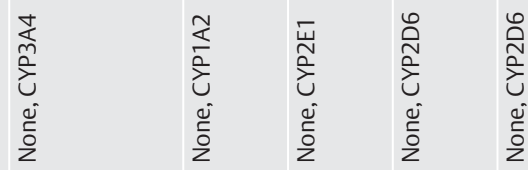

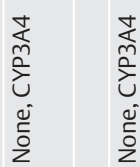

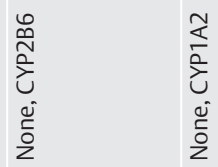
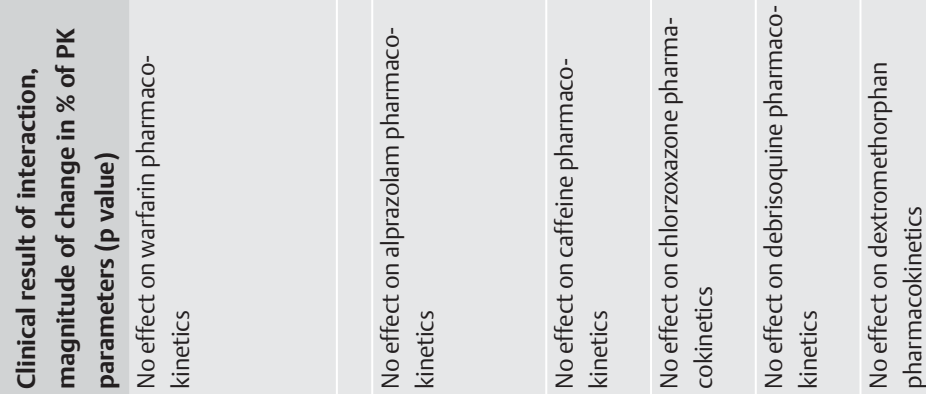

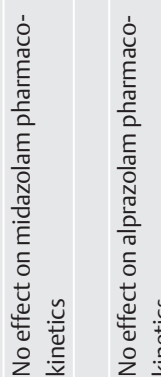

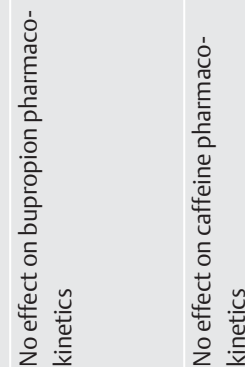

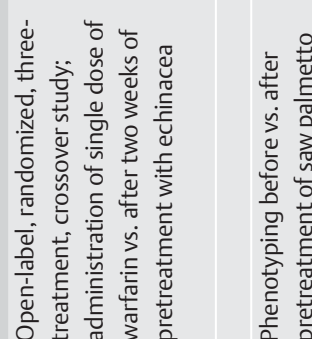
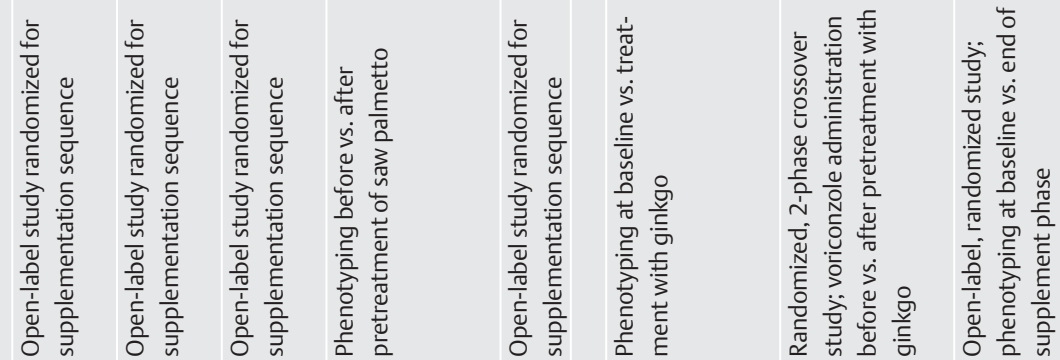

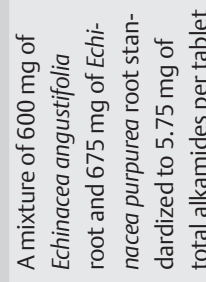

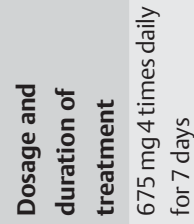

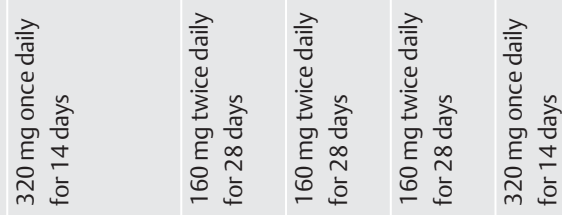

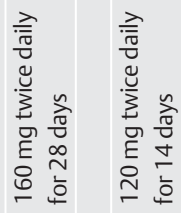

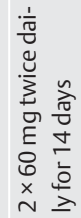

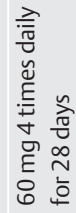

竎 $\frac{N}{n} \simeq$

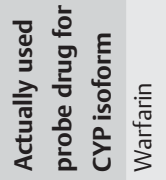

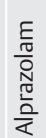

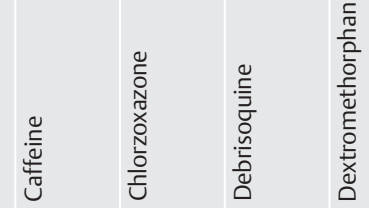

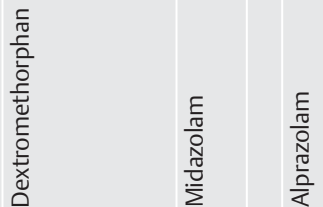

$\frac{5}{\circ \frac{0}{0}}$

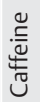

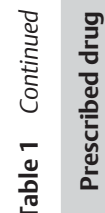

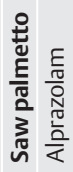

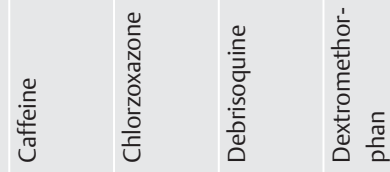

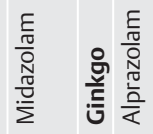

흠

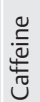



פ
פ
호
폼
$\underline{\underline{\underline{S}}}$
포
皮

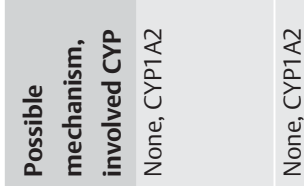

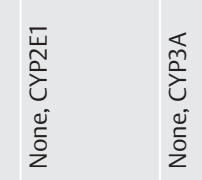

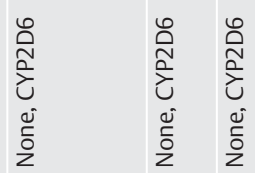

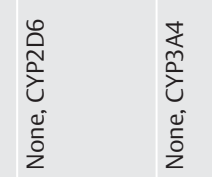

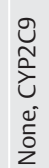

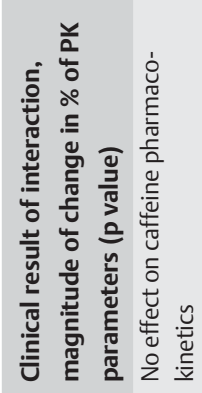

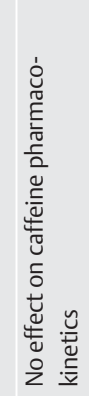

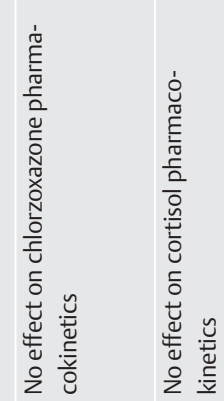

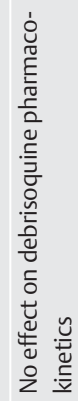

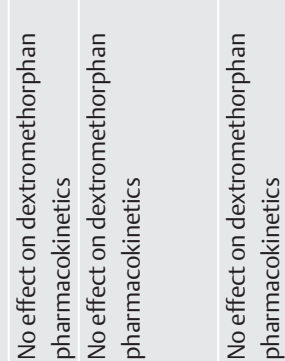

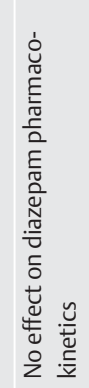

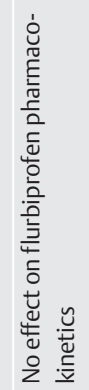

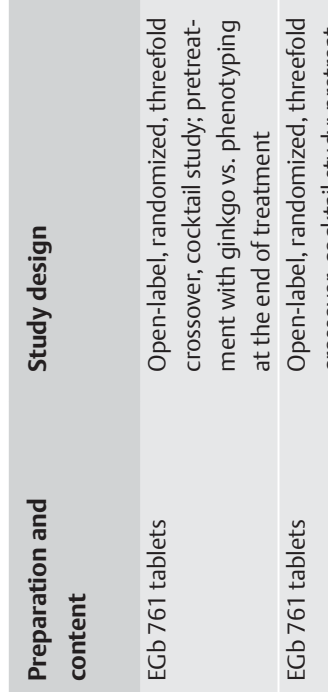

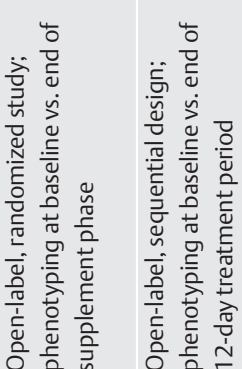

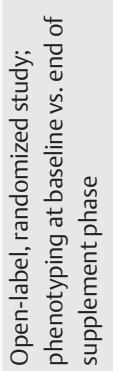

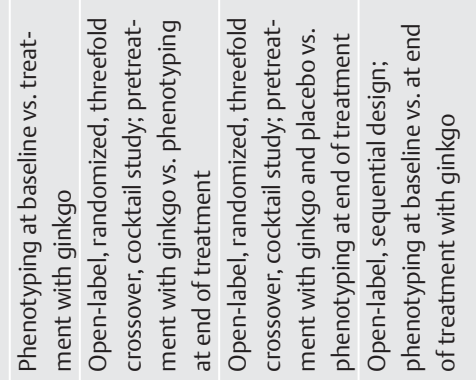

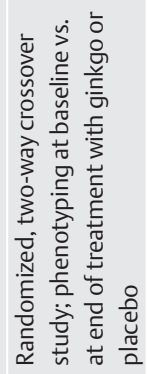

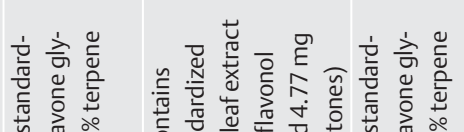

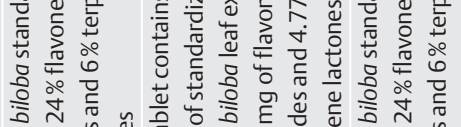

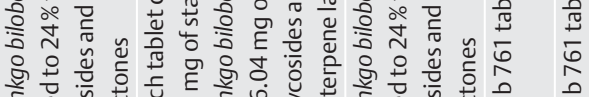

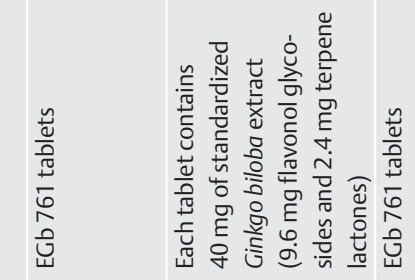

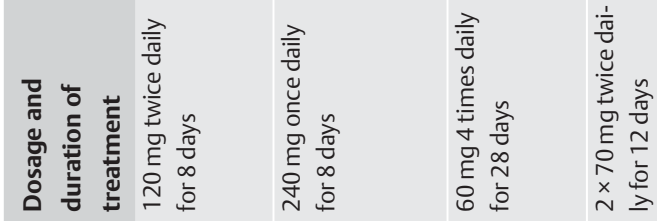

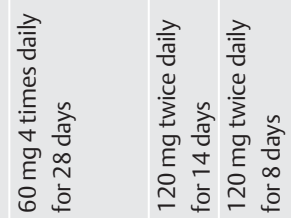

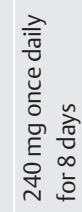

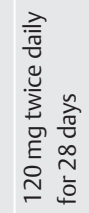

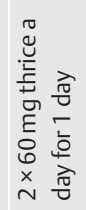

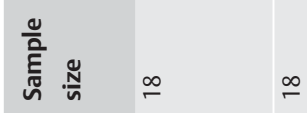

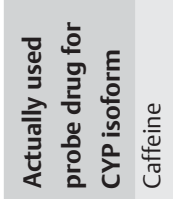

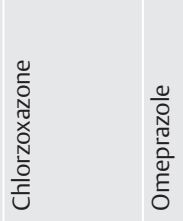

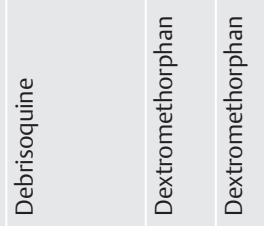

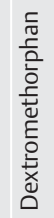

$E$
$\frac{E}{0}$
$\frac{N}{N}$
$\frac{0}{0}$

产

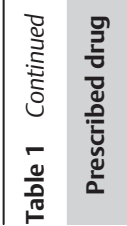

高高旁

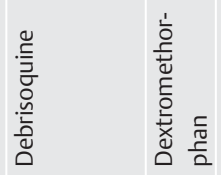

I

$\frac{\sqrt{0}}{\frac{0}{0.0}}$ 


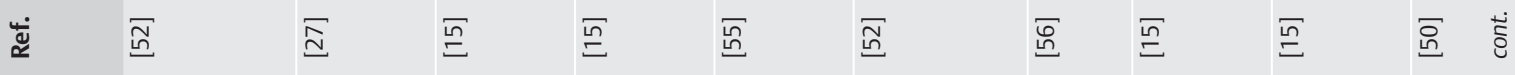

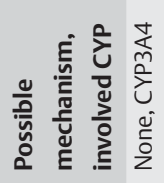

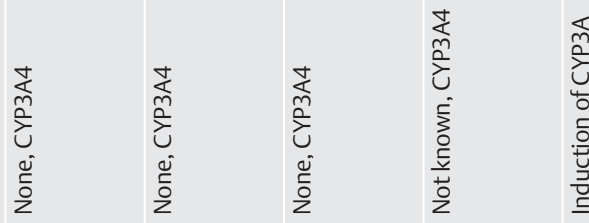

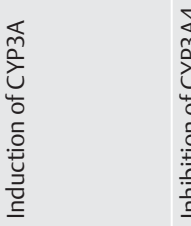

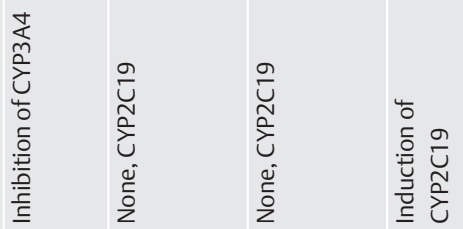
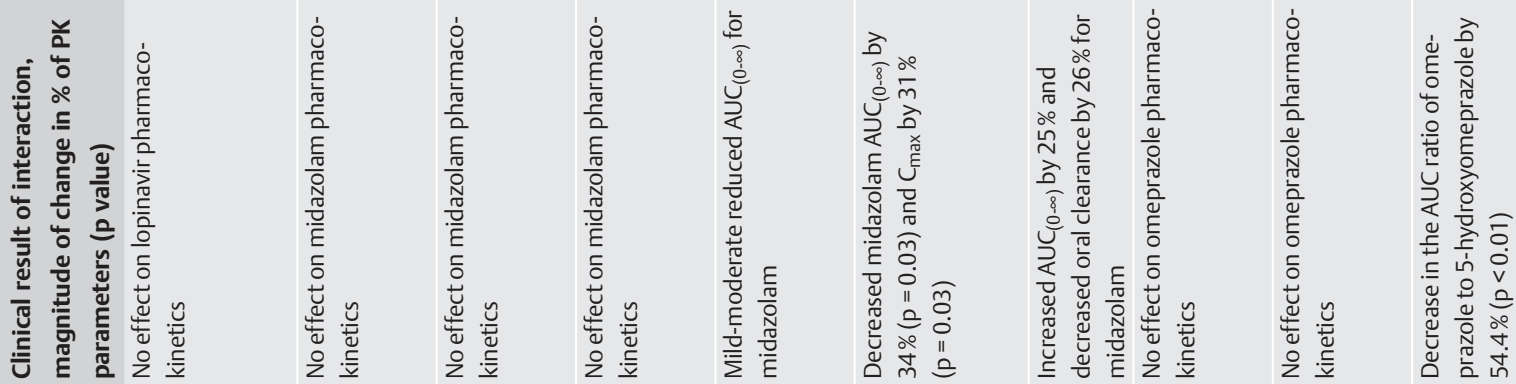

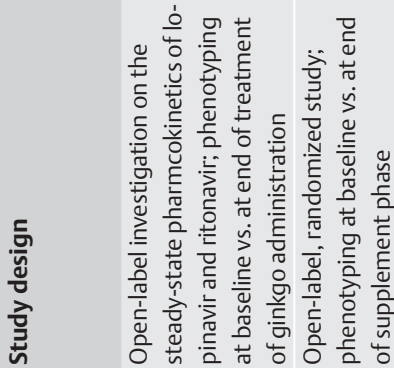

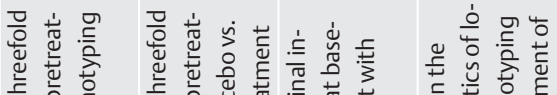

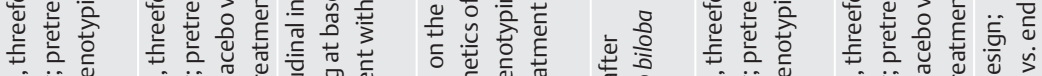

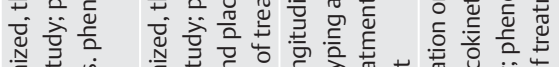

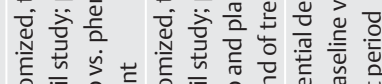

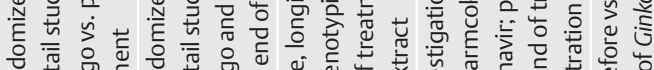

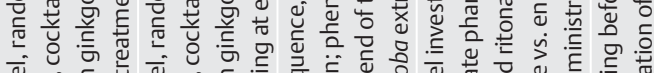

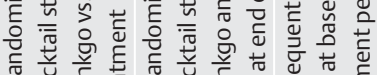

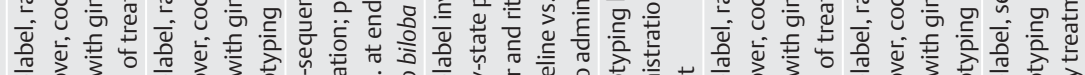

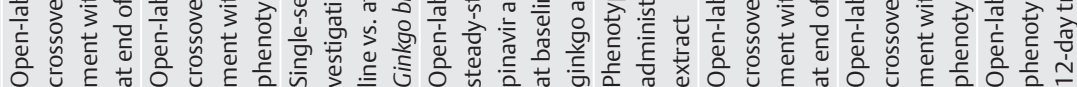

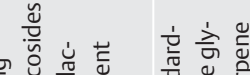

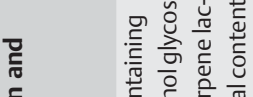

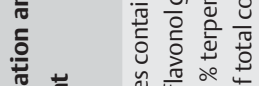

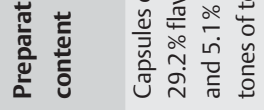

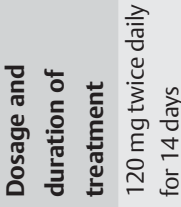

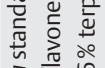

势

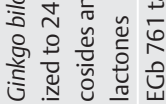

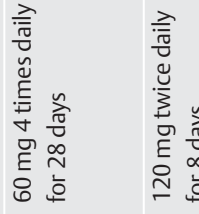

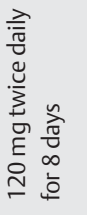

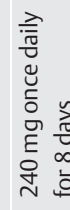

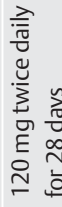

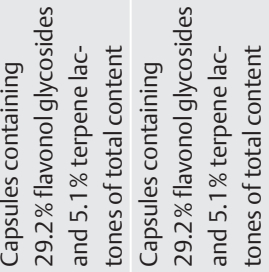

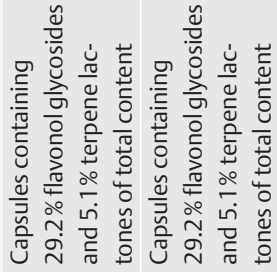

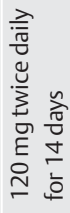

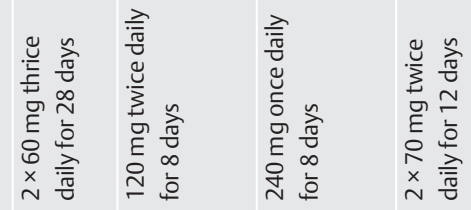

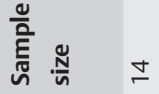

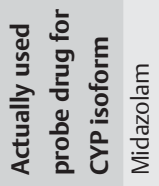

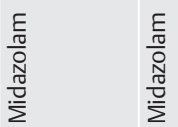

$E$
$\frac{E}{0}$
$\frac{N}{\pi}$
$\frac{N}{\Sigma}$
$\dot{L}$

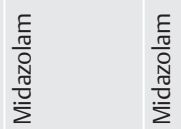

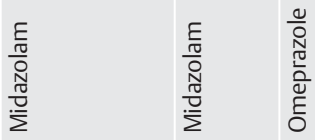

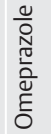

$\frac{0}{0}$
$\frac{N}{0}$
$\frac{0}{0}$
है

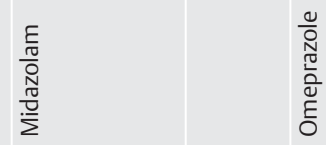



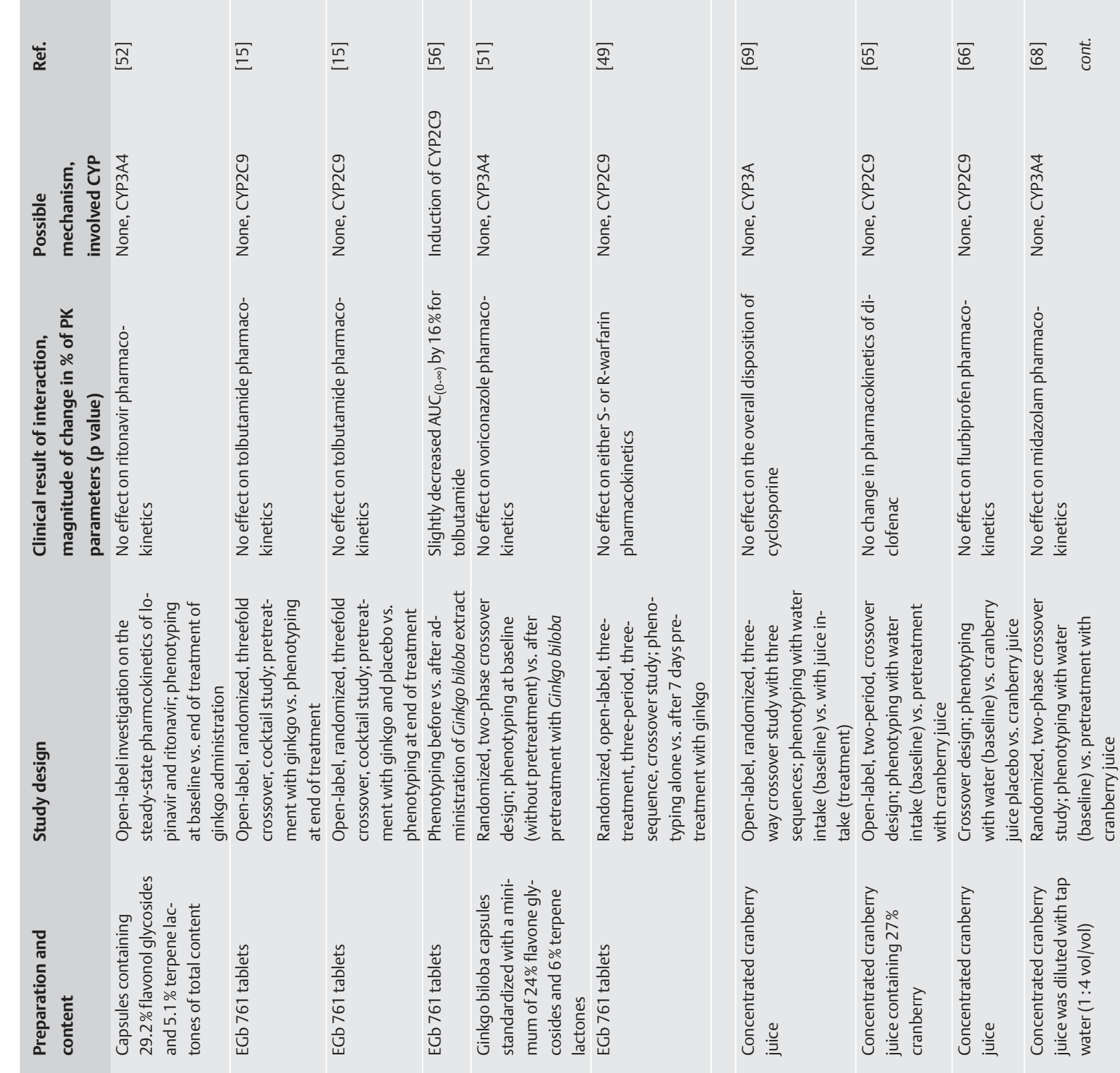

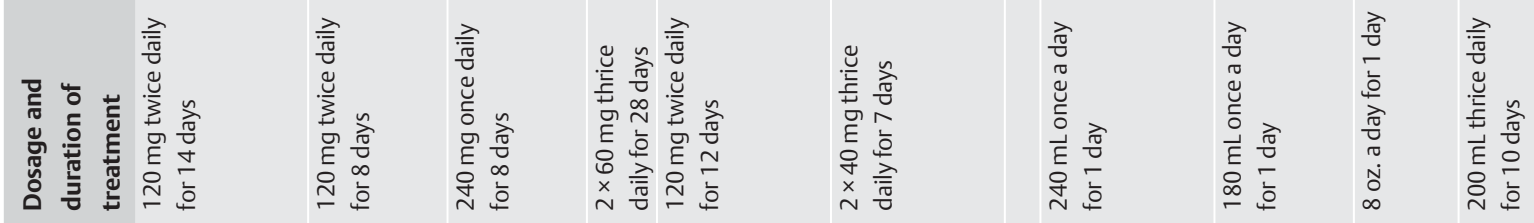
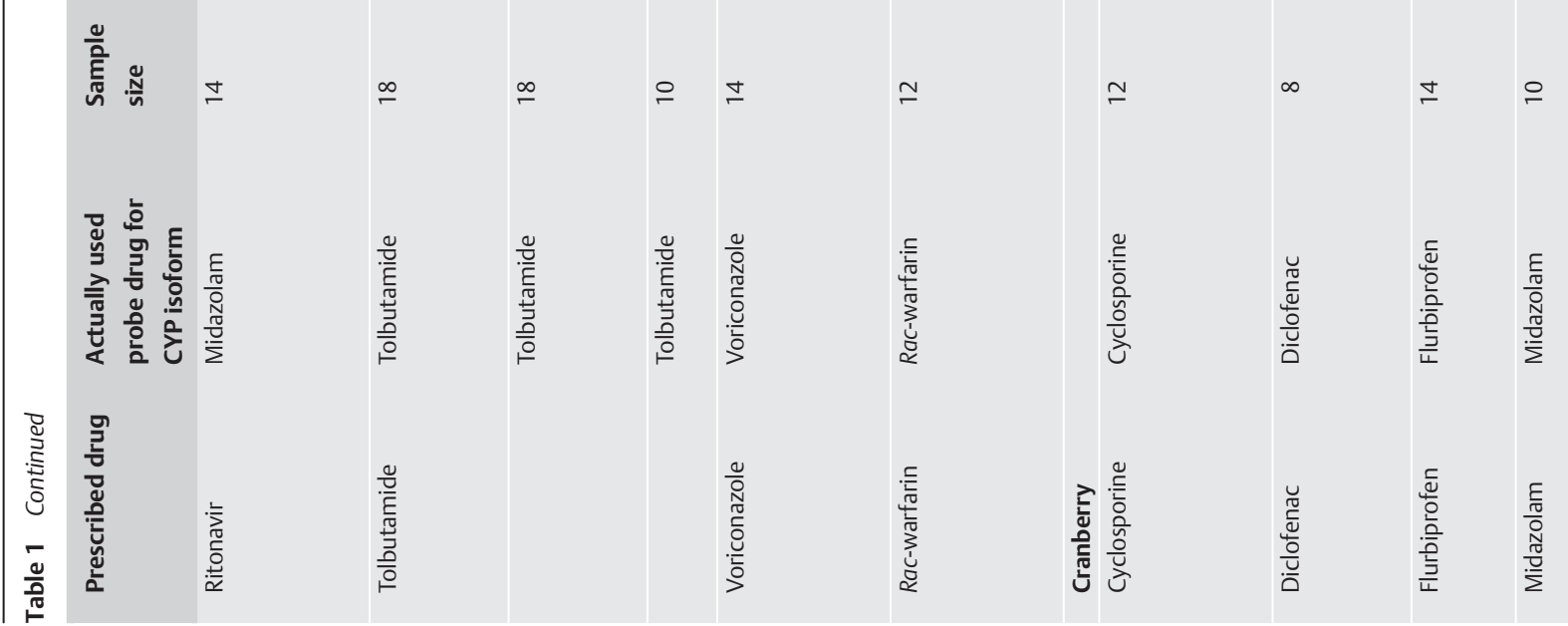


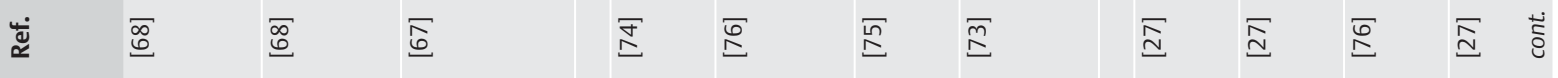

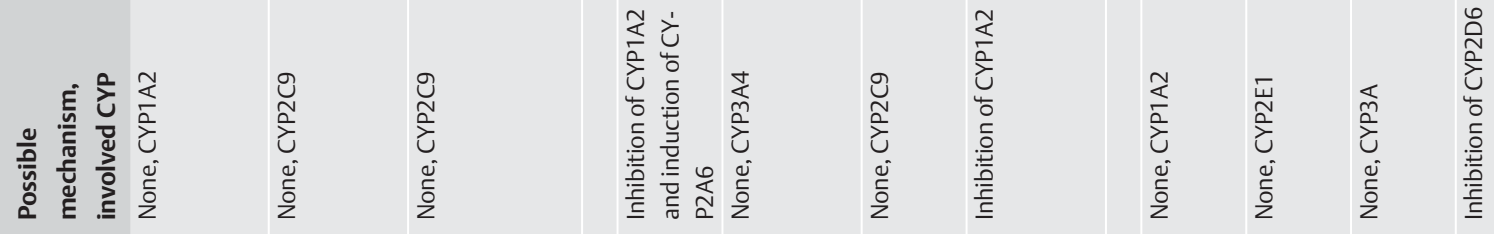

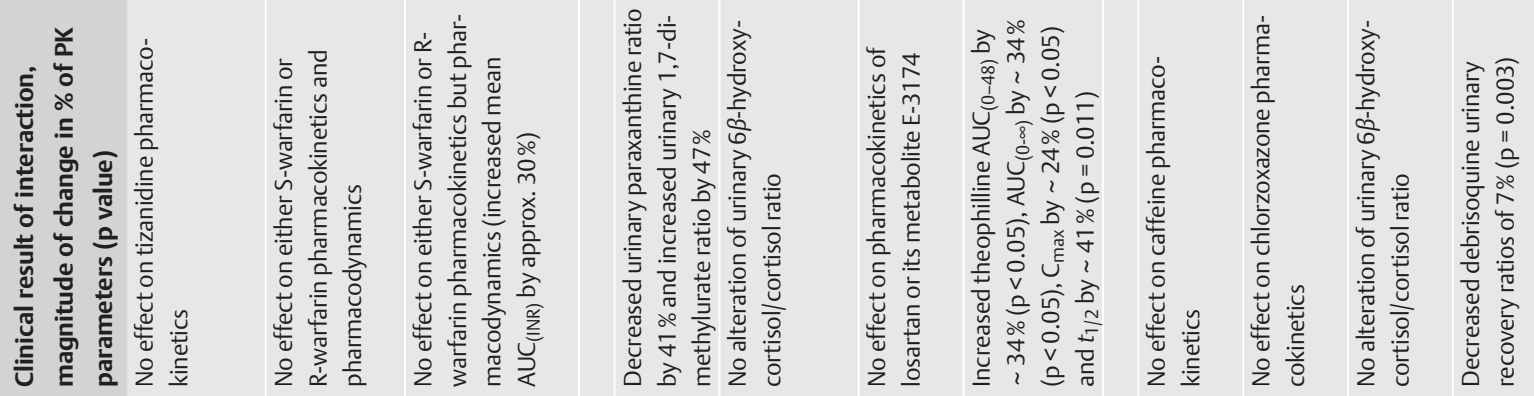

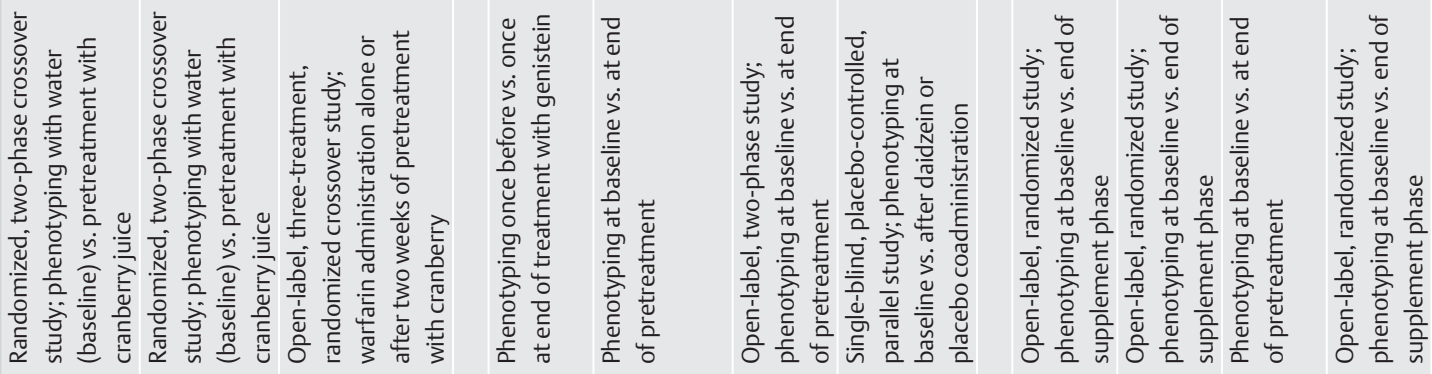

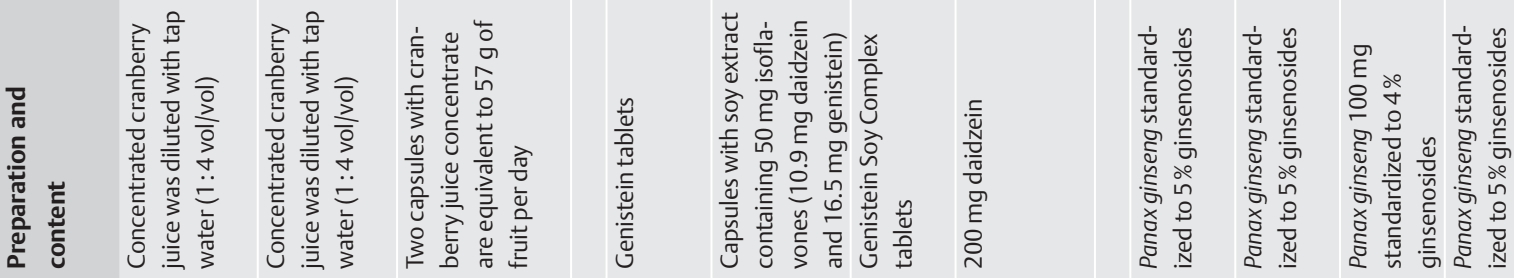

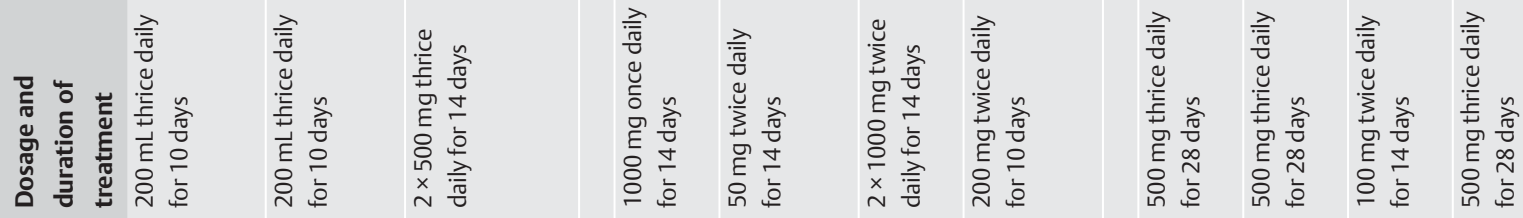

产苞

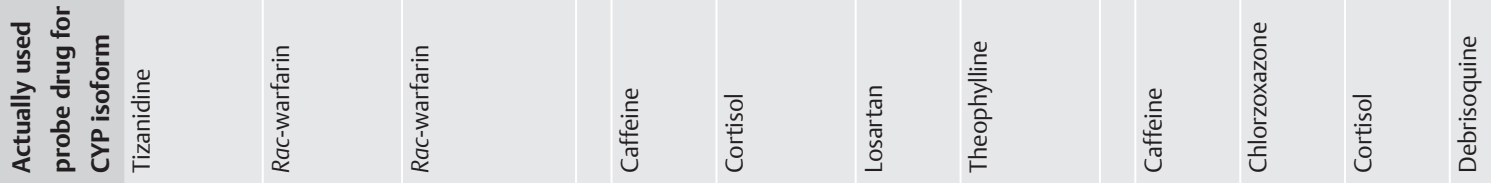

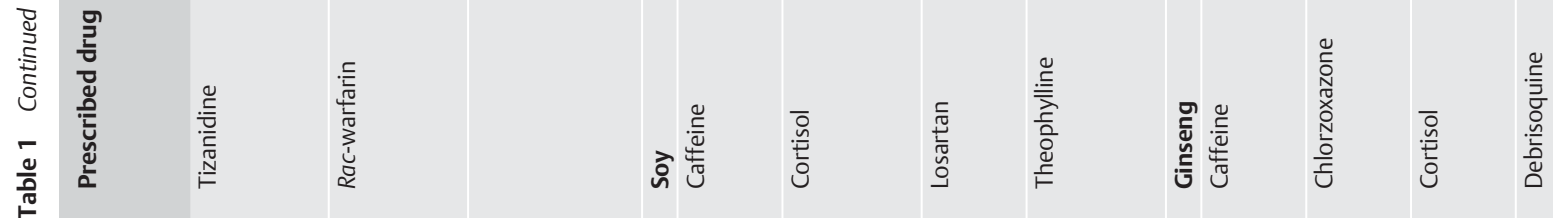




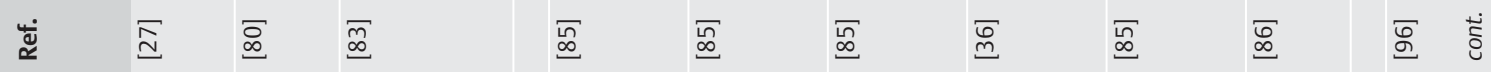

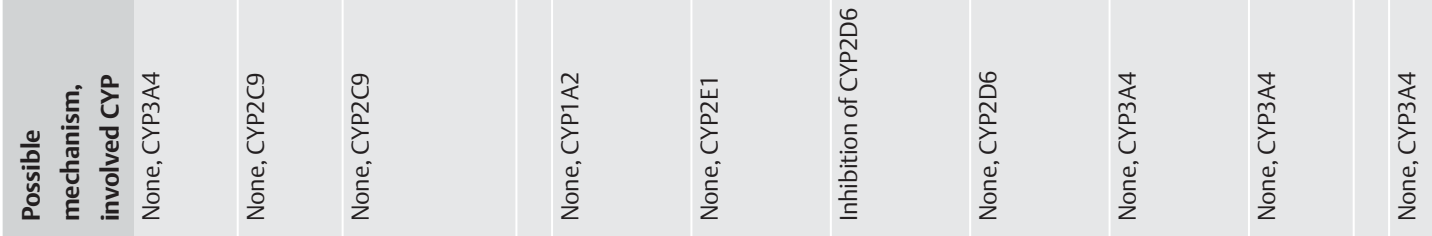
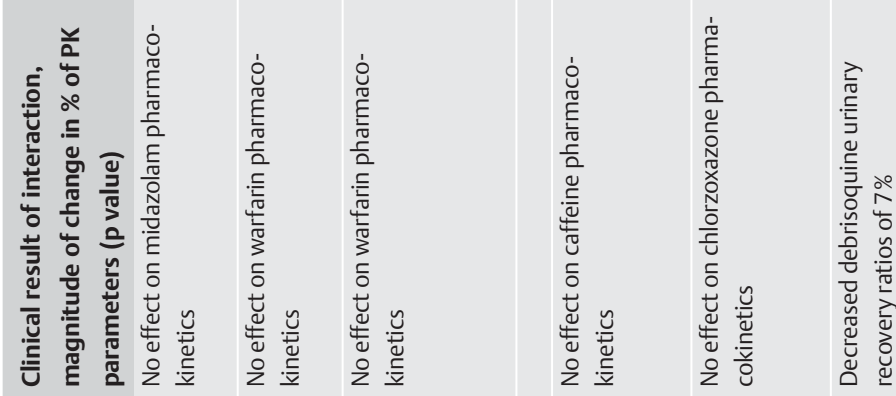

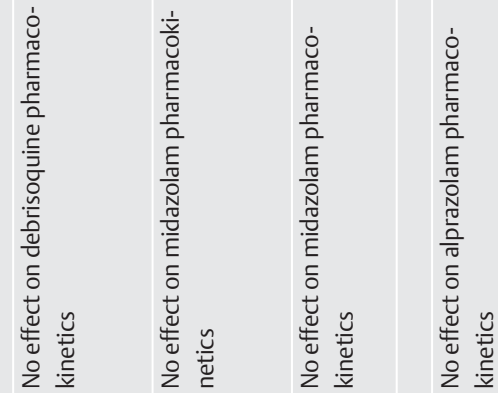

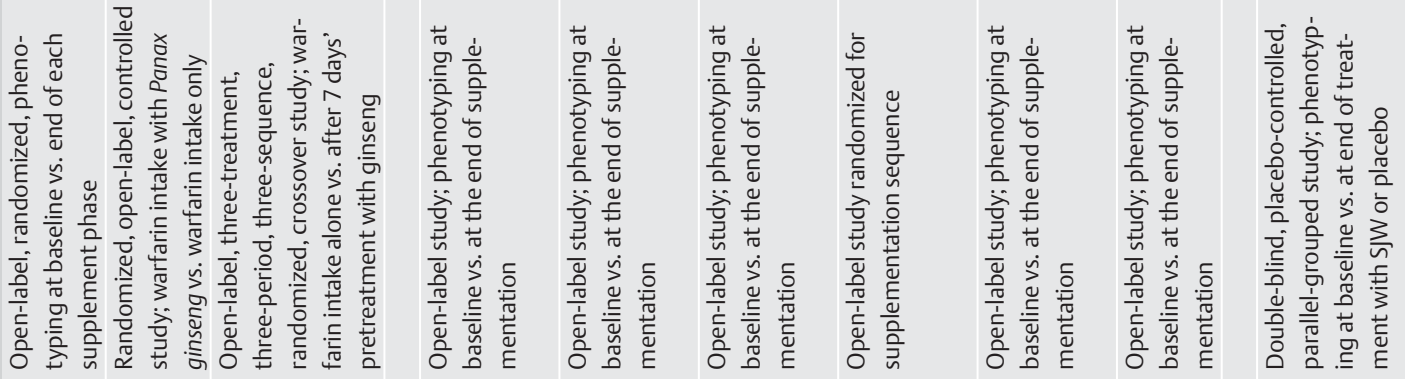

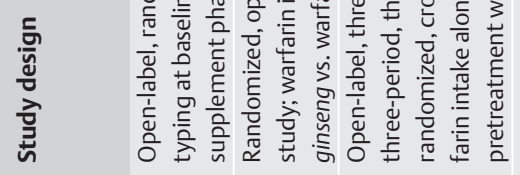

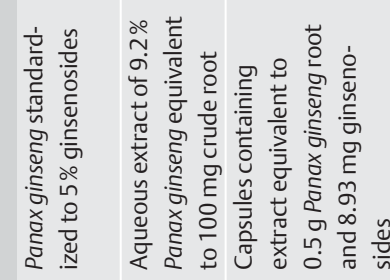

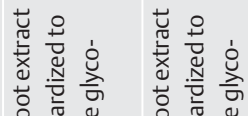

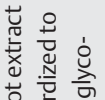

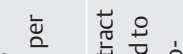

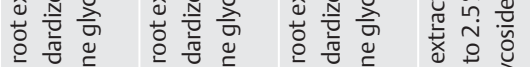

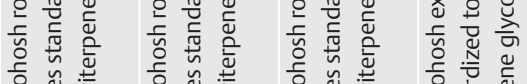

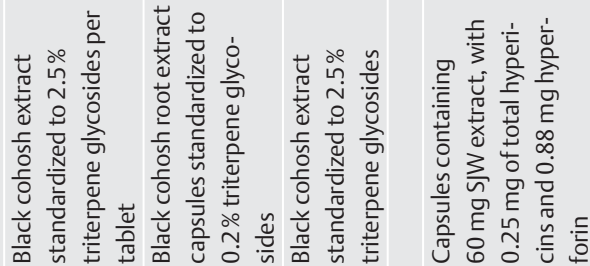

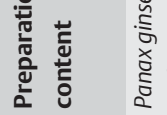

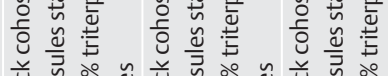

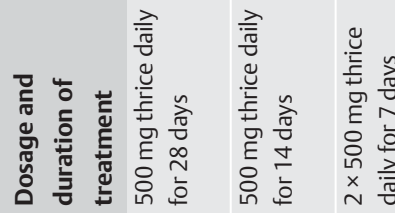

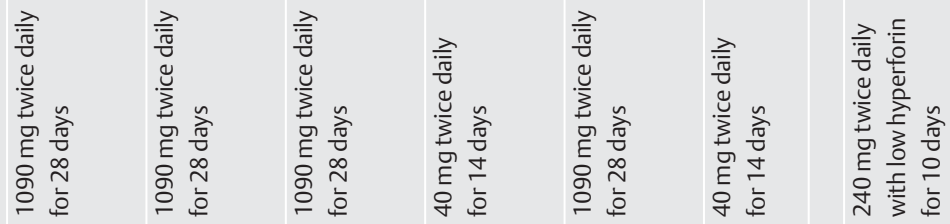

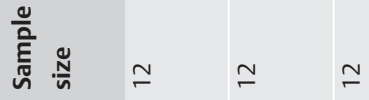

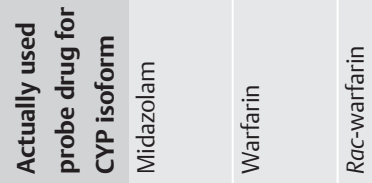

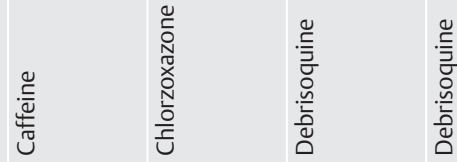

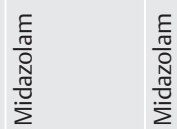

$\frac{1}{2}$
$\frac{\pi}{2}$
$\frac{0}{2}$
$\frac{2}{2}$

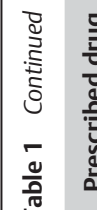

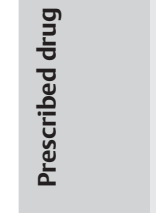

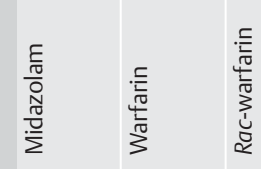

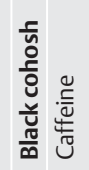

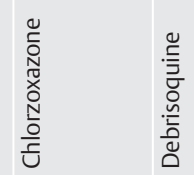

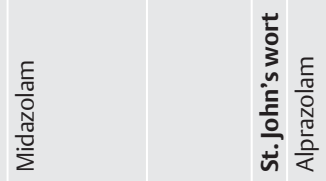




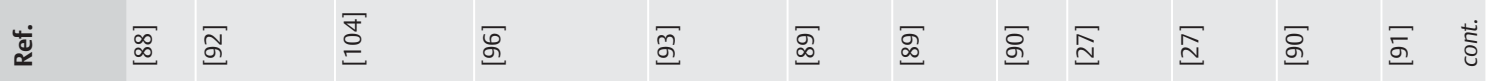

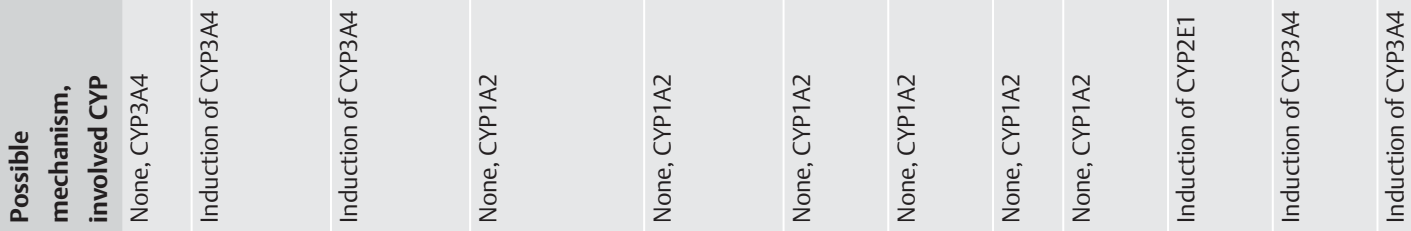
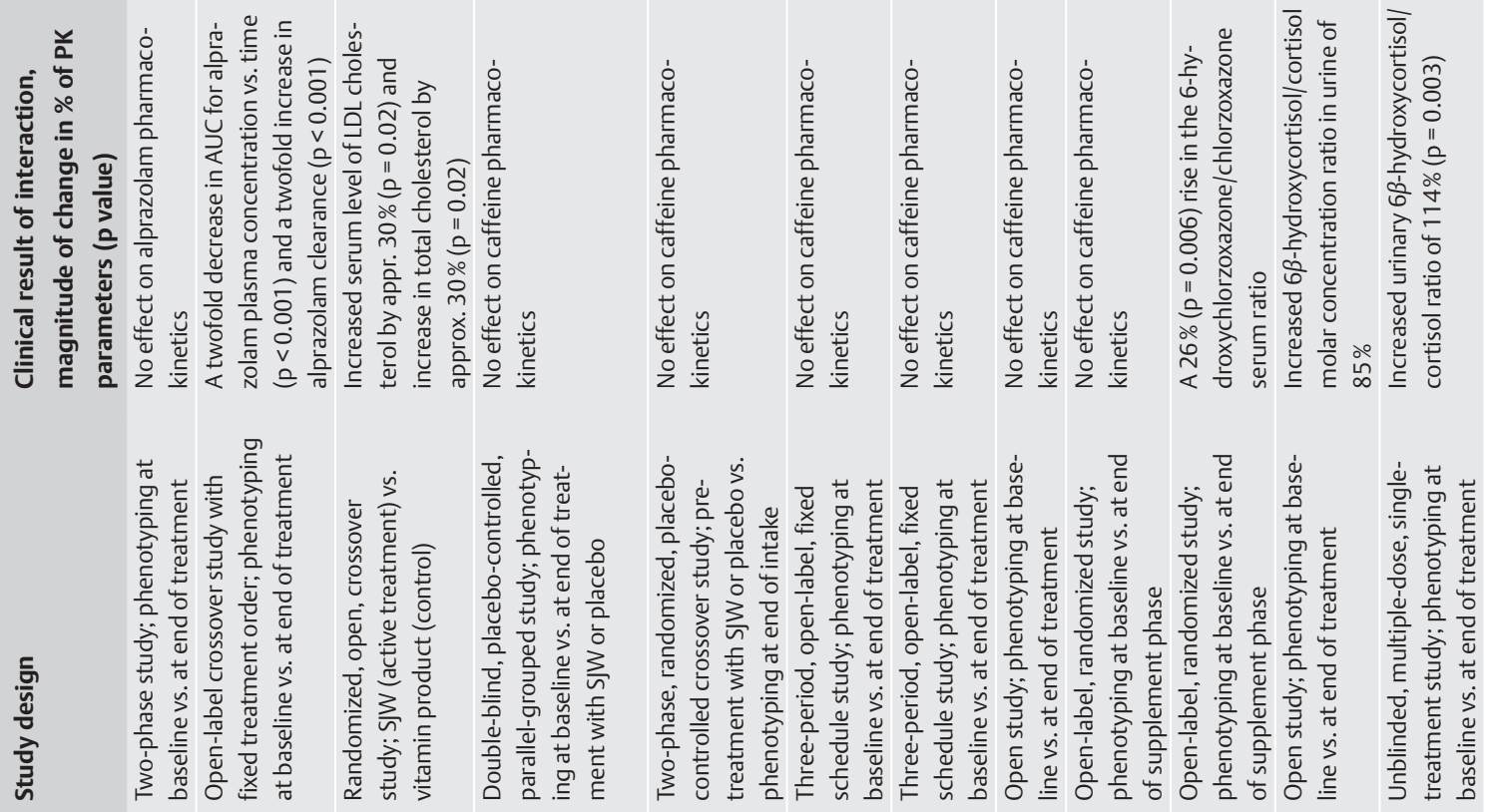

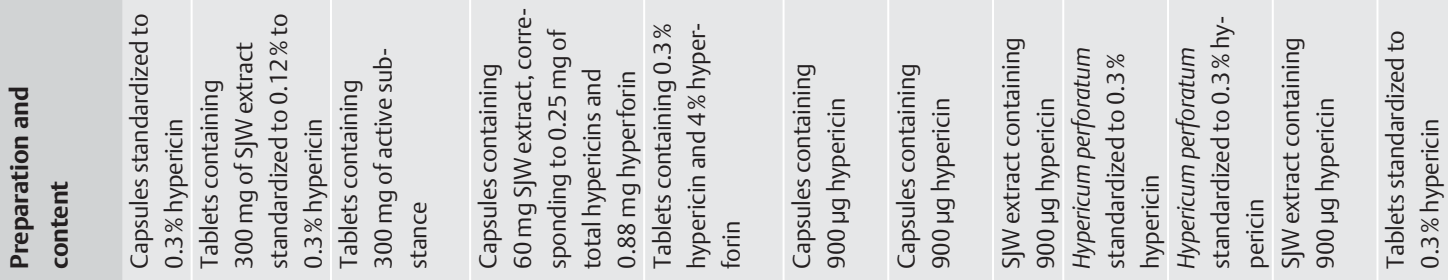

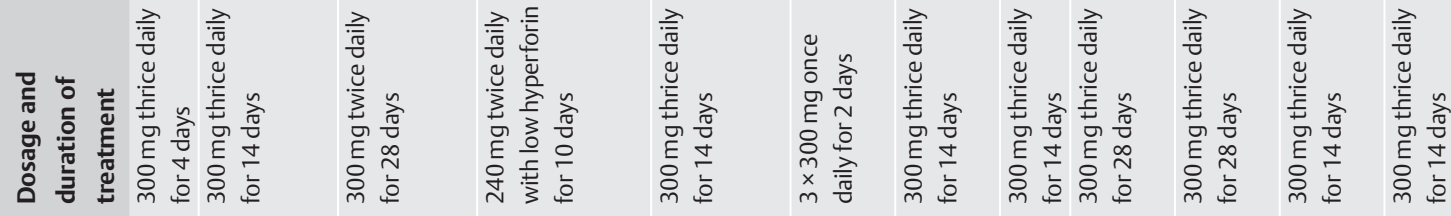
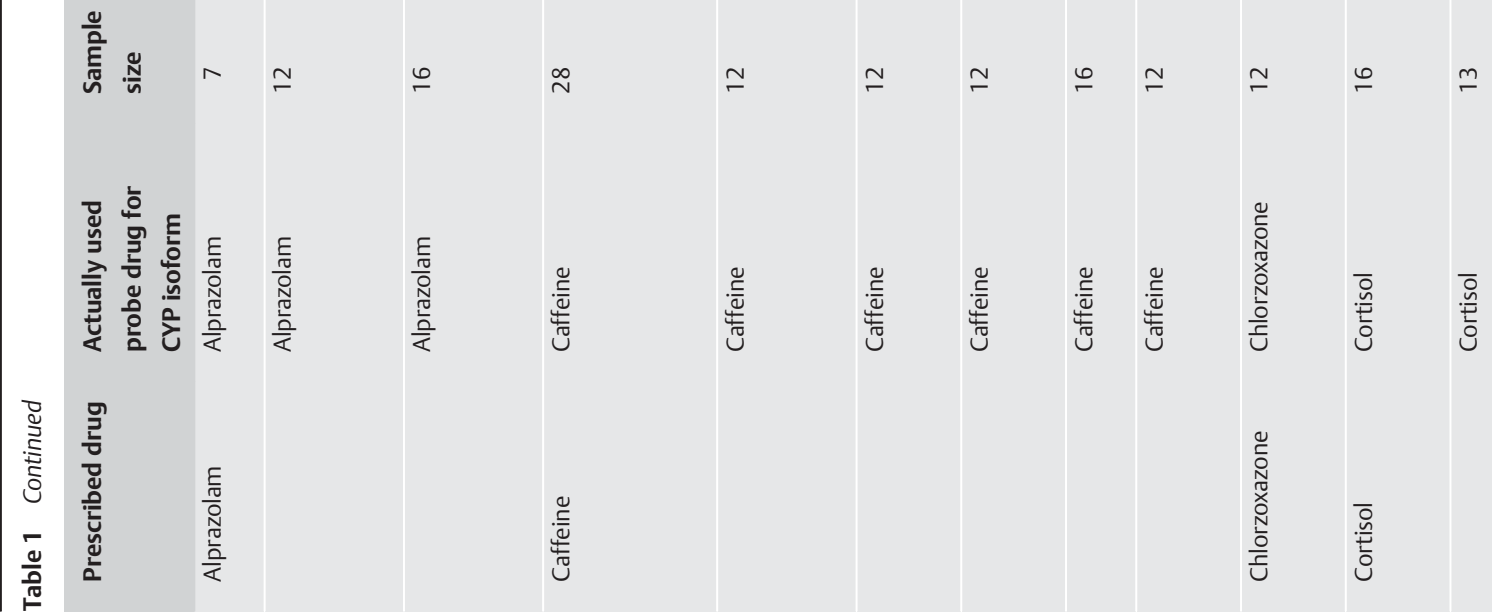


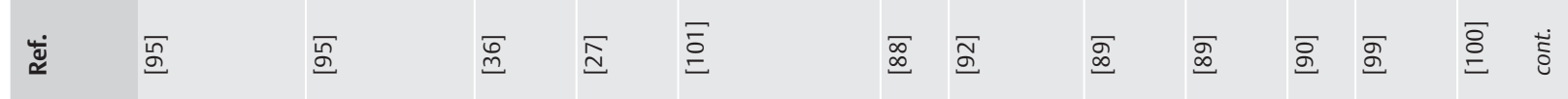

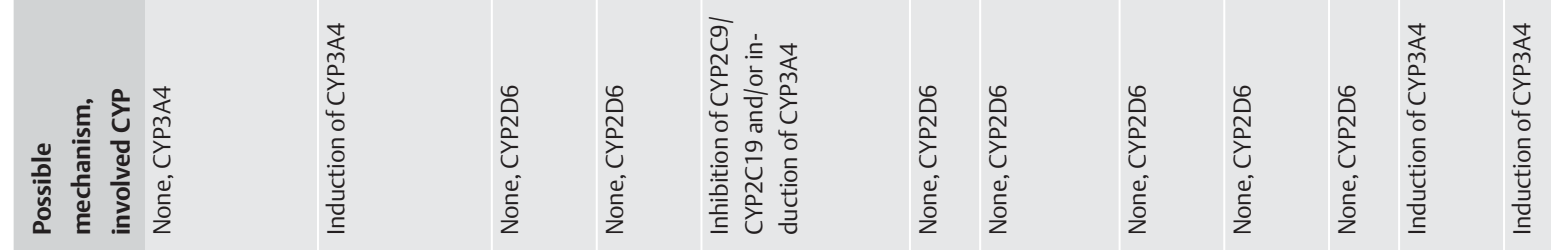
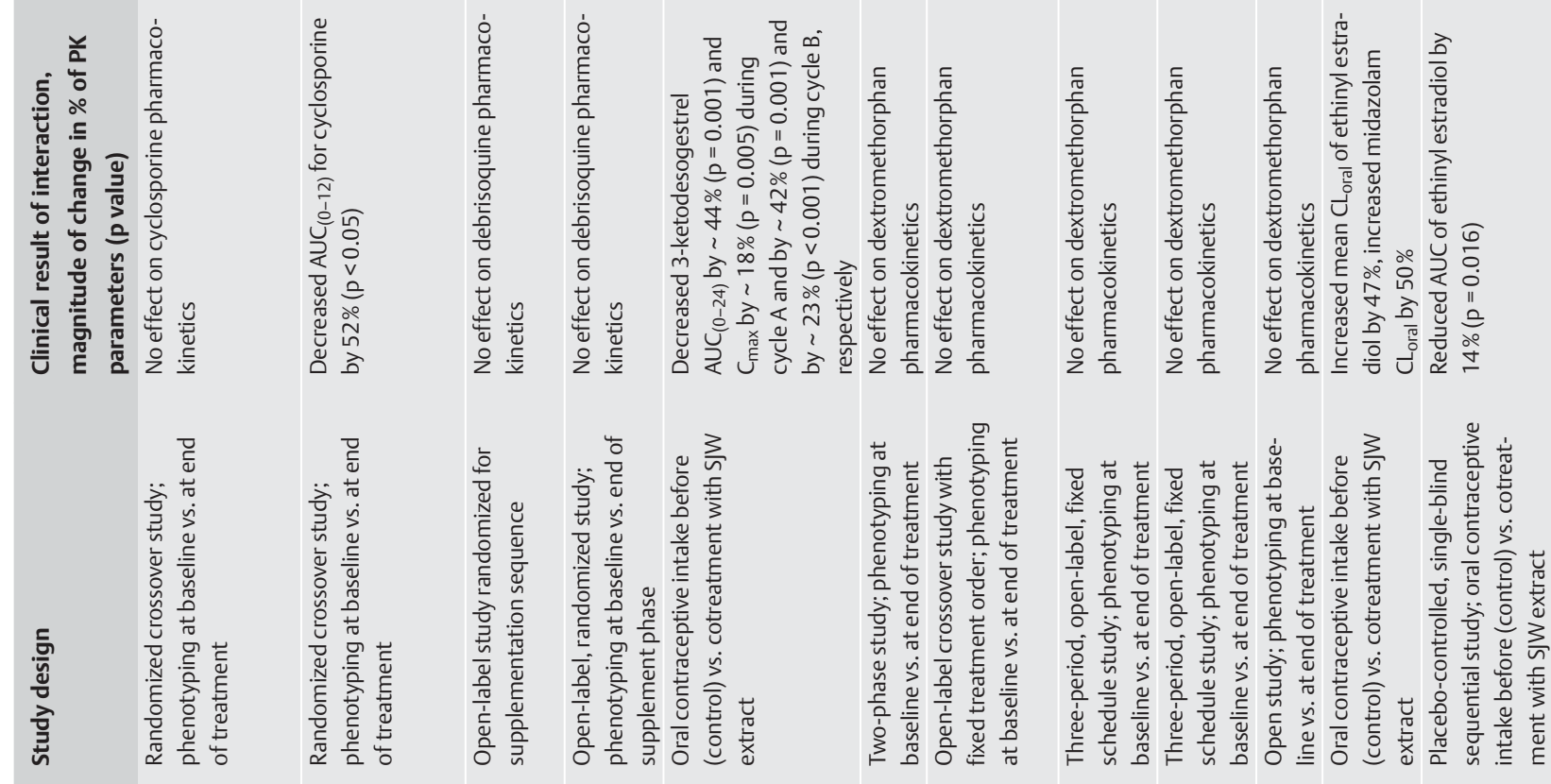

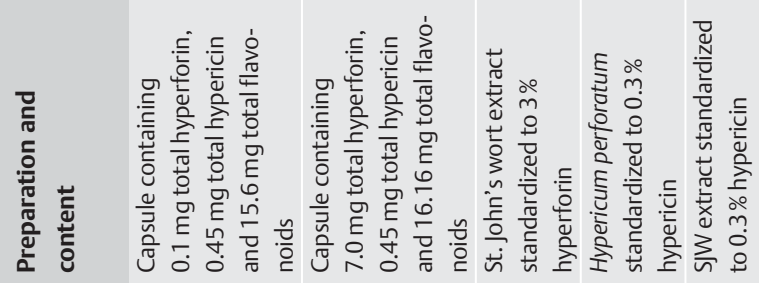

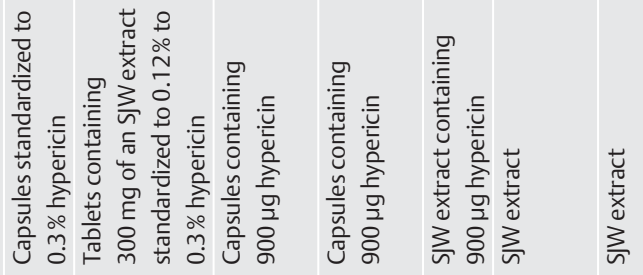

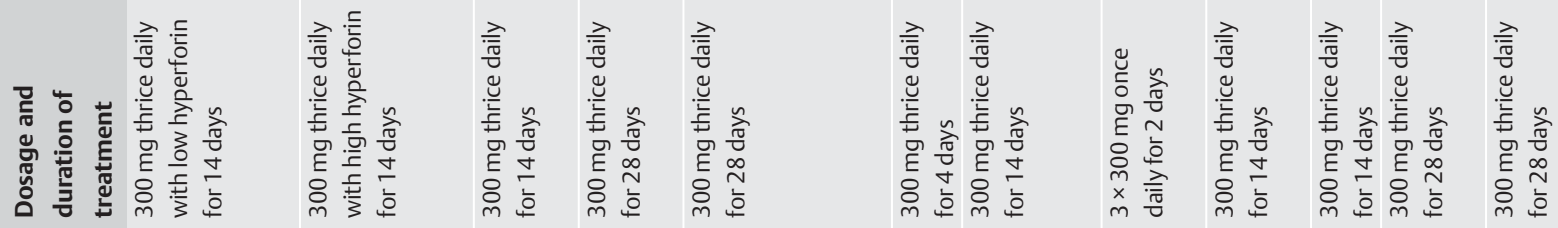
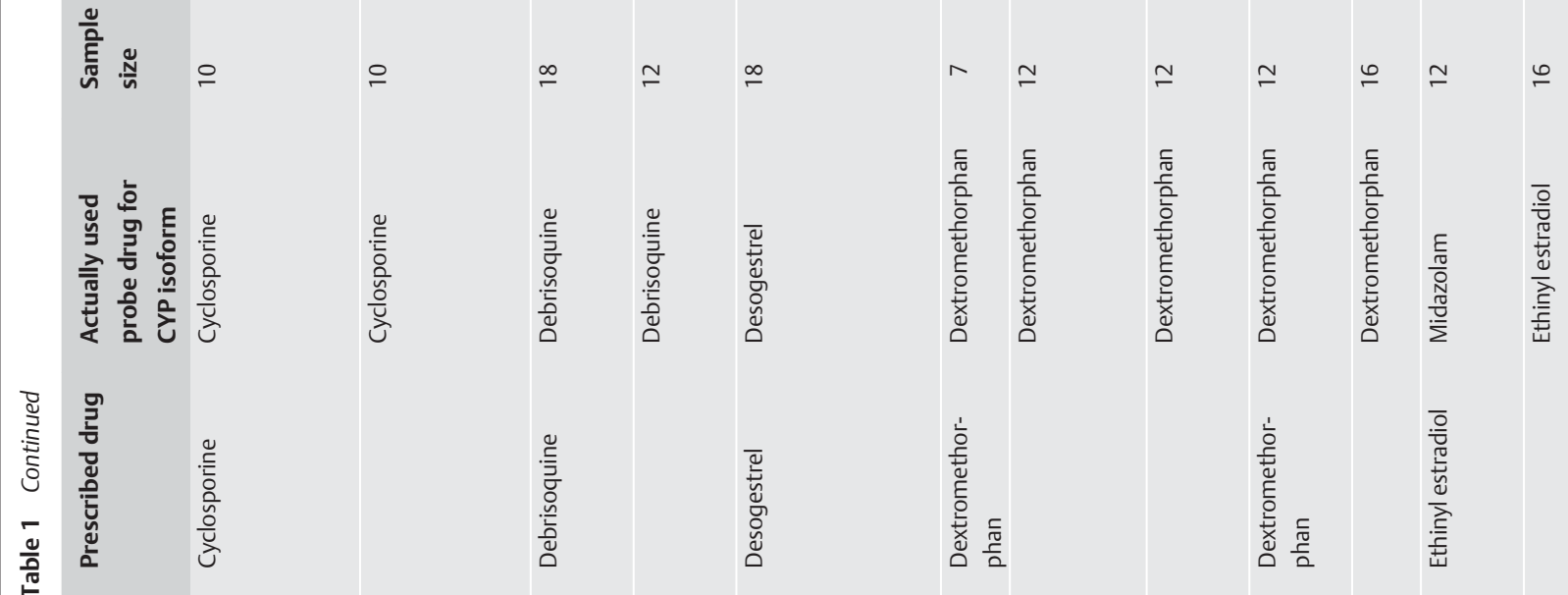


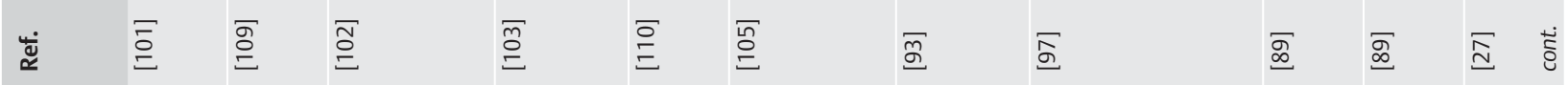

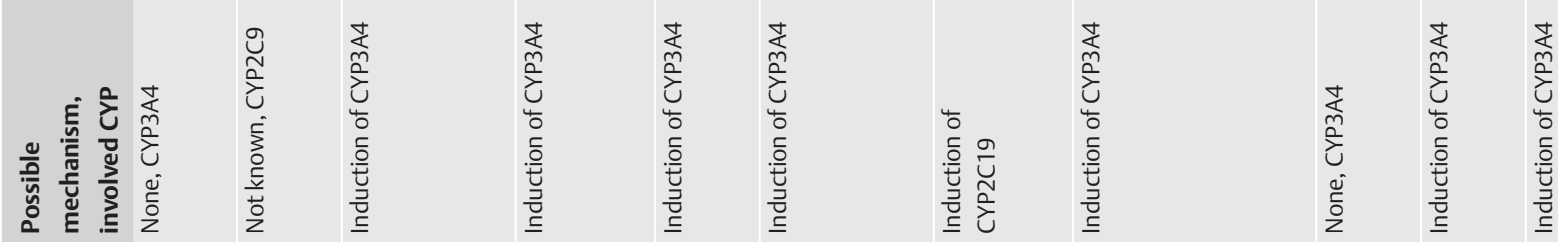

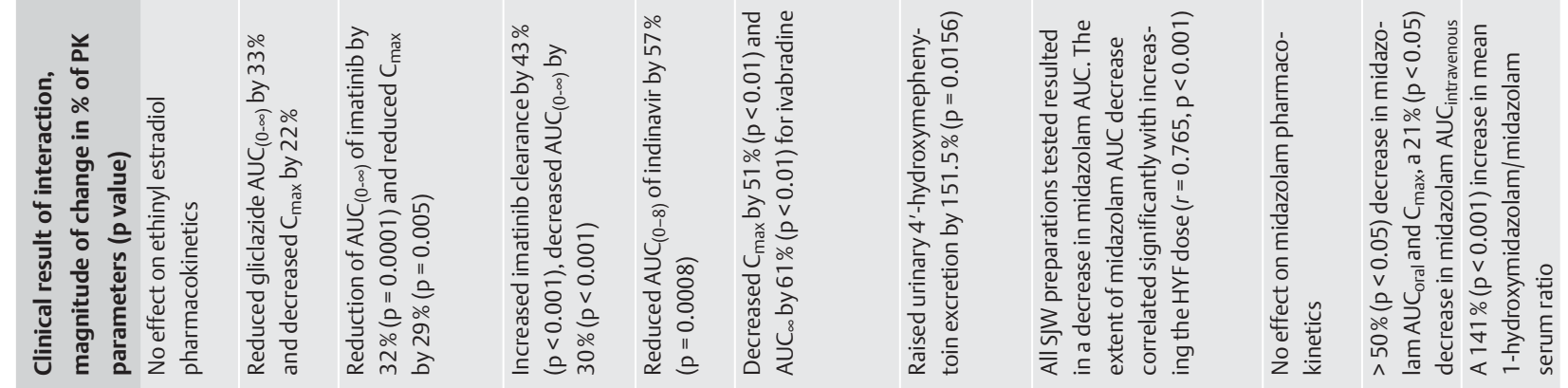

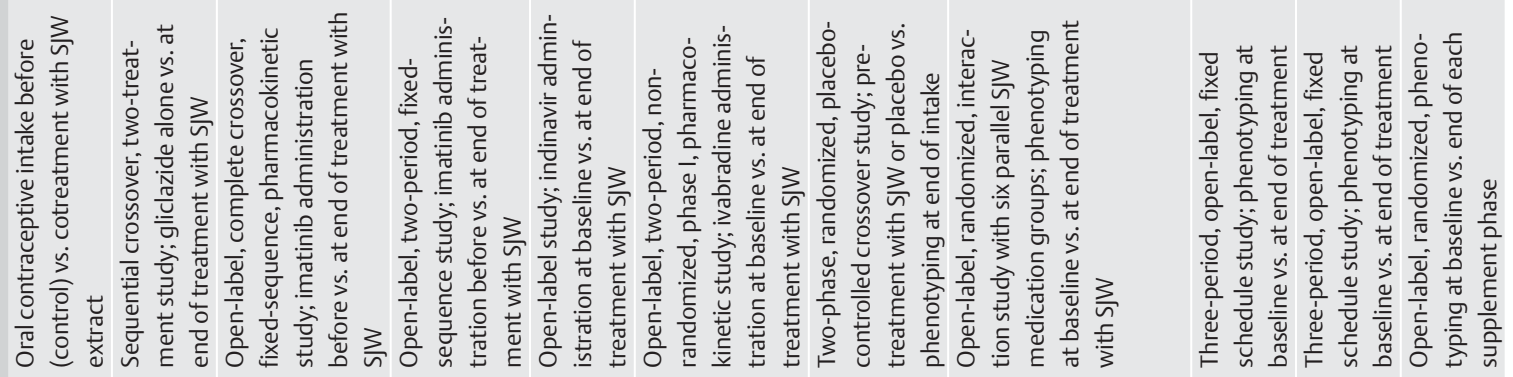

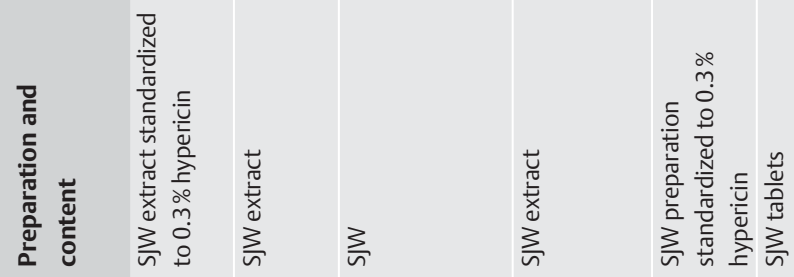

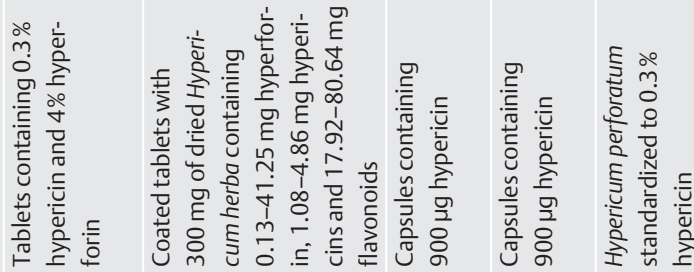

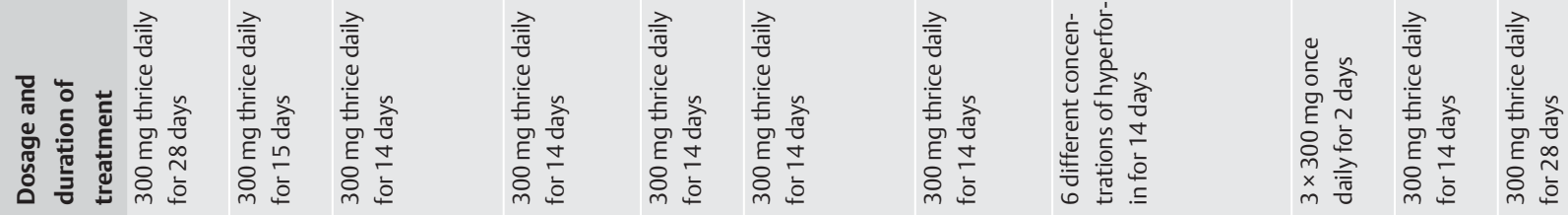

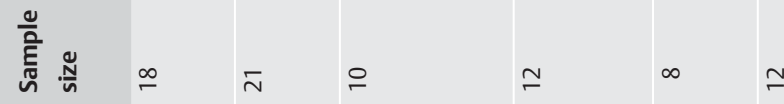

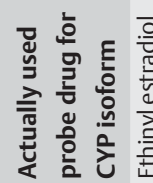

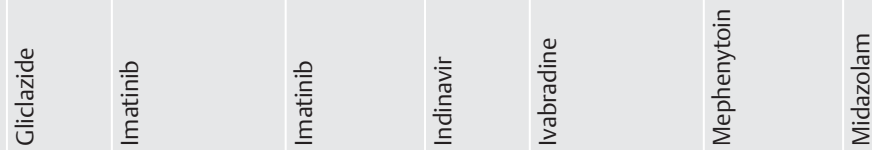

I

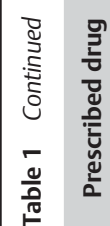

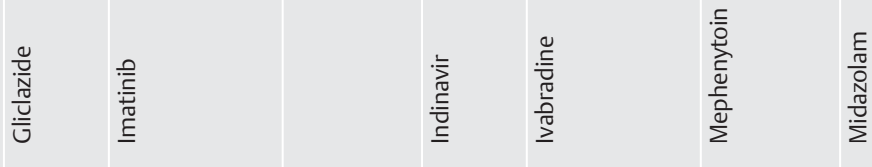




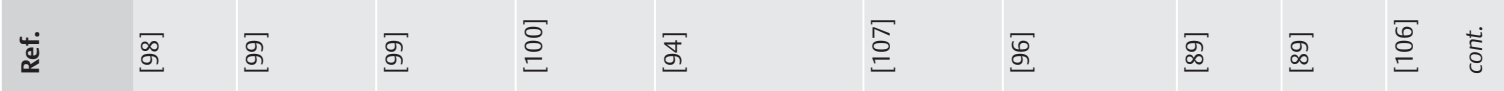

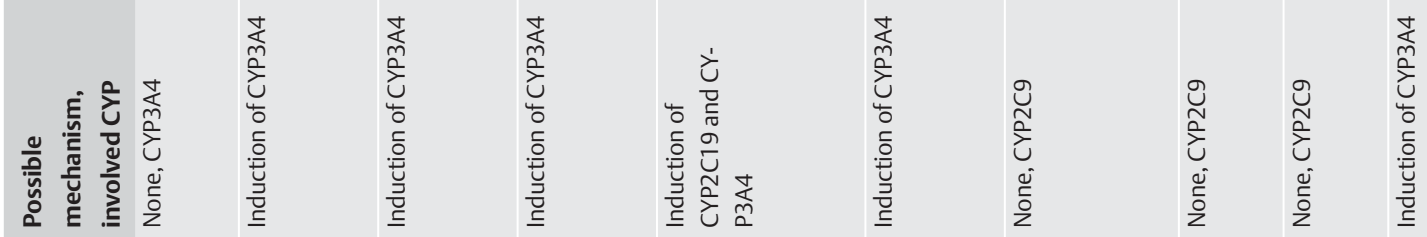
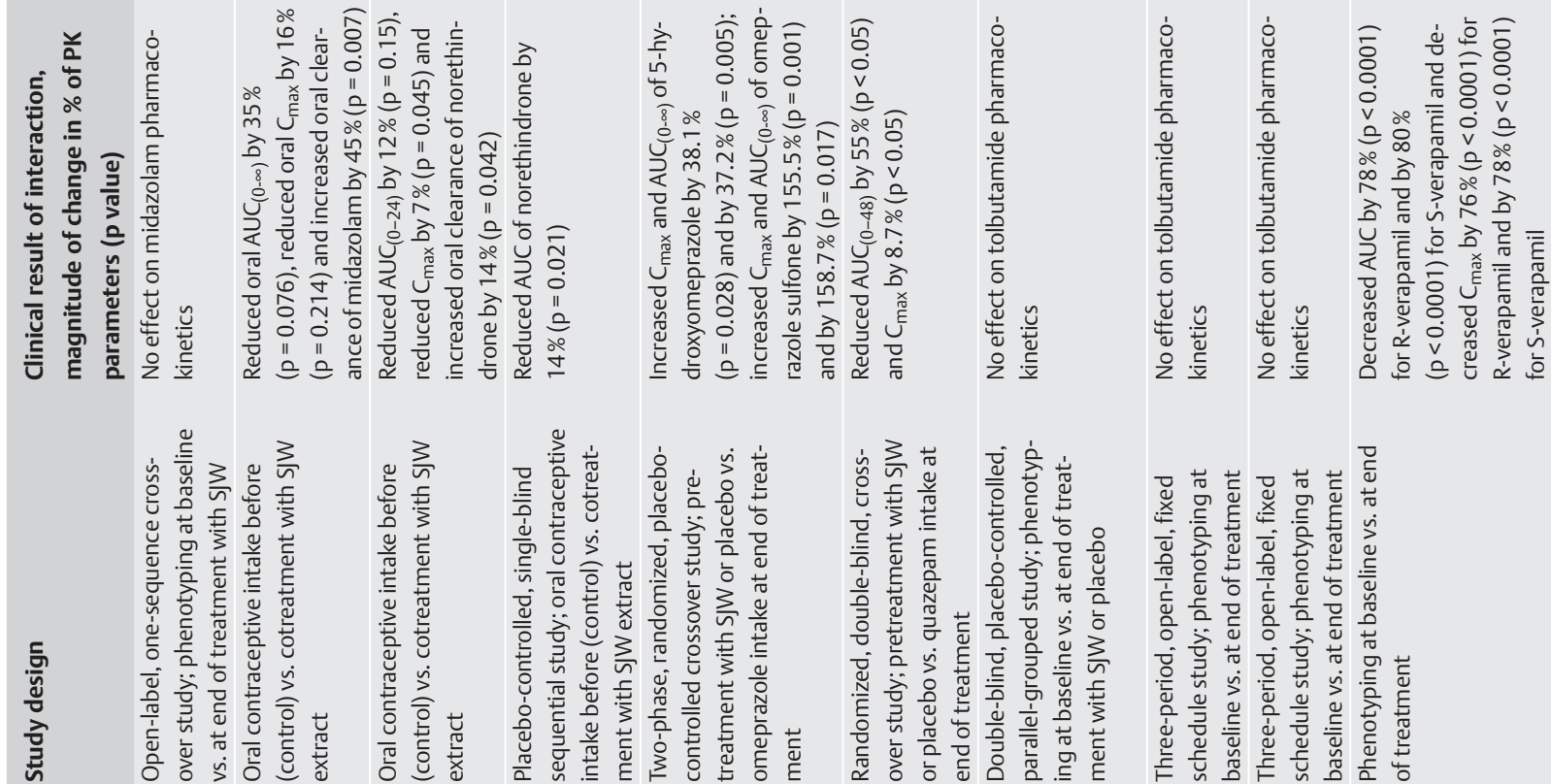

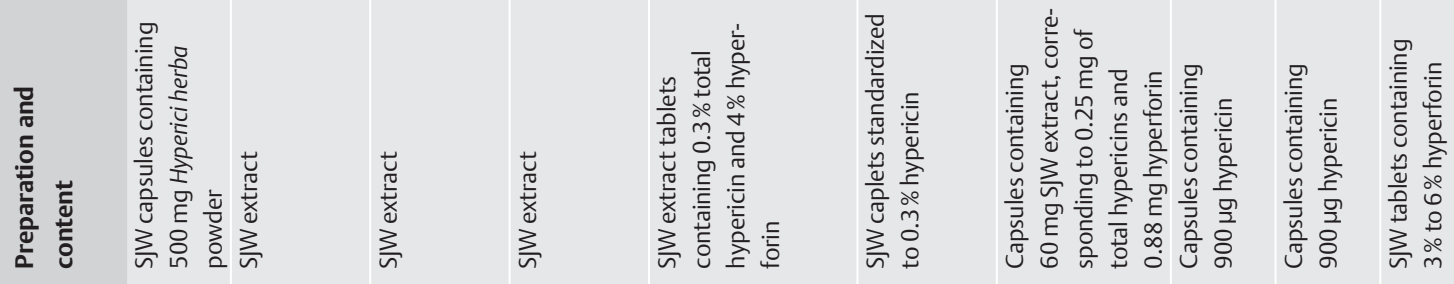

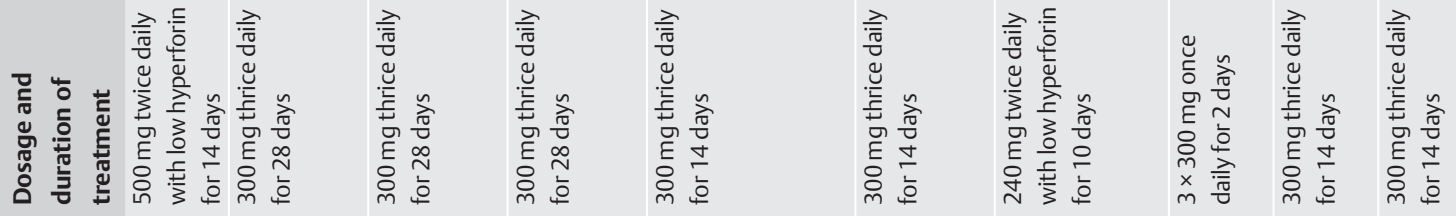

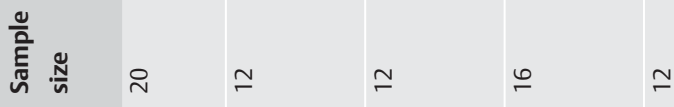

MII I | $\mid$ | $1|1|$

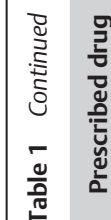

I

l

I I

I 
$\stackrel{\infty}{\dddot{\Xi}} \stackrel{\infty}{\stackrel{\infty}{=}} \underset{\infty}{\infty}$

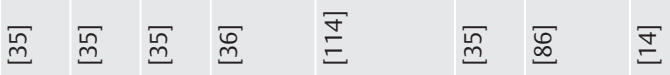

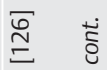

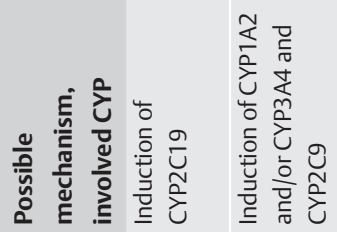

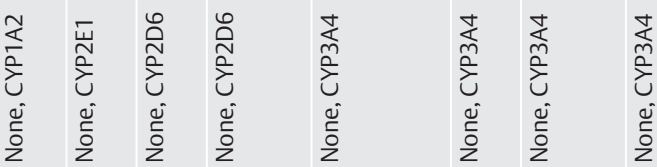

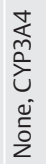
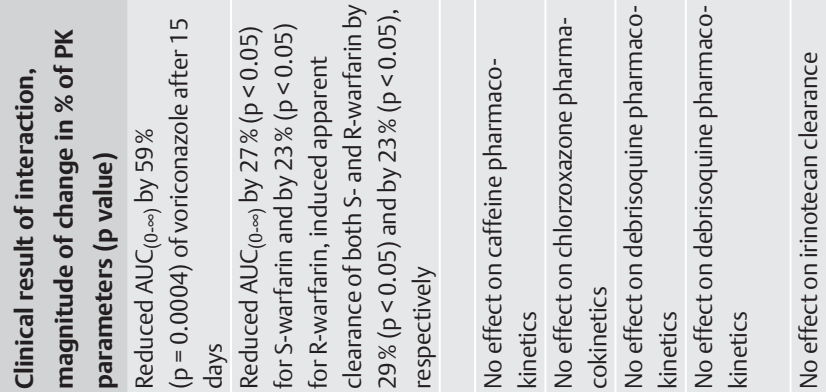

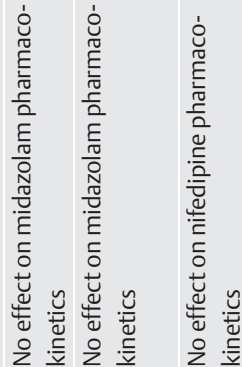

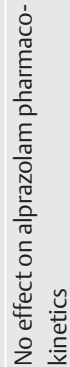

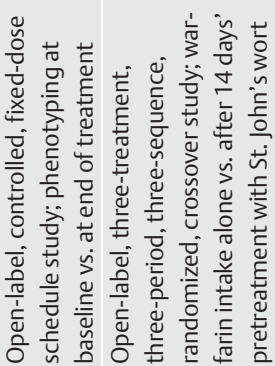

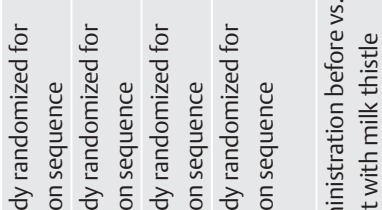

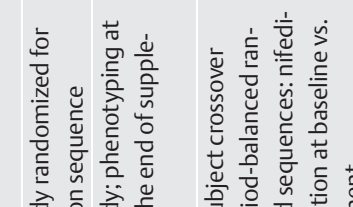

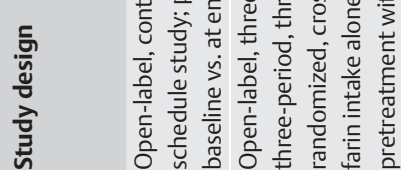

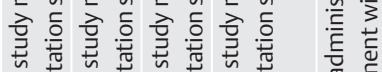

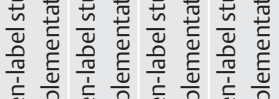

歌

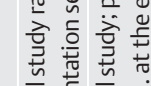

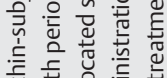

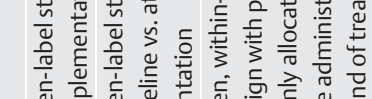

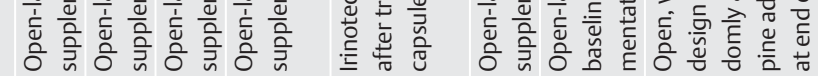
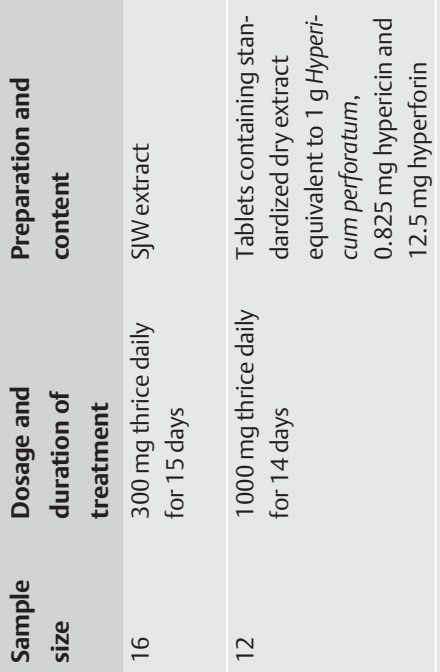

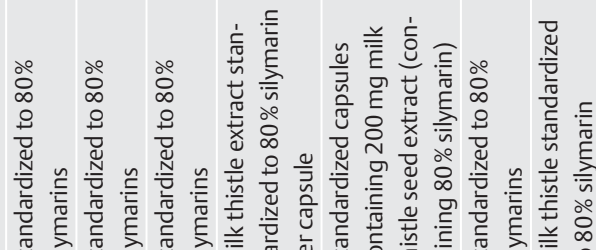

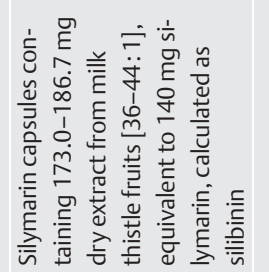

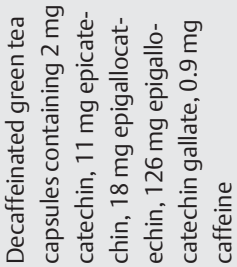

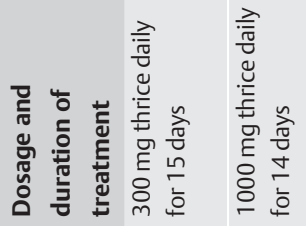

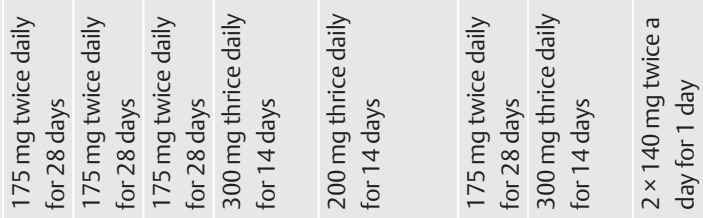

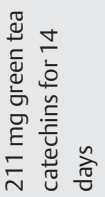

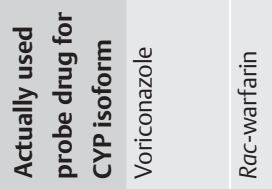

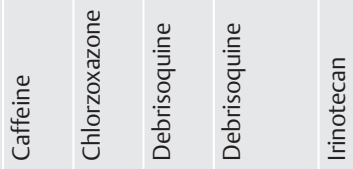

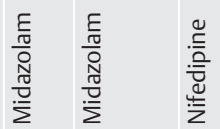

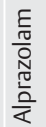

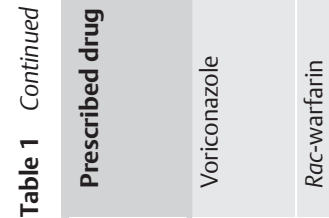

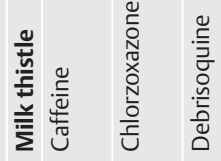

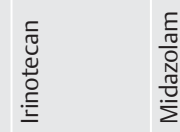

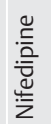

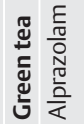




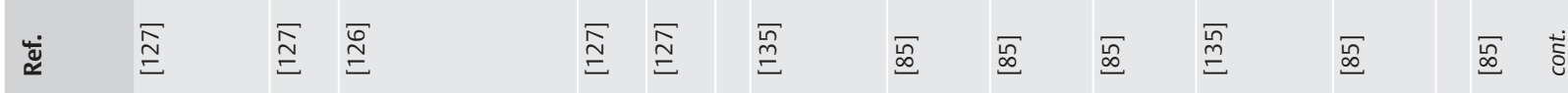

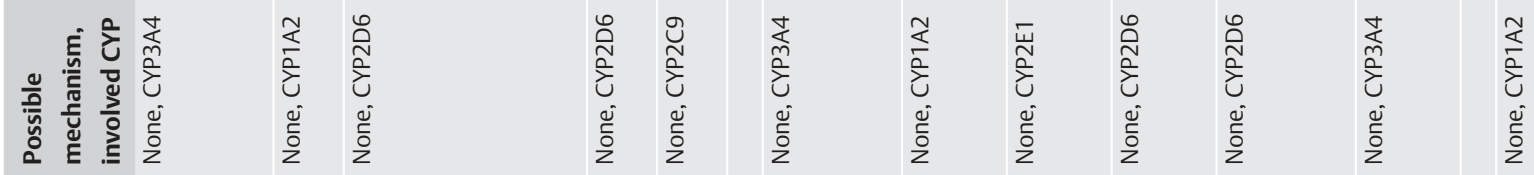
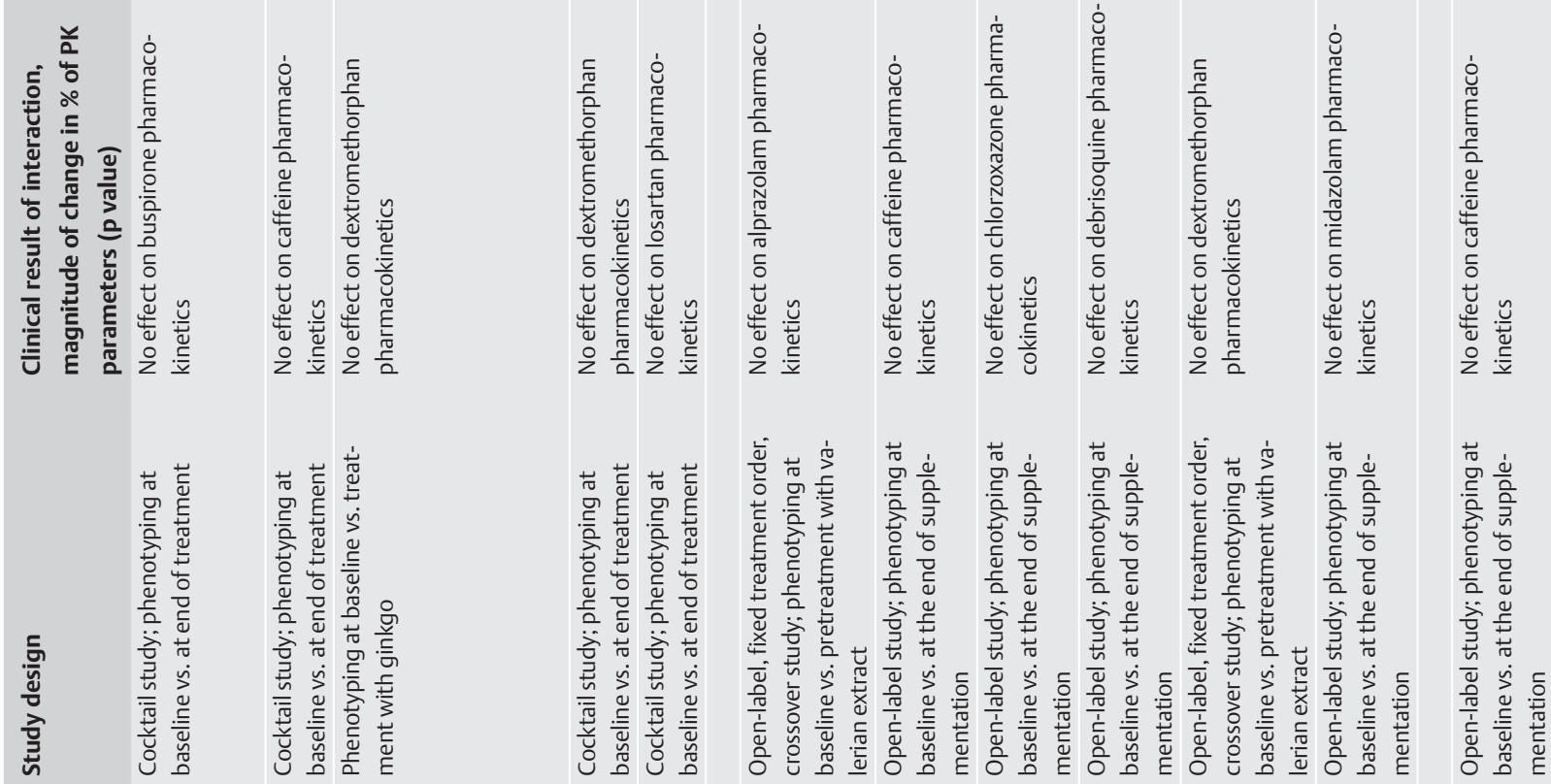

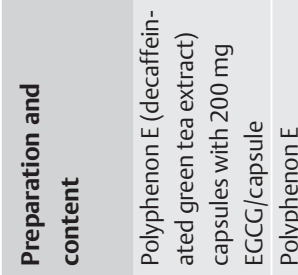

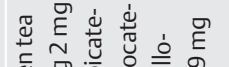

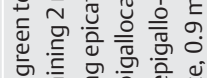

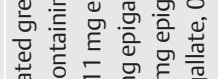

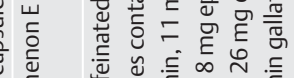

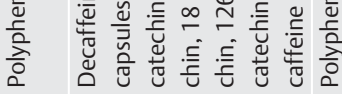

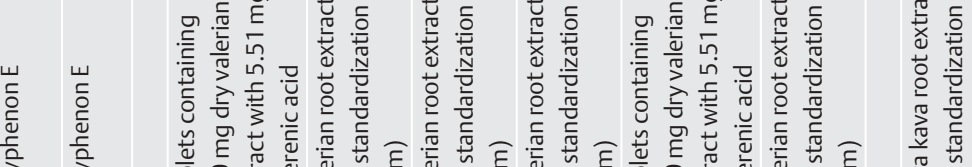

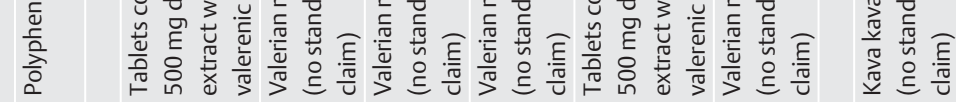

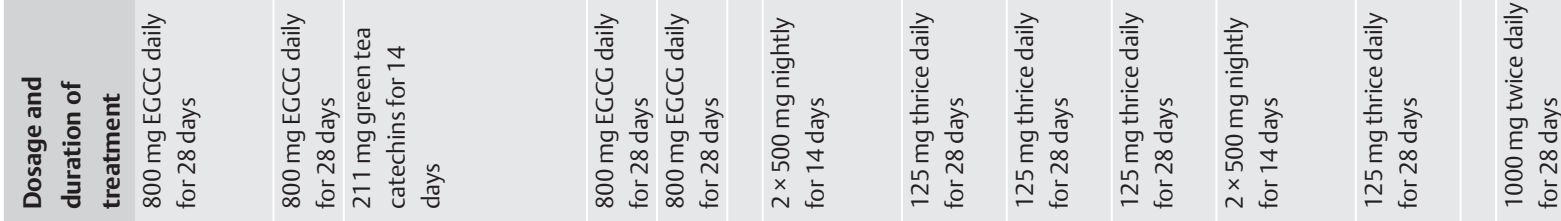

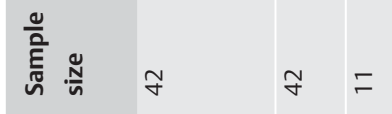

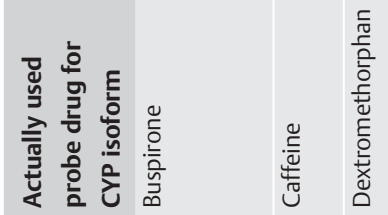

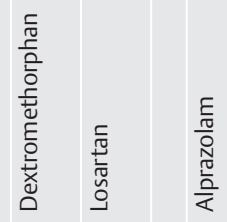

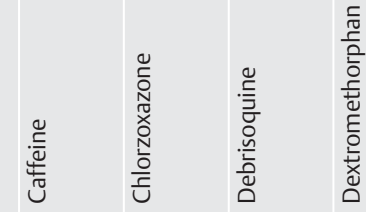

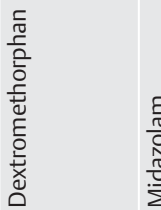

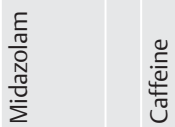

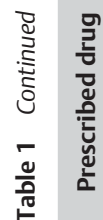

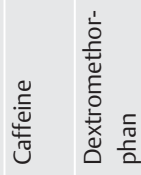

II

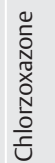

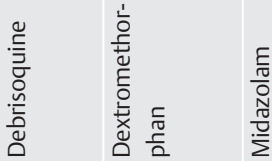

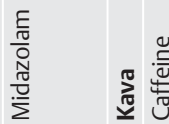


范 离 㐫

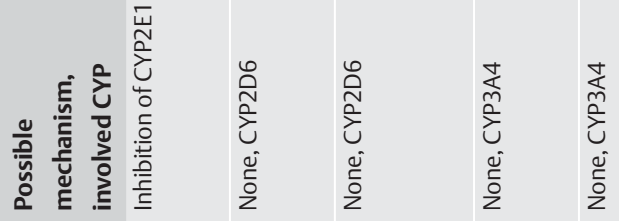

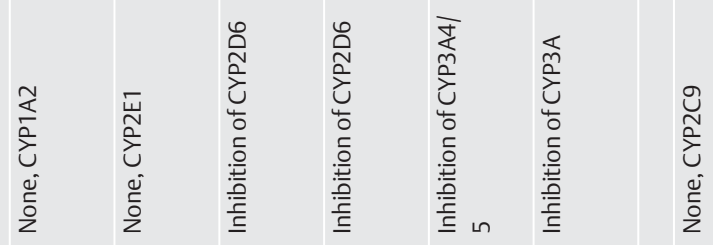
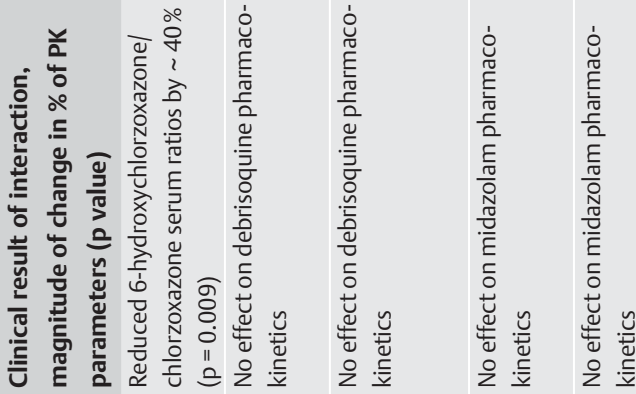

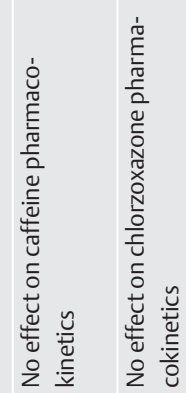

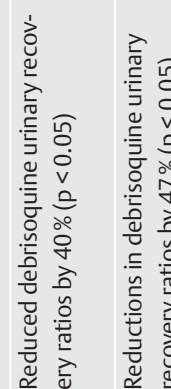

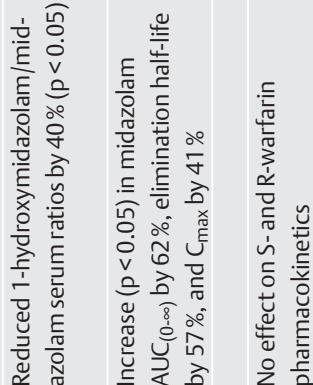

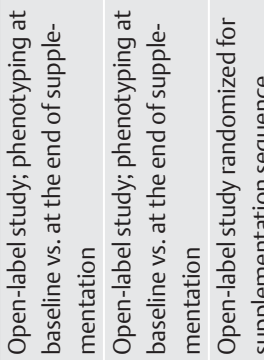

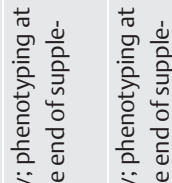

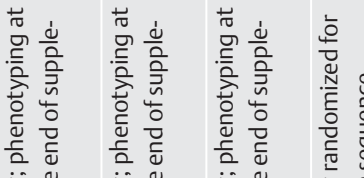

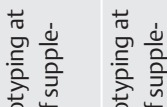

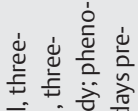

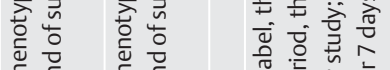

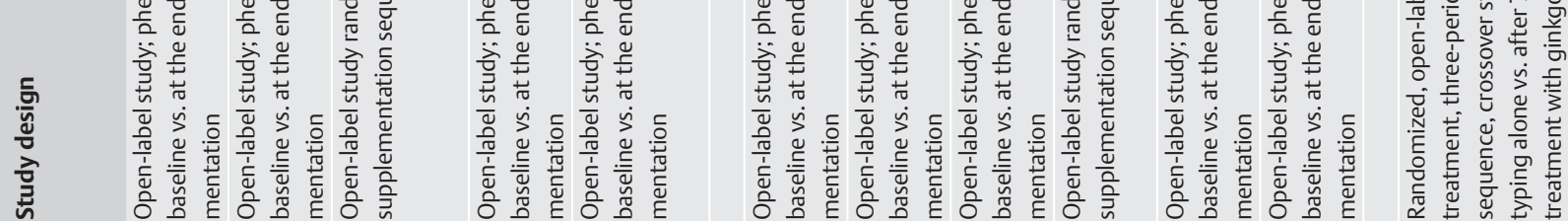

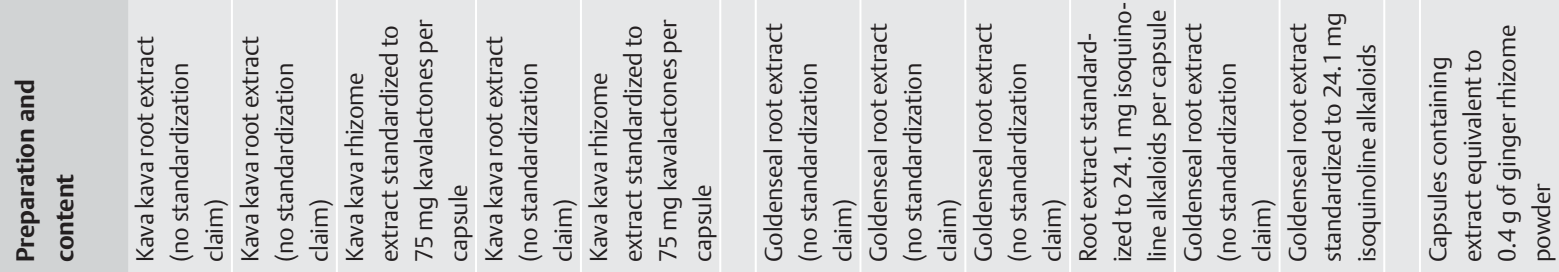

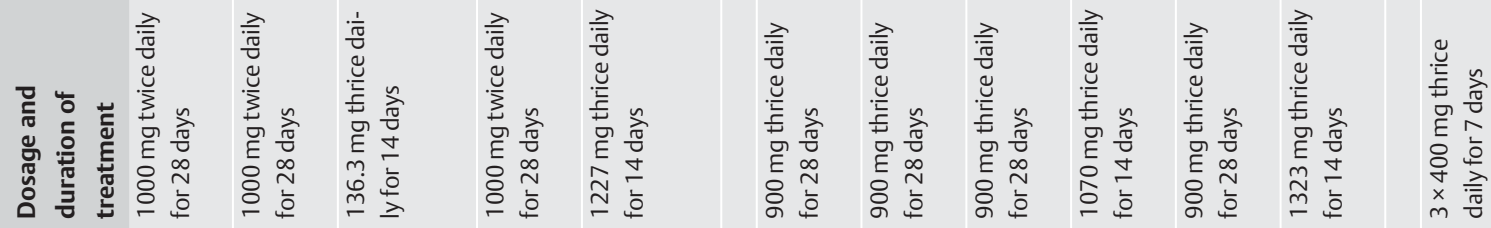

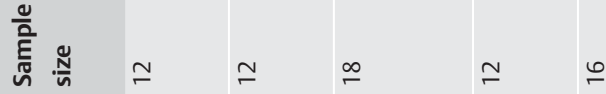

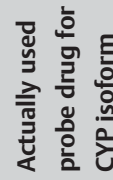

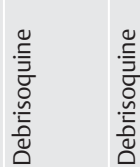

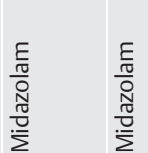

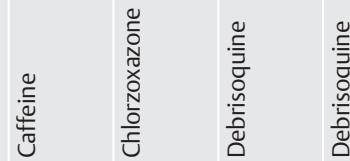

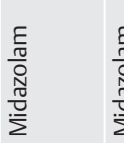

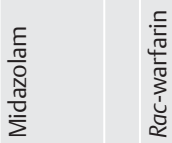

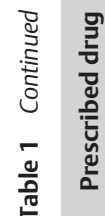

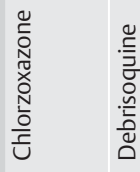

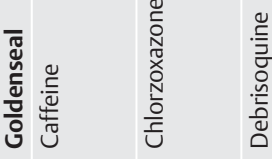

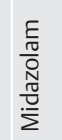

高竞 


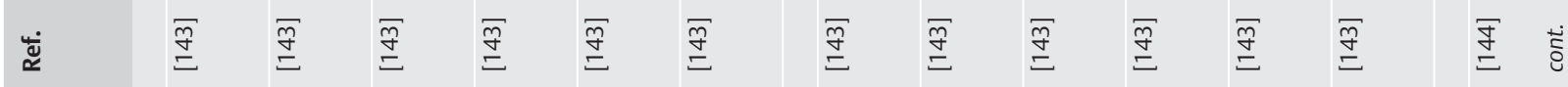

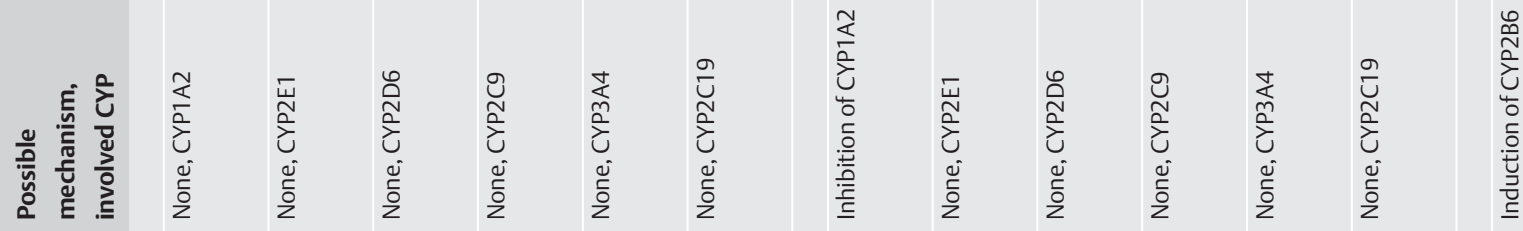

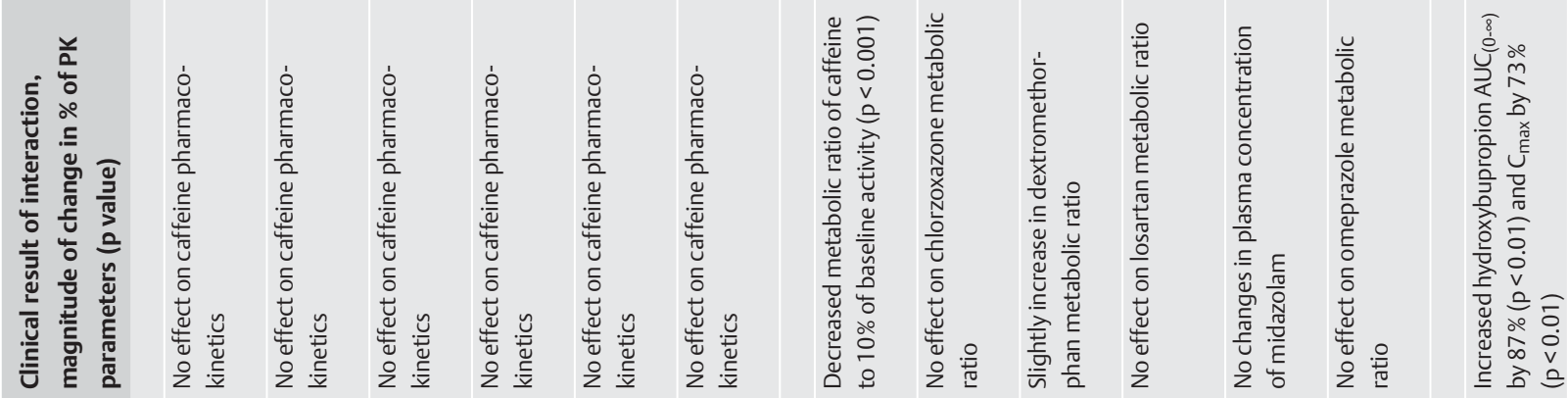

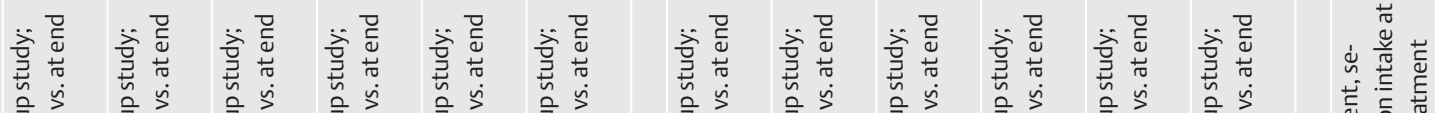

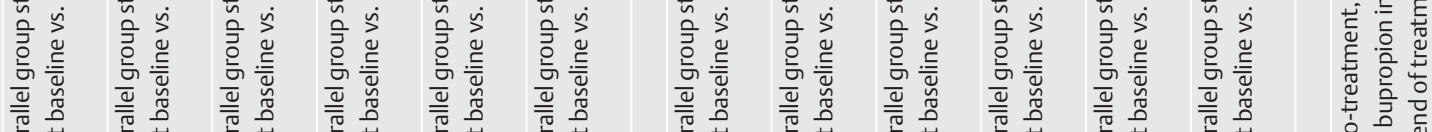

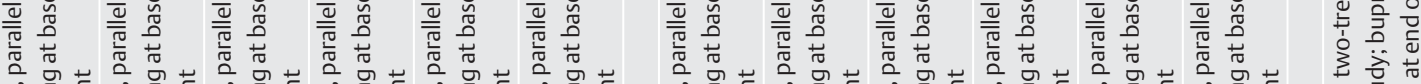

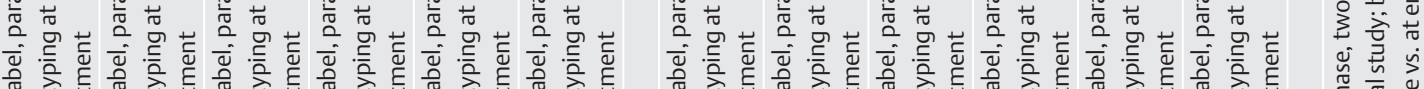
$\begin{array}{lll} & \\ 0\end{array}$

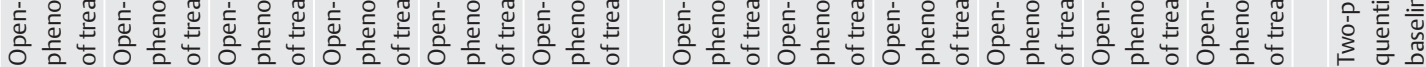

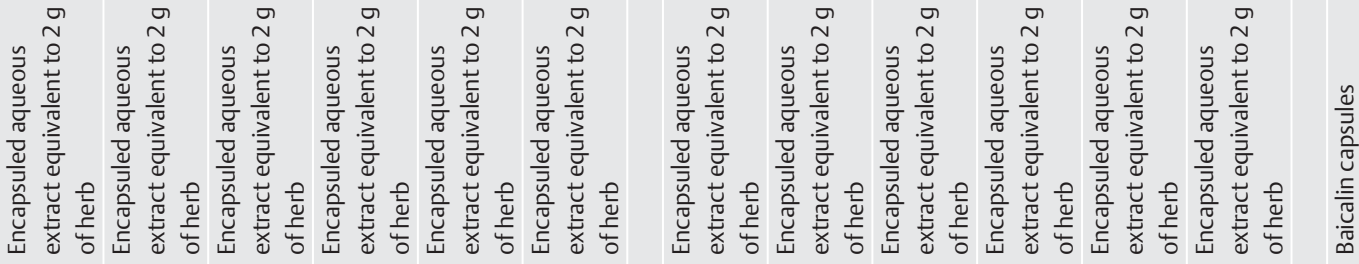

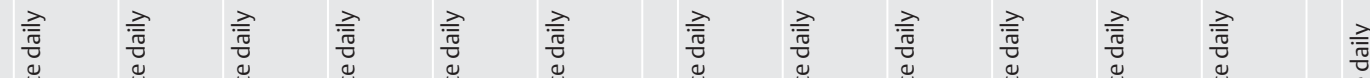

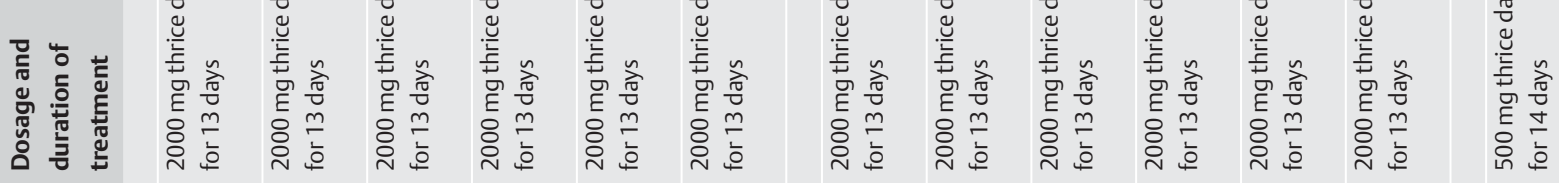
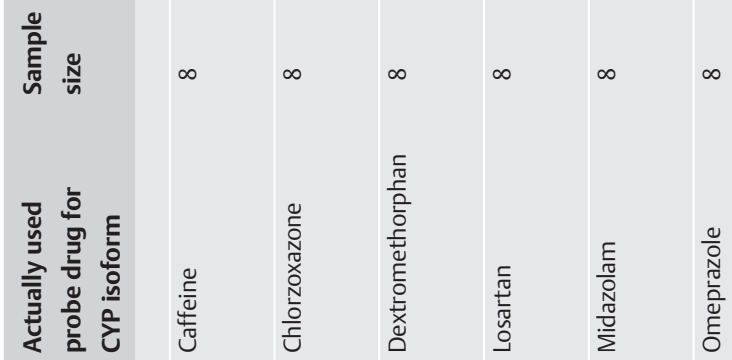

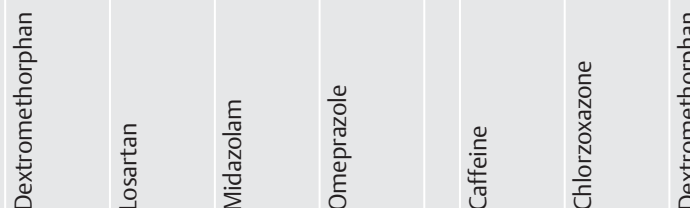

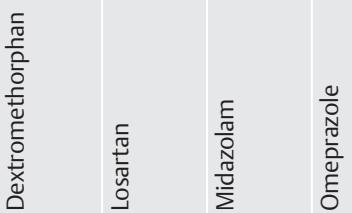




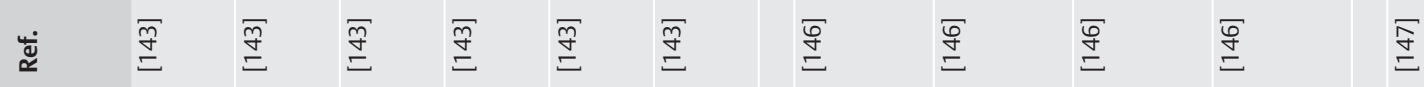

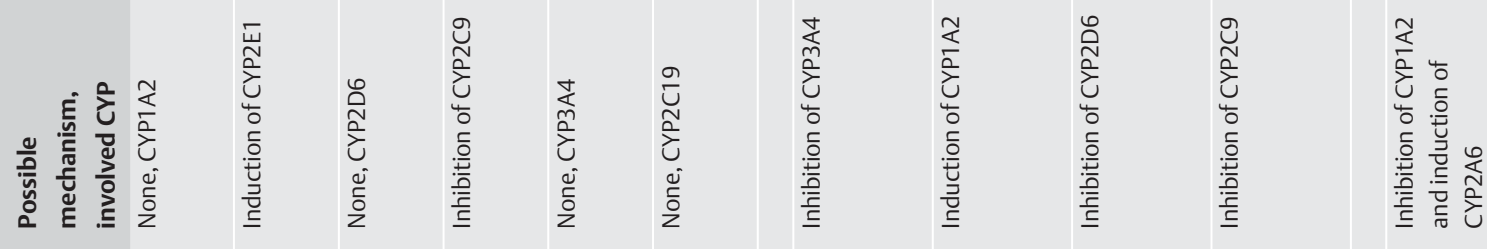

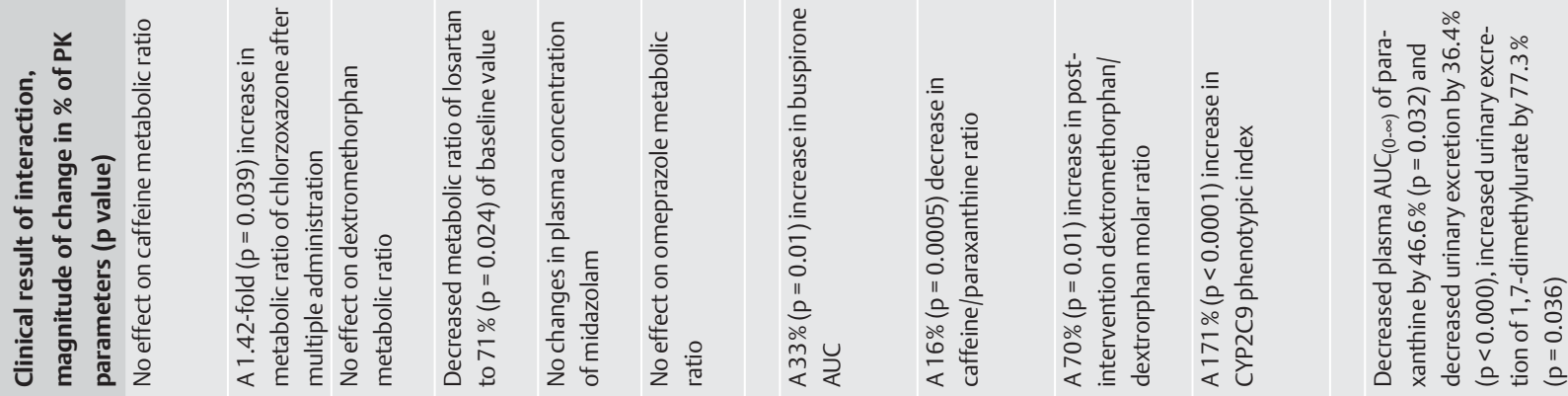

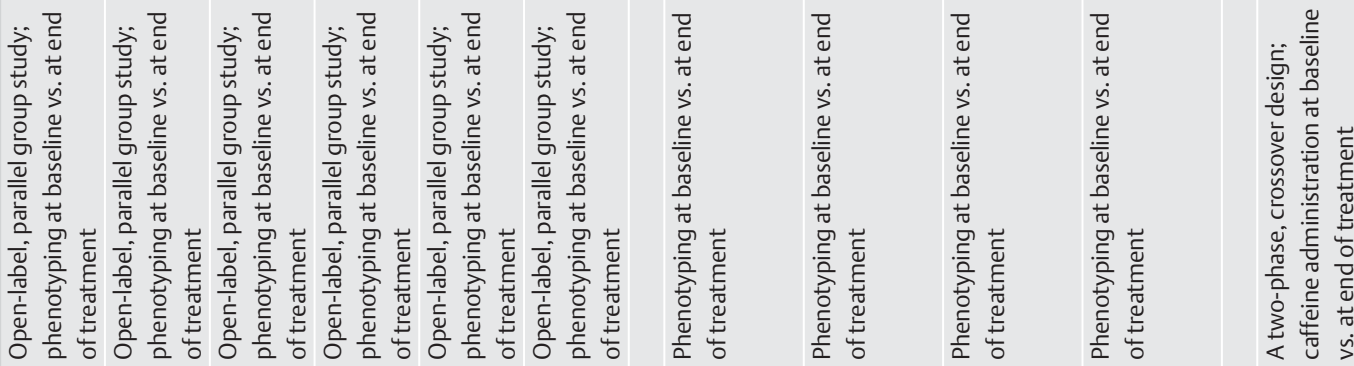

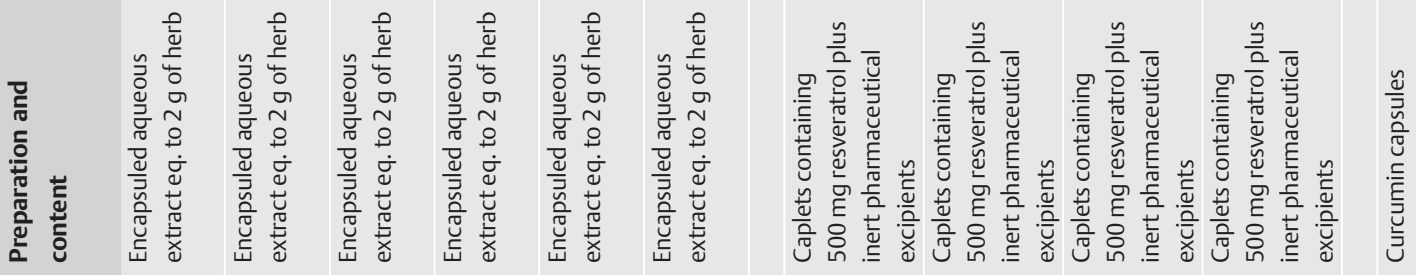

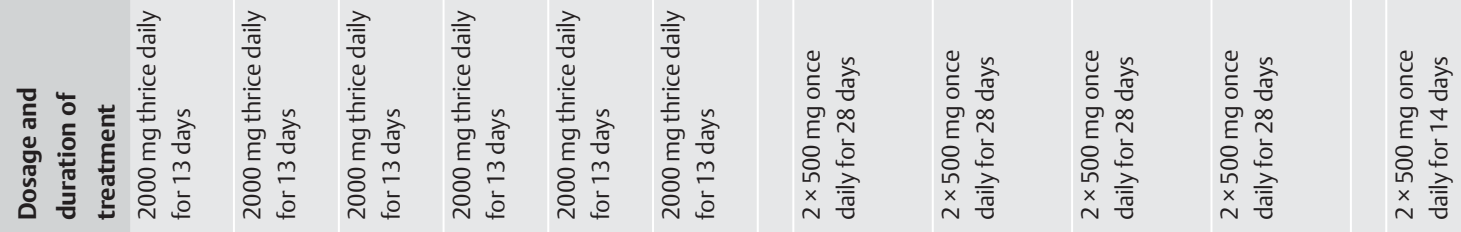

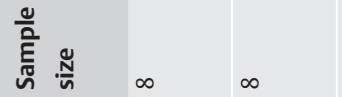

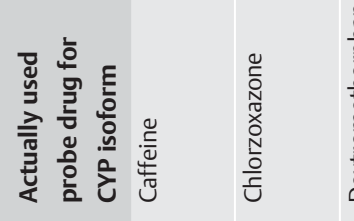

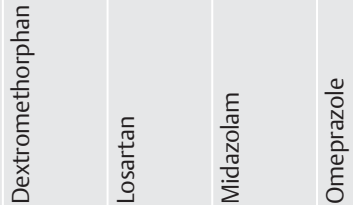

产高高高

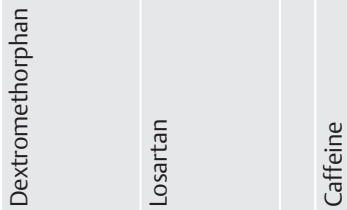

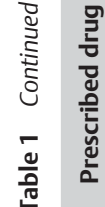

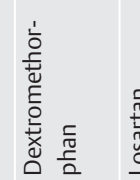
产高

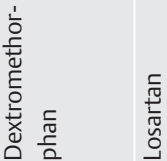

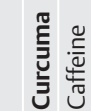




\section{References}

1 Moore LB, Goodwin B, Jones SA, Wisely GB, Serabjit-Singh CJ, Willson TM, Collins JL, Kliewer SA. St. John's wort induces hepatic drug metabolism through activation of the pregnane $\mathrm{X}$ receptor. Proc Natl Acad Sci USA 2000; 97: 7500-7502

2 Bailey DG, Spence JD, Munoz C, Arnold JM. Interaction of citrus juices with felodipine and nifedipine. Lancet 1991; 337: 268-269

3 Fuhr U, Jetter A, Kirchheiner J. Appropriate phenotyping procedures for drug metabolizing enzymes and transporters in humans and their simultaneous use in the "cocktail" approach. Clin Pharmacol Ther 2007; 81: $270-283$

4 Huang SM, Zhang L. Guidance for industry: drug interaction studies study design, data analysis, implications for dosing, and labeling recommendations. Available at http://www.fda.gov/downloads/Drugs/ GuidanceComplianceRegulatoryInformation/Guidances/UCM072101. htm. Accessed December 02, 2011

5 European Medicines Agency. Guideline on the investigation of drug interactions. Available at http://www.ema.europa.eu/docs/en_GB/ document_library/Scientific_guideline/2010/05/WC500090112.pdf. Accessed December 02, 2011

6 US Food and Drug Administration. Drug development and drug interactions: table of substrates, inhibitors and inducers. Available at http:// www.fda.gov/Drugs/DevelopmentApprovalProcess/Development Resources/DrugInteractionsLabeling/ucm093664.htm. Accessed December 02, 2011

7 Tanaka E, Kurata N, Yasuhara H. How useful is the "cocktail approach" for evaluating human hepatic drug metabolizing capacity using cytochrome P450 phenotyping probes in vivo? J Clin Pharm Ther 2003; 28: $157-165$

8 Zhou H, Tong Z, McLeod JF. "Cocktail” approaches and strategies in drug development: valuable tool or flawed science? J Clin Pharmacol 2004; 44: $120-134$

9 Turpault S, Brian W, Van Horn R, Santoni A, Poitiers F, Donazzolo Y, Boulenc $X$. Pharmacokinetic assessment of a five-probe cocktail for CYPs 1A2, 2C9, 2C19, 2D6 and 3A. Br J Clin Pharmacol 2009; 68: 928-935

10 Zhang $L$. A regulatory perspective on the utilization of cocktail approach in assessing drug interactions. Available at http://www.fda. gov/downloads/Drugs/DevelopmentApprovalProcess/DevelopmentResources/DrugInteractionsLabeling/UCM237160.htm. Accessed December 02, 2011

11 Zhang L, Reynolds KS, Zhao P, Huang SM. Drug interactions evaluation: an integrated part of risk assessment of therapeutics. Toxicol Appl Pharmacol 2010; 243: 134-145

12 US Food and Drug Administration. Guidances (Drugs). Available at http://www.fda.gov/Drugs/GuidanceComplianceRegulatory Information/Guidances/default.htm. Accessed December 02, 2011

13 Ma JD, Nguyen ET, Tsunoda SM, Greenberg HE, Gorski JC, Penzak SR, Lee $L S$. Assessment of oral midazolam limited sampling strategies to predict area under the concentration time curve (AUC) during cytochrome P450 (CYP) 3A baseline, inhibition and induction or activation. Int J Clin Pharmacol Ther 2010; 48: 847-853

14 Fuhr U, Beckmann-Knopp S, Jetter A, Luck H, Mengs $U$. The effect of silymarin on oral nifedipine pharmacokinetics. Planta Med 2007; 73: 1429-1435

15 Zadoyan G, Rokitta D, Klement S, Dienel A, Hoerr R, Gramatte T, Fuhr U. Effect of Ginkgo biloba special extract EGb 761(R) on human cytochrome P450 activity: a cocktail interaction study in healthy volunteers. Eur J Clin Pharmacol 2012; 68: 553-560

16 Blumenthal M, Ferrier GKL, Cavaliere C. Total sales of herbal supplements in United States show steady growth. Herbal Gram 2006; 71: 64-66

17 Borrelli F, Capasso R, Izzo AA. Garlic (Allium sativum L.): adverse effects and drug interactions in humans. Mol Nutr Food Res 2007; 51: 13861397

18 Lanzotti V. The analysis of onion and garlic. J Chromatogr A 2006; 1112: $3-22$

19 Shord SS, Shah K, Lukose A. Drug-botanical interactions: a review of the laboratory, animal, and human data for 8 common botanicals. Integr Cancer Ther 2009; 8: 208-227

20 Butterweck V, Derendorf H. Potential of pharmacokinetic profiling for detecting herbal interactions with drugs. Clin Pharmacokinet 2008; 47: 383-397

21 Gallicano K, Foster B, Choudhri S. Effect of short-term administration of garlic supplements on single-dose ritonavir pharmacokinetics in healthy volunteers. Br J Clin Pharmacol 2003; 55: 199-202
22 Hsu A, Granneman GR, Cao G, Carothers L, el-Shourbagy T, Baroldi P, Erdman K, Brown F, Sun E, Leonard JM. Pharmacokinetic interactions between two human immunodeficiency virus protease inhibitors, ritonavir and saquinavir. Clin Pharmacol Ther 1998; 63: 453-464

23 Cox MC, Low J, Lee J, Walshe J, Denduluri N, Berman A, Permenter MG Petros WP, Price DK, Figg WD, Sparreboom A, Swain SM. Influence of garlic (Allium sativum) on the pharmacokinetics of docetaxel. Clin Cancer Res 2006; 12: 4636-4640

24 Macan H, Uykimpang R, Alconcel M, Takasu J, Razon R, Amagase H, Niihara $Y$. Aged garlic extract may be safe for patients on warfarin therapy. J Nutr 2006; 136: 793S-795S

25 Markowitz JS, Devane CL, Chavin KD, Taylor RM, Ruan Y, Donovan JL. Effects of garlic (Allium sativum L.) supplementation on cytochrome P450 2D6 and 3A4 activity in healthy volunteers. Clin Pharmacol Ther 2003; 74: 170-177

26 Piscitelli SC, Burstein AH, Welden N, Gallicano KD, Falloon J. The effect of garlic supplements on the pharmacokinetics of saquinavir. Clin Infect Dis 2002; 34: 234-238

27 Gurley BJ, Gardner SF, Hubbard MA, Williams DK, Gentry WB, Cui Y, Ang CY. Clinical assessment of effects of botanical supplementation on cytochrome P450 phenotypes in the elderly: St John's wort, garlic oil, Panax ginseng and Ginkgo biloba. Drugs Aging 2005; 22: 525-539

28 Taylor JA, Weber W, Standish L, Quinn H, Goesling J, McGann M, Calabrese $C$. Efficacy and safety of echinacea in treating upper respiratory tract infections in children: a randomized controlled trial. JAMA 2003; 290: 2824-2830

29 Freeman C, Spelman K. A critical evaluation of drug interactions with Echinacea spp. Mol Nutr Food Res 2008; 52: 789-798

30 Gertsch J, Schoop R, Kuenzle U, Suter A. Echinacea alkylamides modulate TNF-alpha gene expression via cannabinoid receptor CB2 and multiple signal transduction pathways. FEBS Lett 2004; 577: 563-569

31 Gorski JC, Huang SM, Pinto A, Hamman MA, Hilligoss JK, Zaheer NA, Desai $M$, Miller M, Hall SD. The effect of echinacea (Echinacea purpurea root) on cytochrome P450 activity in vivo. Clin Pharmacol Ther 2004; 75: $89-100$

32 Penzak SR, Robertson SM, Hunt JD, Chairez C, Malati CY, Alfaro RM, Stevenson JM, Kovacs JA. Echinacea purpurea significantly induces cytochrome P450 3A activity but does not alter lopinavir-ritonavir exposure in healthy subjects. Pharmacotherapy 2010; 30: 797-805

33 Wittkowsky AK. Warfarin and other coumarin derivatives: pharmacokinetics, pharmacodynamics, and drug interactions. Semin Vasc Med 2003: 3: 221-230

34 Abdul MI, Jiang X, Williams KM, Day RO, Roufogalis BD, Liauw WS, Xu H, Matthias A, Lehmann RP, McLachlan AJ. Pharmacokinetic and pharmacodynamic interactions of echinacea and policosanol with warfarin in healthy subjects. Br J Clin Pharmacol 2010; 69: 508-515

35 Gurley BJ, Gardner SF, Hubbard MA, Williams DK, Gentry WB, Carrier J, Khan IA, Edwards DJ, Shah A. In vivo assessment of botanical supplementation on human cytochrome P450 phenotypes: Citrus aurantium, Echinacea purpurea, milk thistle, and saw palmetto. Clin Pharmacol Ther 2004; 76: 428-440

36 Gurley BJ, Swain A, Hubbard MA, Williams DK, Barone G, Hartsfield F, Tong Y, Carrier DJ, Cheboyina S, Battu SK. Clinical assessment of CYP2D6-mediated herb-drug interactions in humans: effects of milk thistle, black cohosh, goldenseal, kava kava, St. John's wort, and Echinacea. Mol Nutr Food Res 2008; 52: 755-763

37 Gerber GS. Saw palmetto for the treatment of men with lower urinary tract symptoms. J Urol 2000; 163: 1408-1412

38 Markowitz JS, Donovan JL, Devane CL, Taylor RM, Ruan Y, Wang JS, Chavin KD. Multiple doses of saw palmetto (Serenoa repens) did not alter cytochrome P450 2D6 and 3A4 activity in normal volunteers. Clin Pharmacol Ther 2003; 74: 536-542

39 Diamond BJ, Shiflett SC, Feiwel N, Matheis RJ, Noskin O, Richards JA, Schoenberger NE. Ginkgo biloba extract: mechanisms and clinical indications. Arch Phys Med Rehabil 2000; 81: 668-678

40 Abdel-Kader R, Hauptmann S, Keil U, Scherping I, Leuner K, Eckert A, Muller WE. Stabilization of mitochondrial function by Ginkgo biloba extract (EGb 761). Pharmacol Res 2007; 56: 493-502

41 Tchantchou F, Xu Y, Wu Y, Christen Y, Luo Y. EGb 761 enhances adult hippocampal neurogenesis and phosphorylation of CREB in transgenic mouse model of Alzheimer's disease. FASEB J 2007; 21: 2400-2408

42 Tchantchou F, Lacor PN, Cao Z, Lao L, Hou Y, Cui C, Klein WL, Luo Y. Stimulation of neurogenesis and synaptogenesis by bilobalide and quercetin via common final pathway in hippocampal neurons. Int J Alzheimers Dis 2009; 18: 787-798 
43 Elovic EP, Zafonte RD. Ginkgo biloba: applications in traumatic brain injury. J Head Trauma Rehabil 2001; 16: 603-607

44 Cohen-Salmon C, Venault P, Martin B, Raffalli-Sebille MJ, Barkats M, Clostre F, Pardon MC, Christen Y, Chapouthier G. Effects of Ginkgo biloba extract (EGb 761) on learning and possible actions on aging. J Physiol 1997; 91: 291-300

45 Thiagarajan G, Chandani S, Harinarayana Rao S, Samuni AM, Chandrasekaran $K$, Balasubramanian D. Molecular and cellular assessment of Ginkgo biloba extract as a possible ophthalmic drug. Exp Eye Res 2002; 75: 421-430

46 Rioufol G, Pietri S, Culcasi M, Loufoua J, Staat P, Pop C, Drieu K, Ovize M. Ginkgo biloba extract EGb 761 attenuates myocardial stunning in the pig heart. Basic Res Cardiol 2003; 98: 59-68

47 DeFeudis FV. A brief history of EGb 761 and its therapeutic uses. Pharmacopsychiatry 2003; 36: S2-S7

48 Greenblatt DJ, von Moltke LL, Luo Y, Perloff ES, Horan KA, Bruce A, Reynolds RC, Harmatz JS, Avula B, Khan IA, Goldman P. Ginkgo biloba does not alter clearance of flurbiprofen, a cytochrome P450-2C9 substrate. J Clin Pharmacol 2006; 46: 214-221

49 Jiang X, Williams KM, Liauw WS, Ammit AJ, Roufogalis BD, Duke CC, Day $R O$, McLachlan AJ. Effect of ginkgo and ginger on the pharmacokinetics and pharmacodynamics of warfarin in healthy subjects. Br J Clin Pharmacol 2005; 59: 425-432

50 Yin OQ Tomlinson B, Waye MM, Chow AH, Chow MS. Pharmacogenetics and herb-drug interactions: experience with Ginkgo biloba and omeprazole. Pharmacogenetics 2004; 14: 841-850

51 Lei HP, Wang G, Wang LS, Ou-yang DS, Chen H, Li Q Zhang W, Tan ZR, Fan L, He YJ, Zhou HH. Lack of effect of Ginkgo biloba on voriconazole pharmacokinetics in Chinese volunteers identified as CYP2C19 poor and extensive metabolizers. Ann Pharmacother 2009; 43: 726-731

52 Robertson SM, Davey RT, Voell J, Formentini E, Alfaro RM, Penzak SR. Effect of Ginkgo biloba extract on lopinavir, midazolam and fexofenadine pharmacokinetics in healthy subjects. Curr Med Res Opin 2008; 24: 591-599

53 Lei HP, Ji W, Lin J, Chen H, Tan ZR, Hu DL, Liu LJ, Zhou HH. Effects of Ginkgo biloba extract on the pharmacokinetics of bupropion in healthy volunteers. Br J Clin Pharmacol 2009; 68: 201-206

54 Markowitz JS, Donovan JL, Lindsay DeVane C, Sipkes L, Chavin KD. Multiple-dose administration of Ginkgo biloba did not affect cytochrome P-450 2D6 or 3A4 activity in normal volunteers. J Clin Psychopharmacol 2003; 23: 576-581

55 Penzak SR, Busse KH, Robertson SM, Formentini E, Alfaro RM, Davey Jr. $R T$. Limitations of using a single postdose midazolam concentration to predict CYP3A-mediated drug interactions. J Clin Pharmacol 2008; 48: 671-680

56 Uchida S, Yamada H, Li XD, Maruyama S, Ohmori Y, Oki T, Watanabe H, Umegaki K, Ohashi K, Yamada S. Effects of Ginkgo biloba extract on pharmacokinetics and pharmacodynamics of tolbutamide and midazolam in healthy volunteers. J Clin Pharmacol 2006; 46: 1290-1298

57 Zuo XC, Zhang BK, Jia SJ, Liu SK, Zhou LY, Li J, Zhang J, Dai LL, Chen BM, Yang GP, Yuan H. Effects of Ginkgo biloba extracts on diazepam metabolism: a pharmacokinetic study in healthy Chinese male subjects. Eur J Clin Pharmacol 2010; 66: 503-509

58 Aston JL, Lodolce AE, Shapiro NL. Interaction between warfarin and cranberry juice. Pharmacotherapy 2006; 26: 1314-1319

59 Zuo Y, Wang C, Zhan J. Separation, characterization, and quantitation of benzoic and phenolic antioxidants in American cranberry fruit by GC-MS. J Agric Food Chem 2002; 50: 3789-3794

60 McKay DL, Blumberg JB. Cranberries (Vaccinium macrocarpon) and cardiovascular disease risk factors. Nutr Rev 2007; 65: 490-502

61 Pham $D Q$ Pham $A Q$. Interaction potential between cranberry juice and warfarin. Am J Health Syst Pharm 2007; 64: 490-494

62 Griffiths $P$. The role of cranberry juice in the treatment of urinary tract infections. Br J Community Nurs 2003; 8: 557-561

63 Ngo N, Yan Z, Graf TN, Carrizosa DR, Kashuba AD, Dees EC, Oberlies NH, Paine MF. Identification of a cranberry juice product that inhibits enteric CYP3A-mediated first-pass metabolism in humans. Drug Metab Dispos 2009; 37: 514-522

64 Howell $A B$, Foxman $B$. Cranberry juice and adhesion of antibiotic-resistant uropathogens. JAMA 2002; 287: 3082-3083

65 Ushijima K, Tsuruoka S, Tsuda H, Hasegawa G, Obi Y, Kaneda T, Takahashi M, Maekawa T, Sasaki T, Koshimizu TA, Fujimura A. Cranberry juice suppressed the diclofenac metabolism by human liver microsomes, but not in healthy human subjects. Br J Clin Pharmacol 2009; 68: $194-200$
66 Greenblatt DJ, von Moltke LL, Perloff ES, Luo Y, Harmatz JS, Zinny MA. Interaction of flurbiprofen with cranberry juice, grape juice, tea, and fluconazole: in vitro and clinical studies. Clin Pharmacol Ther 2006; 79: 125-133

67 Mohammed Abdul MI, Jiang X, Williams KM, Day RO, Roufogalis BD, Liauw WS, Xu H, McLachlan AJ. Pharmacodynamic interaction of warfarin with cranberry but not with garlic in healthy subjects. $\mathrm{Br}$ J Pharmacol 2008; 154: 1691-1700

68 Lilja JJ, Backman JT, Neuvonen PJ. Effects of daily ingestion of cranberry juice on the pharmacokinetics of warfarin, tizanidine, and midazolam - probes of CYP2C9, CYP1A2, and CYP3A4. Clin Pharmacol Ther 2007; 81: 833-839

69 Grenier J, Fradette C, Morelli G, Merritt GJ, Vranderick M, Ducharme MP. Pomelo juice, but not cranberry juice, affects the pharmacokinetics of cyclosporine in humans. Clin Pharmacol Ther 2006; 79: 255-262

$70 \mathrm{Wu}$ Z, Rodgers RP, Marshall AG. Characterization of vegetable oils: detailed compositional fingerprints derived from electrospray ionization fourier transform ion cyclotron resonance mass spectrometry. J Agric Food Chem 2004; 52: 5322-5328

71 Messina $M$, Messina $V$. The role of soy in vegetarian diets. Nutrients 2010; 2: 855-888

72 Kishida T, Nagamoto M, Ohtsu Y, Watakabe M, Ohshima D, Nashiki K, Mizushige T, Izumi T, Obata A, Ebihara K. Lack of an inducible effect of dietary soy isoflavones on the mRNA abundance of hepatic cytochrome P-450 isozymes in rats. Biosci Biotechnol Biochem 2004; 68: 508-515

73 Peng WX, Li HD, Zhou HH. Effect of daidzein on CYP1A2 activity and pharmacokinetics of theophylline in healthy volunteers. Eur J Clin Pharmacol 2003; 59: 237-241

74 Chen Y, Xiao CQ He YJ, Chen BL, Wang G, Zhou G, Zhang W, Tan ZR, Cao S, Wang $L P$, Zhou $H H$. Genistein alters caffeine exposure in healthy female volunteers. Eur J Clin Pharmacol 2011; 67: 347-353

75 Wang G, Xiao CQ Li Z, Guo D, Chen Y, Fan L, Qian RH, Peng XJ, Hu DL, Zhou HH. Effect of soy extract administration on losartan pharmacokinetics in healthy female volunteers. Ann Pharmacother 2009; 43: 1045-1049

76 Anderson GD, Rosito G, Mohustsy MA, Elmer GW. Drug interaction potential of soy extract and Panax ginseng. J Clin Pharmacol 2003; 43 : 643-648

77 Izzo AA, Ernst E. Interactions between herbal medicines and prescribed drugs: an updated systematic review. Drugs 2009; 69: 1777-1798

78 Lee MH, Jeong JH, Seo JW, Shin CG, Kim YS, In JG, Yang DC, Yi JS, Choi YE. Enhanced triterpene and phytosterol biosynthesis in Panax ginseng overexpressing squalene synthase gene. Plant Cell Physiol 2004; 45: 976-984

79 Shibata S. Chemistry and cancer preventing activities of ginseng saponins and some related triterpenoid compounds. J Korean Med Sci 2001; 16: S28-S37

80 Lee SH, Ahn YM, Ahn SY, Doo HK, Lee BC. Interaction between warfarin and Panax ginseng in ischemic stroke patients. J Alternat Complement Med 2008; 14: 715-721

81 Briskin DP. Medicinal plants and phytomedicines. Linking plant biochemistry and physiology to human health. Plant Physiol 2000; 124: 507-514

82 Vogler BK, Pittler MH, Ernst E. The efficacy of ginseng. A systematic review of randomised clinical trials. Eur J Clin Pharmacol 1999; 55: $567-$ 575

83 Jiang X, Williams KM, Liauw WS, Ammit AJ, Roufogalis BD, Duke CC, Day $R O$, McLachlan AJ. Effect of St John's wort and ginseng on the pharmacokinetics and pharmacodynamics of warfarin in healthy subjects. $\mathrm{Br}$ J Clin Pharmacol 2004; 57: 592-599

84 Rhyu MR, Lu J, Webster DE, Fabricant DS, Farnsworth NR, Wang ZJ. Black cohosh (Actaea racemosa, Cimicifuga racemosa) behaves as a mixed competitive ligand and partial agonist at the human mu opiate receptor. J Agric Food Chem 2006; 54: 9852-9857

85 Gurley BJ, Gardner SF, Hubbard MA, Williams DK, Gentry WB, Khan IA, Shah A. In vivo effects of goldenseal, kava kava, black cohosh, and valerian on human cytochrome P450 1A2, 2D6, 2E1, and 3A4/5 phenotypes. Clin Pharmacol Ther 2005; 77: 415-426

86 Gurley B, Hubbard MA, Williams DK, Thaden J, Tong Y, Gentry WB, Breen $P$, Carrier DJ, Cheboyina S. Assessing the clinical significance of botanical supplementation on human cytochrome P450 3A activity: comparison of a milk thistle and black cohosh product to rifampin and clarithromycin. J Clin Pharmacol 2006; 46: 201-213 
87 Borrelli F, Izzo AA. Herb-drug interactions with St John's wort (Hypericum perforatum): an update on clinical observations. AAPS J 2009; 11: 710-727

88 Markowitz JS, DeVane CL, Boulton DW, Carson SW, Nahas Z, Risch SC. Effect of St. John's wort (Hypericum perforatum) on cytochrome P-450 2D6 and 3A4 activity in healthy volunteers. Life Sci 2000; 66: PL133-PL139

89 Wang Z, Gorski JC, Hamman MA, Huang SM, Lesko LJ, Hall SD. The effects of St John's wort (Hypericum perforatum) on human cytochrome P450 activity. Clin Pharmacol Ther 2001; 70: 317-326

90 Wenk M, Todesco L, Krahenbuhl S. Effect of St John's wort on the activities of CYP1A2, CYP3A4, CYP2D6, N-acetyltransferase 2, and xanthine oxidase in healthy males and females. Br J Clin Pharmacol 2004; 57: 495-499

91 Roby CA, Anderson GD, Kantor E, Dryer DA, Burstein AH. St John's Wort: effect on CYP3A4 activity. Clin Pharmacol Ther 2000; 67: 451-457

92 Markowitz JS, Donovan JL, DeVane CL, Taylor RM, Ruan Y, Wang JS, Chavin $K D$. Effect of St John's wort on drug metabolism by induction of cytochrome P450 3A4 enzyme. JAMA 2003; 290: 1500-1504

93 Wang LS, Zhu B, Abd El-Aty AM, Zhou G, Li Z, Wu J, Chen GL, Liu J, Tang $Z R$, An W, Li Q Wang D, Zhou HH. The influence of St John's Wort on CYP2C19 activity with respect to genotype. J Clin Pharmacol 2004; 44: $577-581$

94 Wang LS, Zhou G, Zhu B, Wu J, Wang JG, Abd El-Aty AM, Li T, Liu J, Yang TL, Wang D, Zhong XY, Zhou HH. St John's wort induces both cytochrome P450 3A4-catalyzed sulfoxidation and 2C19-dependent hydroxylation of omeprazole. Clin Pharmacol Ther 2004; 75: 191-197

95 Mai I, Bauer S, Perloff ES, Johne A, Uehleke B, Frank B, Budde K, Roots I. Hyperforin content determines the magnitude of the St John's wortcyclosporine drug interaction. Clin Pharmacol Ther 2004; 76: 330340

96 Arold G, Donath F, Maurer A, Diefenbach K, Bauer S, Henneicke-von Zepelin $H H$, Friede $M$, Roots I. No relevant interaction with alprazolam, caffeine, tolbutamide, and digoxin by treatment with a low-hyperforin St John's wort extract. Planta Med 2005; 71: 331-337

97 Mueller SC, Majcher-Peszynska J, Uehleke B, Klammt S, Mundkowski RG, Miekisch W, Sievers H, Bauer S, Frank B, Kundt G, Drewelow B. The extent of induction of CYP3A by St. John's wort varies among products and is linked to hyperforin dose. Eur J Clin Pharmacol 2006; 62: 29-36

98 Mueller SC, Majcher-Peszynska J, Mundkowski RG, Uehleke B, Klammt S, Sievers $H$, Lehnfeld R, Frank B, Thurow K, Kundt G, Drewelow B. No clinically relevant CYP3A induction after St. John's wort with low hyperforin content in healthy volunteers. Eur J Clin Pharmacol 2009; 65: 81-87

99 Hall SD, Wang Z, Huang SM, Hamman MA, Vasavada N, Adigun AQ Hilligoss JK, Miller M, Gorski JC. The interaction between St John's wort and an oral contraceptive. Clin Pharmacol Ther 2003; 74: 525-535

100 Murphy PA, Kern SE, Stanczyk FZ, Westhoff CL. Interaction of St. John's Wort with oral contraceptives: effects on the pharmacokinetics of norethindrone and ethinyl estradiol, ovarian activity and breakthrough bleeding. Contraception 2005; 71: 402-408

101 Pfrunder A, Schiesser M, Gerber S, Haschke M, Bitzer J, Drewe J. Interaction of St John's wort with low-dose oral contraceptive therapy: a randomized controlled trial. Br J Clin Pharmacol 2003; 56: 683-690

102 Smith PF, Bullock JM, Booker BM, Haas CE, Berenson CS, Jusko WJ. Induction of imatinib metabolism by Hypericum perforatum. Blood 2004; 104: $1229-1230$

103 Frye RF, Fitzgerald SM, Lagattuta TF, Hruska MW, Egorin MJ. Effect of St John's wort on imatinib mesylate pharmacokinetics. Clin Pharmacol Ther 2004; 76: 323-329

104 Andren L, Andreasson A, Eggertsen R. Interaction between a commercially available St. John's wort product (Movina) and atorvastatin in patients with hypercholesterolemia. Eur J Clin Pharmacol 2007; 63: 913-916

105 Portoles A, Terleira A, Calvo A, Martinez I, Resplandy G. Effects of Hypericum perforatum on ivabradine pharmacokinetics in healthy volunteers: an open-label, pharmacokinetic interaction clinical trial. J Clin Pharmacol 2006; 46: 1188-1194

106 Tannergren C, Engman H, Knutson L, Hedeland M, Bondesson U, Lennernas $H$. St John's wort decreases the bioavailability of R- and S-verapamil through induction of the first-pass metabolism. Clin Pharmacol Ther 2004; 75: 298-309

107 Kawaguchi A, Ohmori M, Tsuruoka S, Nishiki K, Harada K, Miyamori I, Yano R, Nakamura T, Masada M, Fujimura A. Drug interaction between St John's Wort and quazepam. Br J Clin Pharmacol 2004; 58: 403-410
108 Rengelshausen J, Banfield M, Riedel KD, Burhenne J, Weiss J, Thomsen T, Walter-Sack I, Haefeli WE, Mikus G. Opposite effects of short-term and long-term St John's wort intake on voriconazole pharmacokinetics. Clin Pharmacol Ther 2005; 78: 25-33

109 Xu H, Williams KM, Liauw WS, Murray M, Day RO, McLachlan AJ. Effects of St John's wort and CYP2C9 genotype on the pharmacokinetics and pharmacodynamics of gliclazide. Br J Pharmacol 2008; 153: 15791586

110 Piscitelli SC, Burstein AH, Chaitt D, Alfaro RM, Falloon J. Indinavir concentrations and St John's wort. Lancet 2000; 355: 547-548

111 Kroll DJ, Shaw HS, Oberlies NH. Milk thistle nomenclature: why it matters in cancer research and pharmacokinetic studies. Integr Cancer Ther 2007; 6: 110-119

112 Hogan FS, Krishnegowda NK, Mikhailova M, Kahlenberg MS. Flavonoid, silibinin, inhibits proliferation and promotes cell-cycle arrest of human colon cancer. J Surg Res 2007; 143: 58-65

113 Brantley SJ, Oberlies NH, Kroll DJ, Paine MF. Two flavonolignans from milk thistle (Silybum marianum) inhibit CYP2C9-mediated warfarin metabolism at clinically achievable concentrations. J Pharmacol Exp Ther 2010; 332: 1081-1087

114 van Erp NP, Baker SD, Zhao M, Rudek MA, Guchelaar HJ, Nortier JW Sparreboom A, Gelderblom H. Effect of milk thistle (Silybum marianum) on the pharmacokinetics of irinotecan. Clin Cancer Res 2005; 11: 7800-7806

115 Lu H, Meng X, Li C, Sang S, Patten C, Sheng S, Hong J, Bai N, Winnik B, Ho CT, Yang CS. Glucuronides of tea catechins: enzymology of biosynthesis and biological activities. Drug Metab Dispos 2003; 31: 452-461

116 Feng WY. Metabolism of green tea catechins: an overview. Curr Drug Metab 2006; 7: 755-809

117 Zhang Q Fu H, Pan J, He J, Ryota S, Hara Y, Wang Y, Lubet RA, You M. Effect of dietary Polyphenon E and EGCG on lung tumorigenesis in A/ J Mice. Pharm Res 2010; 27: 1066-1071

118 Yang CS, Chen L, Lee MJ, Balentine D, Kuo MC, Schantz SP. Blood and urine levels of tea catechins after ingestion of different amounts of green tea by human volunteers. Cancer Epidemiol Biomarkers Prev 1998; 7: 351-354

119 Yang TT, Koo MW. Chinese green tea lowers cholesterol level through an increase in fecal lipid excretion. Life Sci 2000; 66: 411-423

120 Yang TT, Koo MW. Inhibitory effect of Chinese green tea on endothelial cell-induced LDL oxidation. Atherosclerosis 2000; 148: 67-73

121 Zhong Z, Froh M, Connor HD, Li X, Conzelmann LO, Mason RP, Lemasters JJ, Thurman RG. Prevention of hepatic ischemia-reperfusion injury by green tea extract. Am J Physiol Gastrointest Liver Physiol 2002; 283: G957-G964

122 Oyama J, Maeda T, Kouzuma K, Ochiai R, Tokimitsu I, Higuchi Y, Sugano M, Makino N. Green tea catechins improve human forearm endothelial dysfunction and have antiatherosclerotic effects in smokers. Circ J 2010; 74: 578-588

123 Oyama J, Maeda T, Sasaki M, Kozuma K, Ochiai R, Tokimitsu I, Taguchi S, Higuchi Y, Makino N. Green tea catechins improve human forearm vascular function and have potent anti-inflammatory and anti-apoptotic effects in smokers. Intern Med 2010; 49: 2553-2559

124 Persson IA, Persson K, Hagg S, Andersson RG. Effects of green tea, black tea and Rooibos tea on angiotensin-converting enzyme and nitric oxide in healthy volunteers. Public Health Nutr 2010; 13: 730-737

125 Nantz MP, Rowe CA, Bukowski JF, Percival SS. Standardized capsule of Camellia sinensis lowers cardiovascular risk factors in a randomized, double-blind, placebo-controlled study. Nutrition 2009; 25: 147-154

126 Donovan JL, Chavin KD, Devane CL, Taylor RM, Wang JS, Ruan Y, Markowitz JS. Green tea (Camellia sinensis) extract does not alter cytochrome p 450 3A4 or 2D6 activity in healthy volunteers. Drug Metab Dispos 2004; 32: 906-908

127 Chow HH, Hakim IA, Vining DR, Crowell JA, Cordova CA, Chew WM, Xu $\mathrm{MJ}$, Hsu CH, Ranger-Moore J, Alberts DS. Effects of repeated green tea catechin administration on human cytochrome P450 activity. Cancer Epidemiol Biomarkers Prev 2006; 15: 2473-2476

128 Kennedy DO, Wightman EL. Herbal extracts and phytochemicals: plant secondary metabolites and the enhancement of human brain function. Adv Nutr 2011; 2: 32-50

129 Houghton PJ. The scientific basis for the reputed activity of Valerian. J Pharm Pharmacol 1999; 51: 505-512

130 Houghton PJ. The biological activity of Valerian and related plants J Ethnopharmacol 1988; 22: 121-142 
131 Leathwood PD, Chauffard F, Heck E, Munoz-Box R. Aqueous extract of valerian root (Valeriana officinalis L.) improves sleep quality in man. Pharmacol Biochem Behav 1982; 17: 65-71

132 Leathwood PD, Chauffard F. Aqueous extract of valerian reduces latency to fall asleep in man. Planta Med 1985; 144-148

133 Dorn M. [Efficacy and tolerability of Baldrian versus oxazepam in nonorganic and non-psychiatric insomniacs: a randomised, double-blind, clinical, comparative study]. Forsch Komplementarmed Klass Naturheilkd 2000; 7: 79-84

134 Donath F, Quispe S, Diefenbach K, Maurer A, Fietze I, Roots I. Critical evaluation of the effect of valerian extract on sleep structure and sleep quality. Pharmacopsychiatry 2000; 33: 47-53

135 Donovan JL, DeVane CL, Chavin KD, Wang JS, Gibson BB, Gefroh HA, Markowitz JS. Multiple night-time doses of valerian (Valeriana officinalis) had minimal effects on CYP3A4 activity and no effect on CYP2D6 activity in healthy volunteers. Drug Metab Dispos 2004; 32: 1333-1336

136 Anke J, Ramzan I. Pharmacokinetic and pharmacodynamic drug interactions with Kava (Piper methysticum Forst. f.). J Ethnopharmacol 2004; 93: 153-160

137 Thompson R, Ruch W, Hasenohrl RU. Enhanced cognitive performance and cheerful mood by standardized extracts of Piper methysticum (Kava-kava). Hum Psychopharmacol 2004; 19: 243-250

138 Kennedy DA, Seely D. Clinically based evidence of drug-herb interactions: a systematic review. Expert Opin Drug Saf 2010; 9: 79-124

139 Gurley BJ, Swain A, Hubbard MA, Hartsfield F, Thaden J, Williams DK, Gentry WB, Tong Y. Supplementation with goldenseal (Hydrastis canadensis), but not kava kava (Piper methysticum), inhibits human CYP3A activity in vivo. Clin Pharmacol Ther 2008; 83: 61-69
140 Brown PN, Roman MC. Determination of hydrastine and berberine in goldenseal raw materials, extracts, and dietary supplements by highperformance liquid chromatography with UV: collaborative study. J AOAC Int 2008; 91: 694-701

141 Lancaster HM, Davidson AL. Commercial pharmaceutical preparations: 4. Hydrastis - golden seal. Can Med Assoc J 1927; 17: 13171320

142 Chatterjee P, Franklin MR. Human cytochrome p 450 inhibition and metabolic-intermediate complex formation by goldenseal extract and its methylenedioxyphenyl components. Drug Metab Dispos 2003; 31: 1391-1397

143 Yi S, Cho JY, Lim KS, Kim KP, Kim J, Kim BH, Hong JH, Jang IJ, Shin SG, Yu $K S$. Effects of Angelicae tenuissima radix, Angelicae dahuricae radix and Scutellariae radix extracts on cytochrome P450 activities in healthy volunteers. Basic Clin Pharmacol Toxicol 2009; in press

144 Fan L, Wang JC, Jiang F, Tan ZR, Chen Y, Li Q Zhang W, Wang G, Lei HP, $\mathrm{Hu}$ DL, Wang D, Zhou HH. Induction of cytochrome P450 2B6 activity by the herbal medicine baicalin as measured by bupropion hydroxylation. Eur J Clin Pharmacol 2009; 65: 403-409

145 Ramassamy C. Emerging role of polyphenolic compounds in the treatment of neurodegenerative diseases: a review of their intracellular targets. Eur J Pharmacol 2006; 545: 51-64

146 Chow HH, Garland LL, Hsu CH, Vining DR, Chew WM, Miller JA, Perloff $M$, Crowell JA, Alberts DS. Resveratrol modulates drug- and carcinogen-metabolizing enzymes in a healthy volunteer study. Cancer Prev Res (Phila) 2010; 3: 1168-1175

147 Chen Y, Liu WH, Chen BL, Fan L, Han Y, Wang G, Hu DL, Tan ZR, Zhou G, Cao $S$, Zhou $\mathrm{HH}$. Plant polyphenol curcumin significantly affects $\mathrm{CY}$ P1A2 and CYP2A6 activity in healthy, male Chinese volunteers. Ann Pharmacother 2010; 44: 1038-1045 